Universidade de São Paulo-UsP

Escola de Engenharia de São Carlos

Departamento de Engenharia Elétrica e de Computação

Programa de Pós-Graduação em Engenharia Elétrica

Guacira Costa de Oliveira

\author{
Curto-Circuito Probabilístico através \\ da Simulação de Monte Carlo para \\ Sistemas de Transmissão em Corrente \\ Contínua
}





\section{Guacira Costa de Oliveira}

\section{Curto-Circuito Probabilístico através da Simulação de Monte Carlo para Sistemas de Transmissão em Corrente Contínua}

Dissertação de mestrado apresentada ao Programa de Engenharia Elétrica da Escola de Engenharia de São Carlos como parte dos requisitos para a obtenção do título de Mestre em Ciências.

Área de concentração: Sistemas Elétricos de Potência

Orientador: Professor Titular Denis Vinicius Coury

São Carlos 
AUTORIZO A REPRODUÇÃO TOTAL OU PARCIAL DESTE TRABALHO, POR QUALQUER MEIO CONVENCIONAL OU ELETRÔNICO, PARA FINS DE ESTUDO E PESQUISA, DESDE QUE CITADA A FONTE.

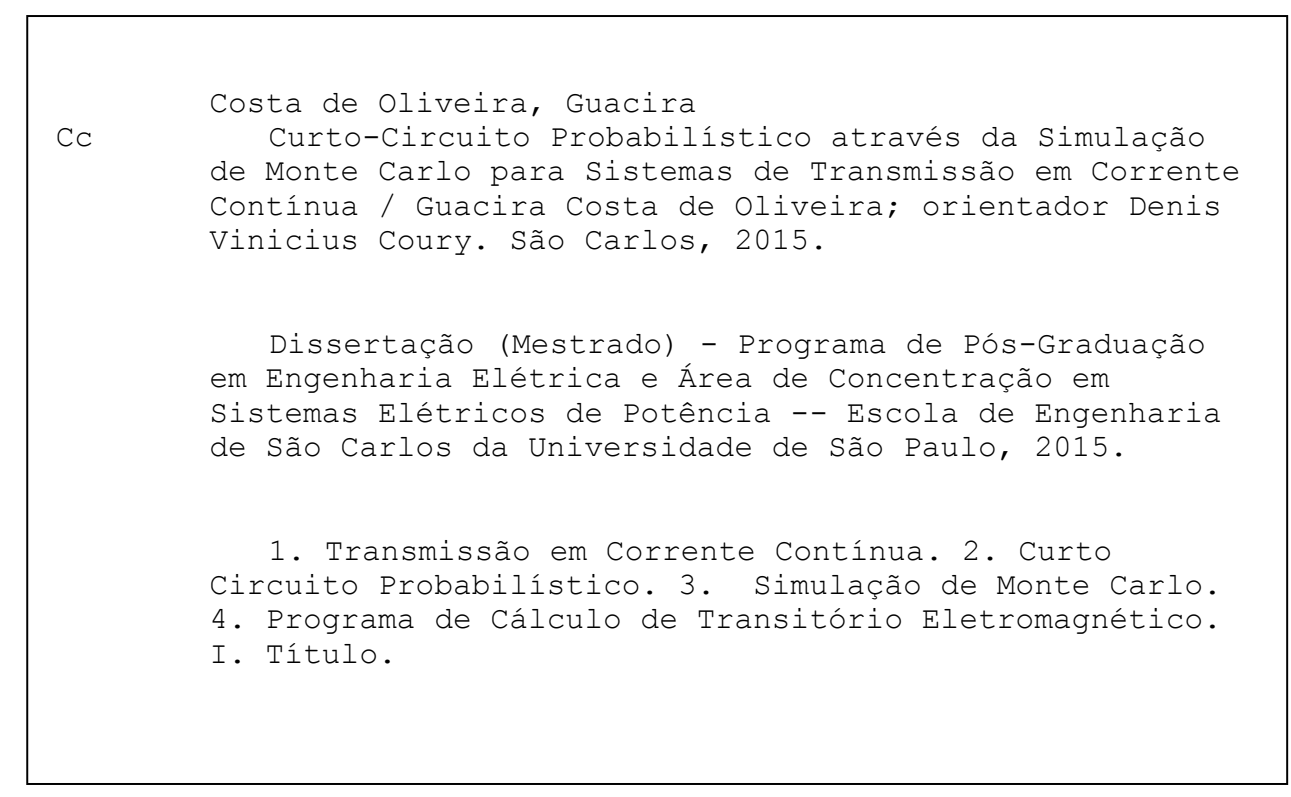




\section{FOLHA DE JULGAMENTO}

Candidata: Engenheira GUACIRA COSTA DE OLIVEIRA.

Título da dissertação: "Curto-circuito probabilístico através da simulação de Monte Carlo para sistemas de transmissão em corrente contínua".

Data da defesa: 08/09/2015

Comissão Julgadora:

Resultado:

Prof. Titular Denis Vinicius Coury (Orientador)

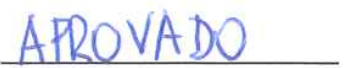

(Escola de Engenharia de São Carlos/EESC)

Prof. Dr. Mario Oleskovicz

(Escola de Engenharia de São Carlos/EESC)

APROVADO

Prof. Dr. Marcos Antonio Dias de Almeida

APNOVADO

(Universidade Federal do Rio Grande do Norte/UFRN)

Coordenador do Programa de Pós-Graduação em Engenharia Elétrica:

Prof. Associado Luis Fernando Costa Alberto

Presidente da Comissão de Pós-Graduação:

Prof. Associado Paulo César Lima Segantine 



\section{Agradecimentos}

A minha melhor amiga e mãe, Nilca e ao meu irmão Rafaell, pelo apoio e confiança.

Ao meu sobrinho Ravel e meu afilhado Manoel, que sempre me cativam com a ternura da infância.

A minha família, por reforçarem minhas convicções e por me darem acolhimento e ânimo a cada regresso.

Aos professores Denis Coury, Renato Monaro, José Carlos e Mário Oleskovicz, agradeço o apoio, a confiança, a partilha do saber e as incontáveis contribuições intelectuais.

Aos amigos Athila Quaresma, Rafael Marsolla, Rui Bertho, Luciano Carli e Fernando Bottura pela colaboração no desenvolvimento desta pesquisa.

A Larissa Lima e os demais amigos da telecom, como também a Natalia, Juliana, Leandro, Paulo, Edmar e Madara por compartilharem dessa caminhada.

Aos meus professores e queridos amigos da UFRN, em especial Ailton Junior e Marina Anders, que permanecem a incentivar e estimular minha carreira.

Aos amigos e professores do IFRN, por me encorajarem a seguir a carreira de engenheira.

Aos colegas de trabalho, integrantes do LSEE, que o fazem um ambiente produtivo e agradável.

Aos que fazem a Escola de Engenharia de São Carlos da Universidade de São Paulo, como também os que fazem o Laboratório de Sistemas de Energia Elétrica, pela estrutura física e equipamentos disponibilizados para o desenvolvimento desse trabalho.

Por fim, à Coordenação de Aperfeiçoamento de Pessoal de Nível Superior (CAPES) devido ao apoio financeiro concedido ao desenvolvimento deste mestrado. 

"Comece pequeno, pense grande e cresça rapidamente." Interpretação da Sequência de Fibonacci. 



\section{Resumo}

\section{Oliveira, Guacira Costa de Curto-Circuito Probabilístico através da Simula- ção de Monte Carlo para Sistemas de Transmissão em Corrente Contínua.}

117 p. Dissertação de mestrado - Escola de Engenharia de São Carlos, Universidade de São Paulo, 2015.

A transmissão de energia em corrente contínua, a partir de conversores fonte de tensão, é oportuna ao progresso do sistema elétrico de potência e tem permitido vantajosas aplicações. Muito se dá, devido ao emprego na conexão de sistemas com frequências distintas, além da redução de perdas na transmissão, provida pelas características operacionais destes. VSCs também promovem o controle do fluxo de potência, possibilitando uma efetiva contextualização no âmbito das redes inteligentes.

Diante deste cenário, este estudo pretende construir um perfil de corrente através do Cálculo de Curto-Circuito Probabilístico, que emprega a Simulação de Monte Carlo, para prover as informações ao desenvolvimento de projetos de equipamentos, ajustes da proteção e controle de sistemas de transmissão em corrente contínua.

A Simulação de Monte Carlo requer muitas iterações, tendo um custo computacional elevado. Se forem executadas em programas comerciais, exige um tempo elevado para leitura dos sinais em arquivos. Devido a isso, um programa de código livre usando linguagem $\mathrm{C}++$, foi desenvolvido para possibilitar acesso aos sinais de interesse ainda em memória, reduzindo desta forma o tempo computacional. Além disso, para melhorar a performance, foram usadas técnicas de processamento paralelo e de computação em nuvem.

Desta forma, este estudo contribui com informações indispensáveis ao projeto de equipamentos de proteção dos sistemas de transmissão em corrente contínua de forma a cooperar com o desenvolvimento consistente desta tecnologia.

Palavras-chave: Transmissão em Corrente Contínua. Curto Circuito Probabilístico. Simulação de Monte Carlo. Programa de Cálculo de Transitório Eletromagnético. 



\section{Abstract}

Oliveira, Guacira Costa de Probabilistic Short-Circuit using Monte Carlo Simulations in Direct Current Transmission Systems. 117 p. Master Thesis - São Carlos School of Engineering, University of São Paulo, 2015.

Transmitting electrical power in direct current using a VSC is suitable for the progress of these systems and has remarkable and advantageous applications. This happens in order to connect two systems with distinct frequencies. This type of line is also used in the reduction of losses in transmission over long distances, provided by their operating characteristics. These converters also promote the control of power flow between distinct generation units, making them effective in the context of Smart Grids.

Based on this, the purpose of this research is to construct a profile of a current using a Probabilistic Short-Circuit Analysis by Monte Carlo Simulation to provide basic data to the optimum development of design equipment in protection and control.

The Monte Carlo Simulation requires many iterations to find an optimal result. An open source program using $\mathrm{C}++$ language was developed to describe all the system model's variables in order to decrease the computation time, as it is time consuming to read signals stored on a disk using commercial software. Moreover, in order to lower computation costs, parallel process techniques and cloud computing were used.

Therefore, this study contributes to the literature by providing essential information for designing equipment for Direct Current transmission protection systems.

Keywords: High-Voltage Direct Current. Probabilistic Short-Circuit. Monte Carlo Simulation. Electromagnetic Transients Program. 



\section{Lista de ilustrações}

Figura 1 Relação entre o custo e o tamanho da linha. . . . . . . . . . . . . . . . 24

Figura 2 Relação entre as perdas e o tamanho da linha. . . . . . . . . . . . . . . 25

Figura 3 Evolução histórica da transmissão de energia elétrica em alta tensão e corrente contínua. . . . . . . . . . . . . . . . . 26

Figura 4 Conversores fonte de corrente. . . . . . . . . . . . . . . . . . . 28

Figura 5 Conversores fonte de tensão. . . . . . . . . . . . . . . . . 28

Figura $6 \quad$ VSC trifásico de dois níveis e sinal sintetizado correspondente. . . . . . 34

Figura $7 \quad$ VSC trifásico de três níveis e sinal sintetizado correspondente. . . . . . 34

Figura 8 Uma fase de um conversor multinível modular, trifásico, de cinco níveis e o sinal sintetizado correspondente. . . . . . . . . . . . . . 35

Figura 9 Topologia back-to-back. . . . . . . . . . . . . . . . . . 36

Figura 10 Topologia monopolar assimétrica. . . . . . . . . . . . . . . . 36

Figura 11 Topologia monopolar simétrica. . . . . . . . . . . . . . 36

Figura 12 Topologia bipolar. . . . . . . . . . . . . . . . . . . 37

Figura 13 Topologia multiterminal. . . . . . . . . . . . . . . . . . 37

Figura 14 Tensões de referência para o controle do fluxo de potência. . . . . . . . . 38

Figura 15 Defasagem relativa entre $\dot{E}_{n}$ e $\dot{V}_{n} \ldots \ldots \ldots \ldots$. . . . . . . . 39

Figura 16 Malha de controles da potência ativa P. . . . . . . . . . . . . . . 39

Figura 17 Malha de controles da potência reativa Q. . . . . . . . . . . . . . . . 40

Figura 18 Malha de controles de $V_{c c}$. . . . . . . . . . . . . . . . . . . . 40

Figura 19 Portadora, referência por fase e saída do PWM implementado. . . . . . 41

Figura 20 Circuito equivalente mediante bloqueio dos IGBTs. . . . . . . . . . . . 42

Figura 21 Modelo do sistema em estudo. . . . . . . . . . . . . . . . . . . 43

Figura $22 \quad$ FDP do evento A, com $N=1 E 3 \ldots \ldots \ldots \ldots \ldots$. . . . . . 47

Figura $23 \quad$ FDP do evento A, com $N=10 E 3 . \ldots \ldots \ldots \ldots$. . . . . . 47

Figura $24 \quad$ FDP do evento B, com $N=1 E 3 \ldots \ldots \ldots \ldots$. . . . . . . . 49

Figura $25 \quad$ FDP do evento B, com $N=10 E 3 . \ldots \ldots \ldots \ldots$ 
Figura 26 Distância euclidiana normalizada, entre histogramas com um número crescente de simulações. . . . . . . . . . . . . . . . . . . . 50 50

Figura 27 DAP do evento A, com $N=10 E 3 \ldots \ldots \ldots \ldots \ldots$

Figura 28 DAP do evento B, com $N=10 E 3 . \ldots \ldots \ldots$. . . . . . . . 52

Figura 29 Sistema em corrente alternada. . . . . . . . . . . . . . . . . 55

Figura 30 Função de distribuição de probabilidade do tipo do curto-circuito de sistemas de transmissão trifásico alternado. . . . . . . . . . . . . 57

Figura 31 Algoritmo do curto-circuito probabilístico para linhas de transmissão em corrente alternada. . . . . . . . . . . . . . . . . . 58

Figura $32 \quad$ FDP do sistema modelo em corrente alternada. . . . . . . . . . . . . 59

Figura 33 DAP do sistema modelo CA . . . . . . . . . . . . . . . . . . 60

Figura 34 Torre CA e torre CC, para um mesmo nível de tensão $(100 \mathrm{kV})$ e relação entre dimensões. . . . . . . . . . . . . . . . . . . . 61

Figura 35 Função de distribuição de probabilidade do tipo de curto-circuito CA e a probabilidade equivalente de cada tipo CC . . . . . . . . . . . . . 61

Figura 36 Função de distribuição de probabilidade real para impedância e posição da falta. . . . . . . . . . . . . . . . . . . . . 63

Figura 37 Função de distribuição da operação de um conversor (valores de P e Q). 63

Figura 38 Sistema simplificado simulado através de espaço de estados. . . . . . . 66

Figura 39 Tensão do filtro capacitivo $\left(V_{C 1}\right.$ e $\left.V_{C 2}\right)$ do sistema simulado no Gnucap e em linguagem $\mathrm{C}++$, por espaço de estados (edo). . . . . . . . . . . 67

Figura 40 Representação do bipolo sobre o indutor L, o resistor R e o capacitor C. 68

Figura 41 Equivalentes de Norton do induto L, resistor R e capacitor C. . . . . . 69

Figura 42 Algoritmo para seleção adequada do modelo de linha para simulação. 70

Figura 43 Modelo de linha de transmissão com parâmetros concentrados. . . . . . 71

Figura 44 Modelo Bergeron de linha de transmissão com perdas. . . . . . . . . . . 72

Figura 45 Camadas do programa OEMTP. . . . . . . . . . . . . 73

Figura 46 Medidores de tensão e corrente dos polos. . . . . . . . . . . . . . 74

Figura 47 Corrente no polo positivo e no polo negativo. . . . . . . . . . . . . 75

Figura 48 Tensão no polo positivo e no polo negativo. . . . . . . . . . . . . . 75

Figura 49 Corrente no braço do VSC da fase A. . . . . . . . . . . . . . 76

Figura 50 Tensão de referência para o PWM por fase, gerada pelo controle. . . . 76

Figura 51 Sistema de teste. . . . . . . . . . . . . . . . 80

Figura 52 Equivalente da fonte ideal e reator referidos à baixa tensão. . . . . . . . 80

Figura 53 Algoritmo do curto-circuito probabilístico para linhas de transmissão em corrente contínua. . . . . . . . . . . . . . . . . 82

Figura 54 Esquema das máquinas na Cloud USP com a comunicação através da Open MPI. . . . . . . . . . . . . . . . . 83 
Figura 55 Sinais do sistema de teste para um curto-circuito entre polos em $50 \%$ do cabo. . . . . . . . . . . . . . . . . . . . 84

Figura 56 Sinais do sistema de teste para um curto-circuito de polo positivo a terra em $10 \%$ do cabo. . . . . . . . . . . . . . . 85

Figura 57 Degraus na referência da potência P e da potência Q. . . . . . . . . . . 86

Figura 58 Lógica de sobrecorrente. . . . . . . . . . . . . . . . . . . . . . 87

Figura 59 Sinais da lógica de sobrecorrente. . . . . . . . . . . . . . . . . . 87

Figura 60 Sinais de P e Q e referências definidas pela SMC . . . . . . . . . . . . 88

Figura 61 FDP das correntes de curto-circuito geradas pela CCP-CC. . . . . . . . 90

Figura 62 FDP das correntes de curto-circuito do tipo polo a polo. . . . . . . . . 90

Figura 63 FDP das correntes de curto-circuito do tipo polo a terra. . . . . . . . . 91

Figura 64 DAP das correntes de curto-circuito geradas pela CCP-CC. . . . . . . . 91

Figura 65 FDP das correntes de curto-circuito geradas pela CCP-CC. . . . . . . . 95

Figura 66 FDP das correntes de curto-circuito geradas pela CCP-CC para faltas polo a polo. . . . . . . . . . . . . . . . . . . . . 995

Figura 67 FDP das correntes de curto-circuito geradas pela CCP-CC para faltas polo a terra. . . . . . . . . . . . . . . . . . . . 996

Figura 68 DAP das correntes de curto-circuito geradas pela CCP-CC. . . . . . . 96

Figura 69 Distância euclidiana normalizada entre FDPs com um número crescente de simulações. . . . . . . . . . . . . . . . . . . . . . . . . . . . . . 98

Figura 70 FDP com número de classe definido pelo SRC e SR. . . . . . . . . . . . 99 



\section{Lista de tabelas}

Tabela 1 Comparação entre conversores CSV e VSC, em casos especificados. . 29

Tabela 2 Probabilidade de intervalos do evento A. . . . . . . . . . . . . 51

Tabela 3 Probabilidade de intervalos do evento B. . . . . . . . . . . . . . . 51

Tabela 4 Probabilidade para intervalos de correntes de curto-circuito do sistema modelo CA. . . . . . . . . . . . . . . . . . . . . 59

Tabela $5 \quad$ Ajustes dos controles VSC $1 . \ldots \ldots \ldots \ldots \ldots$

Tabela 6 Ajustes dos controles VSC 2. . . . . . . . . . . . . . . . . 85

Tabela $7 \quad$ Valores dos degrais nas referências de $\mathrm{P}$ e Q . . . . . . . . . . . . 86

Tabela 8 Probabilidade para intervalos de correntes de curto-circuito do sistema modelo CC. . . . . . . . . . . . . . . . . . . . . . . . 92

Tabela 9 Descritivo do conteúdo do cartão do ATP. . . . . . . . . . . . . . 93

Tabela 10 Probabilidade para intervalos de correntes de curto-circuito do sistema modelo CC controlado. . . . . . . . . . . . . . . . . . . . . . 97 



\section{Lista de siglas}

ATP Alternative Transient Program

CA Corrente Alternada

CC Corrente Contínua

CIGRÉ Conseil International des Grands Réseaux Électriques

CSC Current Source Converter

CCP Cálculo de Curto-Circuito Probabilístico

CloudUSP Plataforma de Computação em Nuvem da Universidade de São Paulo

DAP Densidade Acumulada de Probabilidade

EMTP Electromagnetic Transients Program

FDP Função de Densidade de Probabilidade

HVAC High Voltage Alternating Current

HVDC High Voltage Direct Current

IGBT Insulated Gate Bipolar Transistor

MCV Método de Controle Vetorial

MOSFET Metal Oxide Semiconductor Field Effect Transistor

Open MPI Message Passing Interface

OEMTP Open Electromagnetic Transients Program

PI Proporcional Integral

PLL Phase Locked Loop 
PWM Pulse Width Modulation

SEP Sistema Elétrico de Potência

SMC Simulação de Monte Carlo

SRC Square-Root Choice

SR Sturge's Rule

VSC Voltage Source Converter

VA Variável Aleatória 


\section{Sumário}

1 Sistemas de Transmissão em Corrente Contínua: Uma Introdução 23

1.1 Concepção, Evolução e Estado da Arte dos Sistemas HVDC . . . . . . . . 26

1.2 Conversores de Potência . . . . . . . . . . . . . . . . . . . . 27

1.3 Motivação e Objetivo . . . . . . . . . . . . . . . . . . . . . . . . . . 29

1.4 Estrutura do Trabalho . . . . . . . . . . . . . . . . . . . . . 30

$2 \quad$ Transmissão de Energia Elétrica Através de Sistemas VSC-HVDC 33

2.1 Topologias dos Dispositivos de Chaveamento . . . . . . . . . . . . . . . 34

2.2 Topologias das Linhas de Corrente Contínua . . . . . . . . . . . . . . . . 35

2.3 Técnica de Controle dos Conversores VSC . . . . . . . . . . . . . . . . . . 38

2.3 .1 Fluxo de Potência . . . . . . . . . . . . . . . . . . . . 38

2.3.2 Blocos de Controle . . . . . . . . . . . . . . . . . . . . . . 39

2.4 Modo de Proteção dos Conversores . . . . . . . . . . . . . . . . . . . . . . 41

2.5 Modelo do Sistema Utilizado . . . . . . . . . . . . . . . . . . . . . . . 42

2.6 Considerações . . . . . . . . . . . . . . . . . . . . 43

3 Curto-Circuito Probabilístico em Sistemas Elétricos de Potência 45

3.1 Conceitos Inerentes aos Fenômenos Estocásticos . . . . . . . . . . . . . . 45

3.2 Número de Amostras . . . . . . . . . . . . . . . . . . . . . . . . . . . . . 48

3.3 Densidade Acumulada de Probabilidade . . . . . . . . . . . . . . . . 51

3.4 Correlação entre Sinais . . . . . . . . . . . . . . . . . . 53

3.5 Contexto da Simulação de Monte Carlo . . . . . . . . . . . . . . . . . . . 53

3.6 O Sistema Elétrico de Potência e as Aplicações da Teoria de CurtoCircuito Probabilístico . . . . . . . . . . . . . . . . . 54

3.7 Cálculo de Curto-Circuito Probabilístico em Linhas de Transmissão em Corrente Alternada . . . . . . . . . . . . . . . . . . . . 55

3.8 Cálculo de Curto-Circuito Probabilístico em Linhas de Transmissão em Corrente Contínua Através da Simulação de Monte Carlo . . . . . . . . . 60 
4 Cálculo de Transitórios Eletromagnéticos em Sistemas de Energia Elétrica

4.1 Espaço de Estados . . . . . . . . . . . . . . . . . . . . . . . . . 66

4.2 Equações de Diferença . . . . . . . . . . . . . . . . . . . 67

4.2.1 Representação dos Componentes Elementares . . . . . . . . . . . . 68

4.3 Modelo de Simulação para as Linhas de Transmissão . . . . . . . . . . . . 69

4.3 .1 Modelo Pi . . . . . . . . . . . . . . . . . . . . 70

4.3.2 Modelo Bergeron . . . . . . . . . . . . . . . . . 71

4.4 Biblioteca de Código Livre para Simulação dos Transitórios Eletromagnéticos . . . . . . . . . . . . . . . . . . . . 72

4.4.1 Estrutura do OEMTP . . . . . . . . . . . . . . . . 73

4.5 Considerações . . . . . . . . . . . . . . . . . . . . 77

5 Emprego da Simulação de Monte Carlo para Obter o Cálculo de Curto-Circuito Probabilístico em Sistemas VSC-HVDC $\quad 79$

5.1 Sistema de Teste . . . . . . . . . . . . . . . . . . . . 79

5.2 Programa de Simulação de Transitório Eletromagnético e Plataforma de Simulação . . . . . . . . . . . . . . . . . . . . . . 80

5.3 Validação do Programa de Simulação de Transitório . . . . . . . . . . . . 83

5.4 Integração do OEMTP com a Open Relay . . . . . . . . . . . . . . . 85

5.5 Curtos-Circuitos Probabilísticos em Sistemas VSC-HVDC - Cenário 1 . . 88 5.5 .1 Considerações do Cenário $1 \ldots$. . . . . . . . . . . . . . 92

5.6 Curtos-Circuitos Probabilísticos em Sistemas VSC-HVDC - Cenário 2 . . 92 5.6.1 Considerações do Cenário 2 . . . . . . . . . . . . . . . . 97

5.7 Número de Simulações . . . . . . . . . . . . . . . . . . . . . . . . . 97

5.8 Quantidade de Barras/Classes dos Histogramas . . . . . . . . . . . . . . . 98

5.9 Considerações . . . . . . . . . . . . . . . . . . . . . . . . . . 99

6 Considerações Finais 101

6.1 Continuidade da Pesquisa . . . . . . . . . . . . . . . . . . . . . . . . . . 104

6.2 Publicações . . . . . . . . . . . . . . . . . . . . . . . . . 104

Referências $\quad 105$

$\begin{array}{ll}\text { Anexos } & 111\end{array}$

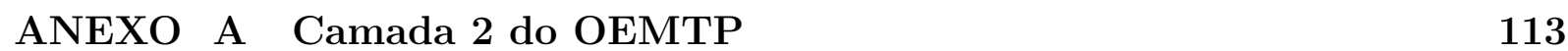




\section{Sistemas de Transmissão em Corrente Contínua: Uma Introdução}

A exploração dos recursos energéticos está aumentando rapidamente devido ao crescimento da população no planeta, assim como a ênfase na industrialização em larga escala para o desenvolvimento dos países e a necessidade de sustentar índices positivos de crescimento econômico (MOURAD; BOUZID; MOHAMED, 2013).

Com o aumento do consumo de energia elétrica é necessária a expansão e consolidação de uma matriz energética capaz de assegurar o fornecimento ao consumidor final, além da gestão da variabilidade da geração. Na tarefa de consolidar a matriz energética, a distância entre os centros de geração e as regiões com alta demanda de energia, é um obstáculo, por que além do elevado custo envolvido, estes sistemas atravessarão regiões territoriais com diferentes condições geográficas e climáticas onde estarão mais sujeitos a ocorrência de curtos-circuitos. Este problema pode ser superado com estratégias baseada em reforços graduais e extensão da infraestrutura existente, como também, com a inclusão e desenvolvimento de linhas de transmissão em alta tensão em longa distância.

No tocante a transmissão de energia através de longas distâncias, as linhas em corrente contínua, denominadas no inglês por High Voltage Direct Current (HVDC), apresentam vantagens frente a transmissão em corrente alternada, do inglês High Voltage Alternating Current (HVAC). A relação de custo em função do tamanho da linha é ilustrada na Figura 1. Os custos relacionados são referentes ao investimento com linhas e com as estações dos respectivos sistemas de transmissão, onde o HVDC é o bipolo 1, do sistema Canadense Nelson River (HYDRO, 2014) e o HVAC, é um sistema hipotético com as mesmas características nominais. É perceptível que apesar dos investimentos iniciais com as estações serem mais elevados nos sistema em corrente contínua, a inclinação da curva é menos acentuada que a curva de custo do sistema alternado. Isso devido ao número de condutores ser menor em sistemas em Corrente Contínua (CC), de forma que quando o tamanho das linhas superam $600 \mathrm{~km}$, as vantagens de custo surgem.

No que diz respeito as perdas na transmissão, a Figura 2 mostra a relação destas com 
Figura 1 - Relação entre o custo e o tamanho da linha.

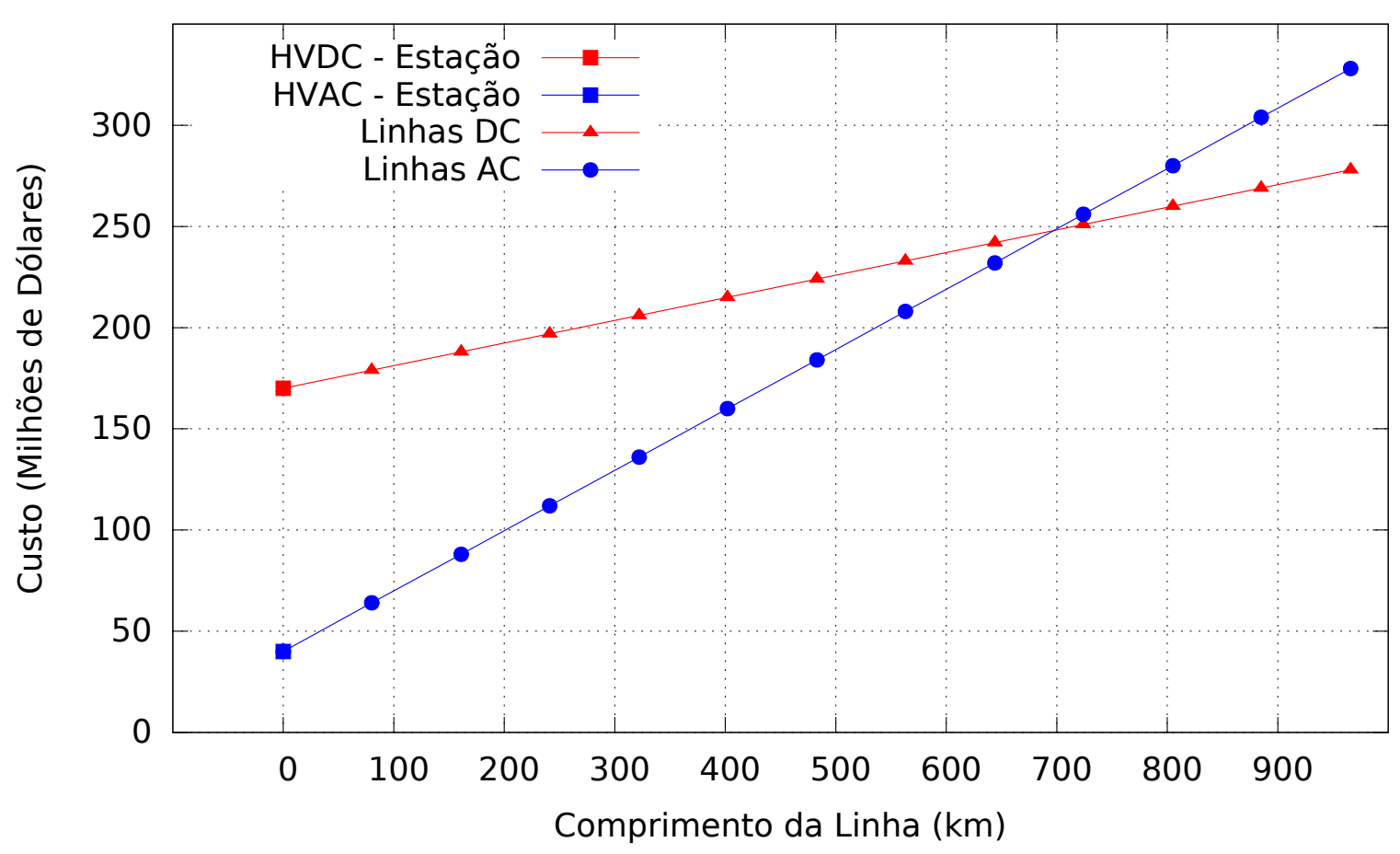

Fonte: Meah e Ula (2007).

o comprimento da linha. A figura mostra dois sistemas reais Chineses, ambos de $500 \mathrm{kV}$, sendo um deles em corrente contínua e o outro em corrente alternada. Pela mesma figura, também se confronta duas propostas de sistemas de transmissão, em corrente contínua com tensão nominal $800 \mathrm{kV}$ e em corrente alternada com tensão nominal $1000 \mathrm{kV}$. A respeito dos dois sistemas de $500 \mathrm{kV}$, o percentual de perdas do sistema em corrente contínua tem um crescimento menor do que o do sistema em corrente alternada, em relação ao comprimento da linha. No que se refere aos sistemas propostos de $800 \mathrm{kV}$ e $1000 \mathrm{kV}$, estes mostram perdas menores que os sistemas em $500 \mathrm{kV}$, dado que as correntes que atravessam os condutores são menores, provocando menor aquecimento e, consequentemente, menores perdas.

O sistema de $800 \mathrm{kV}$, também apresenta um investimento inicial elevado, embora que com o aumento do comprimento das linhas, o custo torna-se menor que o do sistema em corrente alternada, apontando vantagens comerciais na escolha do sistema HVDC.

Sistemas HVDC ${ }^{1}$ usando conversores do tipo Voltage Source Converter (VSC), além de proverem redução de perdas e redução dos custos da transmissão, permitem um controle independente da potência ativa e reativa. Esta forma de controle da potência, facilita o desenvolvimento de sistemas multiterminais, fazendo esta configuração atrativa para aplicações em que gerações não convencionais ${ }^{2}$ são incluídas no sistema elétrico pré-existente.

\footnotetext{
${ }^{1}$ Este estudo fará uso da terminologia HVDC para denominar as linhas de transmissão em alta tensão e corrente contínua.

${ }^{2}$ Exemplo de gerações não convencionais são plantas eólicas e solares, tanto onshore, quanto offshore.
} 
Figura 2 - Relação entre as perdas e o tamanho da linha.

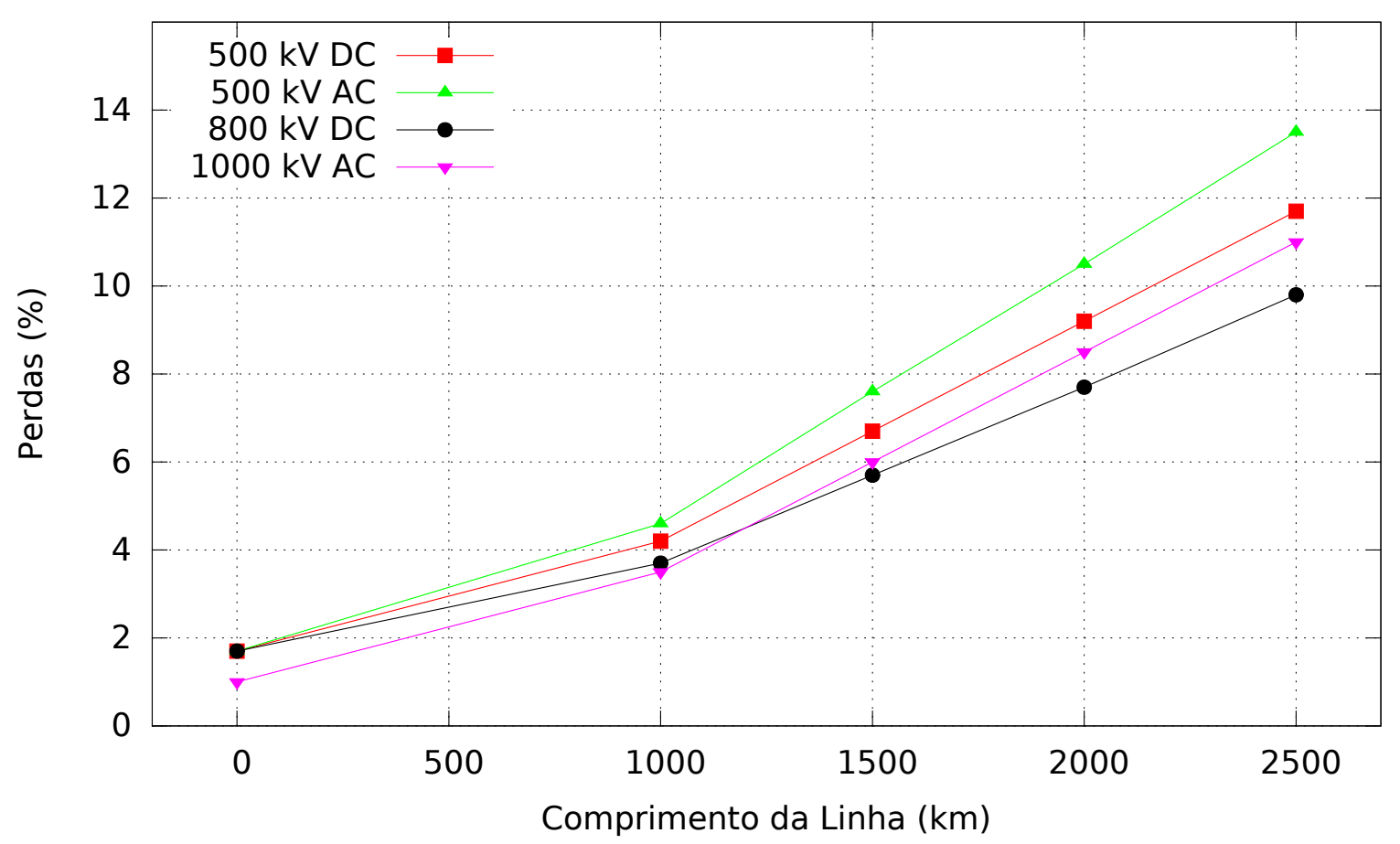

Fonte: Zhang, Rehtanz e Song (2006).

Devido a popularização de sistemas de transmissão em corrente contínua, estudos que contemplem sua implantação e seu aperfeiçoamento são desejados. Uma vez que, os níveis de curto-circuito descrevem informações importantes a respeito dos sistemas e essas são necessárias em diferentes estudos elétricos, notadamente nos estudos de ajuste e coordenação de proteção, na adequação de disjuntores e nas análises de perturbações (ELÉTRICO, 2014), estes são alvo de investigação nesta pesquisa, que busca propor contribuições para os sistemas HVDC.

Devido a importância de se conhecer os fenômenos de curtos-circuitos e assumir que estes ocorrem em consequência de intempéries, desgaste físico dos elementos ou falha na operação, ao ponto que tais causas são reconhecidas como fenômenos não determinísticos, o uso de ferramentas estatísticas poderão descreve-los.

A partir da década de 80, diversas ferramentas estatísticas veem sendo empregadas nos diversos níveis do Sistema Elétrico de Potência (SEP) (FORD; SENGUPTA, 1982). No que diz respeito ao Cálculo de Curto-Circuito Probabilístico (CCP), encontram-se aplicações nos sistemas de corrente alternada no contexto de geração distribuída (BRACALE et al., 2012; BALOUKTSIS; TSANAKAS; VACHTSEVANOS, 1986; MAMEDE, 2004), na melhoria da qualidade da energia (RODRIGUES et al., 2005) e no aperfeiçoamento das técnicas de proteção (ZIMA-BOCKARJOVA et al., 2009).

Vale esclarecer que o cálculo de curto-circuito probabilístico é a estimativa das correntes de falta, levando em consideração as características aleatórias que a define. 
Isto posto, o estudo do Cálculo de Curto-Circuito Probabilístico (CCP) desempenhará função importante nesta pesquisa.

\subsection{Concepção, Evolução e Estado da Arte dos Sis- temas HVDC}

O uso da energia elétrica em sua forma alternada ganhou notoriedade logo durante a idealização do sistema de transmissão e de distribuição de energia, no fim do século XIX. Isso, devido ao uso dos transformadores de potência e também devido ao menor custo despendido na construção dos geradores e motores para esta natureza de sinal. Apesar disso, ainda no século XVIII, já haviam algumas cidades que possuíam instalações em corrente contínua, como exemplo, em Nova York a iluminação era realizada por circuitos em corrente contínua desde 1882. Com o passar dos anos, os sistemas de energia elétrica foram se tornando maiores e mais complexos e as ideias de implementação de sistemas em corrente contínua tornaram-se mais praticáveis.

Atrelada ao avanço dos sistemas baseados em corrente contínua, se deu a evolução da eletrônica de potência e seus dispositivos baseados em semicondutores. A Figura 3, mostra os eventos importantes, que levaram os sistema CC a atingirem a atual aplicabilidade.

Figura 3 - Evolução histórica da transmissão de energia elétrica em alta tensão e corrente contínua.

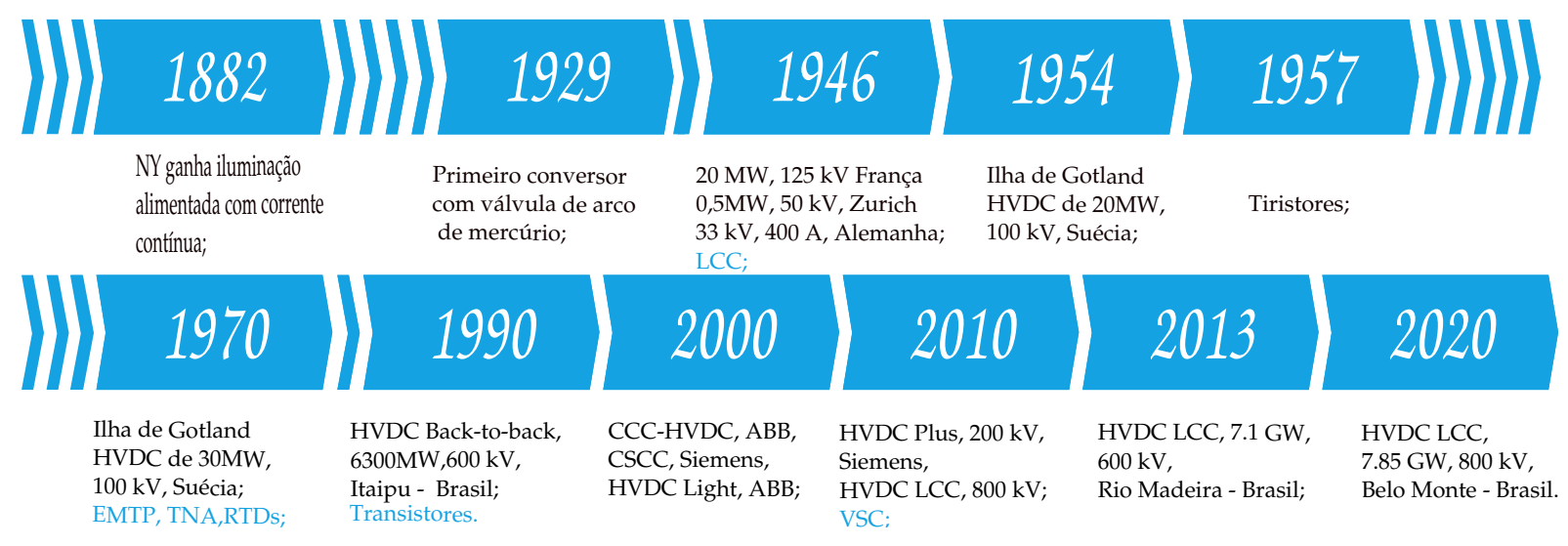

Fonte: Adaptada de Paucar (2014)

O prelúdio desse sistema ocorreu no final da década de 1920, quando o uso das válvulas a arco de mercúrio ampliaram as perspectivas do sistema desenvolvido por René Thury, o precursor da transmissão de energia em corrente contínua. Esta tecnologia de válvula foi usada, em carácter experimental, na Suíça, na França e na Alemanha e apresentava vantagens quanto a simplicidade e alta eficiência. Teve sua primeira aplicação comercial na década de 1950 na Suíça, ainda que os Alemães tenham comissionado um sistema comercial, denominado Elbe-Berlin, em 1941 e sido impedidos pelos Russos de colocá-lo em operação, no fim da Segunda Guerra Mundial. 
As válvulas de mercúrio apresentavam algumas limitações, as principais eram: os arcos elétricos que ocorrem dentro do tubo de mercúrio, limitando a tensão útil; o tempo de aquecimento do mercúrio e a pequena flexibilidade em relação aos níveis de tensão nominal, além de questões ambientais relacionadas a exposição ao mercúrio. Devido a essas e outras implicações quanto ao seu uso, estas foram substituídas por válvulas com tiristores. Estes, por sua vez, reuniram conversão e controle em um dispositivo que levou a uma economia significativa de espaço e peso, entretanto suas perdas eram superiores.

Na década de 1960 houve grande investimento para aperfeiçoar a tecnologia de fabricação das válvulas com tiristores, o que permitiu um avanço considerável em seu desenvolvimento. Em 1970, os tiristores foram usados em substituição a parcela das válvulas de mercúrio no sistema da Ilha de Gotland, Suíça. Essa e outras aplicações atribuíram destaque quanto ao desempenho e viabilidade econômica dos tiristores, os tornando mais competitivos e justificando o seu emprego em sistemas atuais (TIKU, 2014). Nesta mesma década ferramentas computacionais também sugiram e permitiram a análise de transitórios eletromagnéticos em circuitos elétricos, denominada no inglês por Electromagnetic Transients Program (EMTP). Também foram desenvolvidos ferramentas com hardware dedicado, para efetuar simulações em tempo real, como exemplo o Transient Network Analyser (WATSON; ARRILLAGA; ENGINEERS, 2003).

No final da década de 1990, com o desenvolvimento dos semicondutores e da tecnologias de fabricação dos dispositivos de chaveamento, os transistores ganharam aplicação nos conversores de potência, por serem favoráveis ao controle do fluxo de potência, como também, por viabilizarem a expansão do número de terminais, constituindo os emergentes sistemas multiterminais (ASPLUND G., 1998).

Ao passo que a eletrônica de potência evoluiu, uma diversidade de configurações de sistemas HVDC se mantiveram em operação por todo o mundo, inclusive projetos brasileiros bem sucedidos, como é o caso da usina de Itaipu (ITAIPU, 2010), que opera desde 1984. No presente estão sendo comissionados um montante significativo de novos projetos (ABB, 2014), entre eles o sistema de transmissão do Rio Madeira, desenvolvido no território brasileiro (ESMERALDO; ARAÚJO; JR., 2010).

\subsection{Conversores de Potência}

A evolução da eletrônica de potência, juntamente ao aperfeiçoamento das técnicas de fabricação dos semicondutores, produziram uma grande diversidade de configurações de sistemas HVDC. Esta diversidade pode ser classificada quanto a natureza dos conversores empregados. Em operação há a tecnologia baseada em tiristores, os conversores fonte de corrente equivalente e baseada em transistores, conversores fonte de tensão equivalente ${ }^{3}$.

\footnotetext{
${ }^{3}$ Este estudo fará uso da terminologia, em inglês Current Source Converter (CSC) e Voltage Source Converter (VSC), para referir-se aos conversores fonte de corrente e tensão, respectivamente.
} 
De forma que, as baixas perdas de chaveamento dos tiristores e aplicação em níveis de potência superiores competem com a flexibilização do controle de bloqueio dos transistores, fazendo as duas tecnologias apropriadas para aplicações atuais.

A Figura 4 e a 5, representam conversores do tipo CSC e VSC, respectivamente. $\mathrm{Na}$ primeira delas, os tiristores são arranjados por fase. Nestes, a parcela alternada atua como uma fonte de tensão constante e requer um filtro capacitivo para eliminação de harmônico, enquanto que a parcela contínua, atua como fonte de corrente contínua e requer indutâncias armazenadoras de energia. Quanto aos tiristores, só permitem o controle para condução e o chaveamento ocorre na frequência da rede e as perdas são baixas.

Figura 4 - Conversores fonte de corrente.

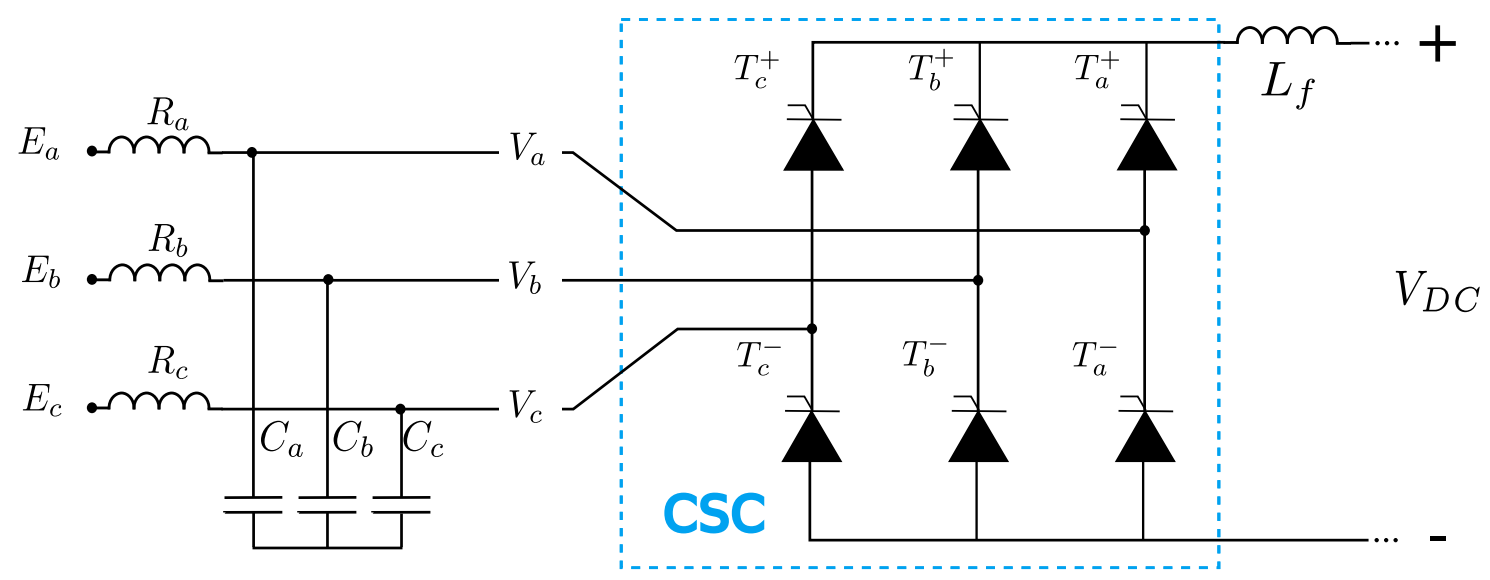

Figura 5 - Conversores fonte de tensão.

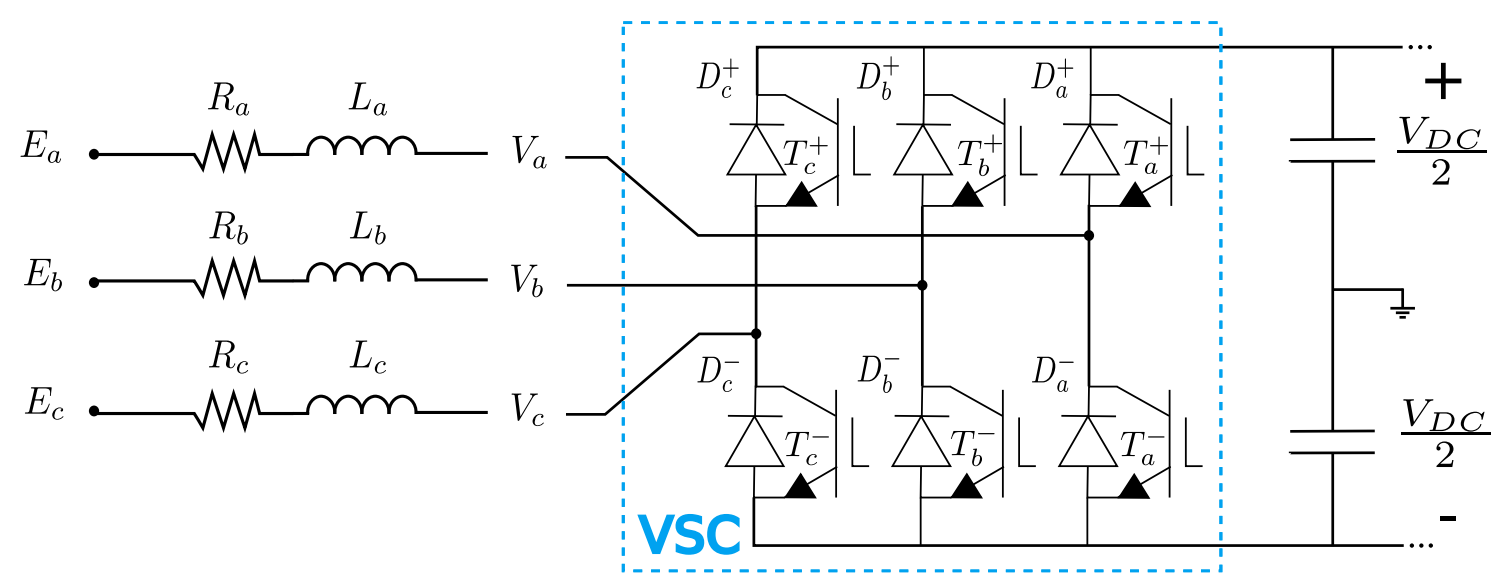


Na Figura 5, os transistores também são arranjados por fase, com diodos reversos. A parcela alternada atua como fonte de corrente constante enquanto que a parcela contínua atua como fonte de tensão constante e carece de filtro capacitivo. Quanto aos transistores, estes possuem controle externo para chaveamento. Esse controle comuta a chave para a posição de bloqueio e condução de corrente. Quanto aos diodos paralelos, estes operam também no modo de bloqueio, protegendo os transistores contra tensões reversas causadas pela interrupção de corrente, deste modo, nesta condição, o diodo fornece caminho para a corrente circular (SOOD, 2004).

Para os conversores CSC e VSC, um paralelo foi traçado na Tabela 1, para que as vantagens e desvantagens sejam apontadas, quando cada umas das tecnologias é empregada.

Tabela 1 - Comparação entre conversores CSV e VSC, em casos especificados.

\begin{tabular}{|c|c|c|}
\hline Caso & $\mathrm{CSC}$ & VSC \\
\hline Faltas no sistema CA & Falha na comutação & $\begin{array}{l}\text { Permanece operando (com } \\
\text { limitações) }\end{array}$ \\
\hline Rede CA fracas & Não é possível conectar & É possível conectar \\
\hline $\begin{array}{l}\text { Problemas na qualidade de } \\
\text { energia }\end{array}$ & Não compensa reativo & $\begin{array}{l}\text { Compensação de reativo, de } \\
\text { tensão harmônica entre ou- } \\
\text { tros }\end{array}$ \\
\hline $\begin{array}{l}\text { Falta na parcela CC do sis- } \\
\text { tema }\end{array}$ & $\begin{array}{l}\text { Amortecimento da corrente } \\
\text { de falta pelos indutores de } \\
\text { alisamento }\end{array}$ & $\begin{array}{l}\text { Sem amortecimento da cor- } \\
\text { rente de falta }\end{array}$ \\
\hline Perdas por chaveamento & Menores & Maiores \\
\hline Capacidade de sobrecarga & Maior & Menor \\
\hline $\begin{array}{l}\text { Construção de sistemas } \\
\text { multiterminais }\end{array}$ & Não permite & Permite \\
\hline
\end{tabular}

Fonte: Watson, Arrillaga e Engineers (2003).

Como é observado, cada conversor possui características favoráveis para diferentes casos, o que implica que o emprego de um, em vez do outro, dependerá das condições de projeto a serem atendidas. Como critério para a metodologia, foi utilizado um sistema de teste que emprega conversores do tipo VSC, devido a viabilidade técnica e econômica para as futuras gerações de linhas de transmissão HVDC.

No Capítulo 2, são apresentados maiores detalhes da transmissão com linhas VSCHVDC.

\subsection{Motivação e Objetivo}

Simultâneo ao progresso dos sistemas de transmissão em corrente contínua, a demanda é crescente por algoritmos e equipamentos de proteção, com aplicação nestes. O suprimento desta demanda depende de informações sobre o comportamento do sistema quando 
submetidos a transitórios eletromagnéticos, em todas as possíveis condições de operação. Nesse âmbito os curtos-circuitos nas linhas de transmissão representam a parcela mais significativa destes transitórios, portanto, demarcando o campo de investigação desta pesquisa.

Algumas ferramentas matemáticas são utilizadas para efetuar o cálculo de curtocircuito, como método de componentes simétricas e simulação de transitórios eletromagnéticos. Contudo, o método de componentes simétricas mostra-se inadequado para análise de sinais em corrente contínua, restando a simulação de transitórios eletromagnéticos, como alternativa a estes sistemas.

Apesar de haverem diversos programas comerciais que executam simulações de transitórios eletromagnéticos, a execução do CCP nestes seria ineficaz, por despenderem de muito tempo para acessar os dados em arquivos. Este fato motivou o desenvolvimento da biblioteca de código livre Open Electromagnetic Transients Program (OEMTP) que executa o transitório eletromagnético do circuito. Para complementar a OEMTP, a biblioteca Open Relay (MONARO et al., 2012) é empregada para executar as tarefas de controle e operação das estações conversoras. Portanto, a operação integrada destas duas bibliotecas de código livre, permite que os sinais elétricos sejam acessados ainda em memória, oferendo dinamismo e eficiência às simulações.

Neste horizonte, este estudo pretende extrair as informações a respeito dos curtoscircuitos através do CCP nos sistemas HVDC. Busca-se assim caracterizar as correntes de faltas que possam vir a ocorrer, de forma a prover as informações básicas ao desenvolvimento ótimo de projetos de equipamentos e ajustes da proteção e controle.

\subsection{Estrutura do Trabalho}

Este estudo pretende abordar a temática proposta no decorrer de seis capítulos, sendo o primeiro destes o capítulo corrente, onde se contextualiza e se exibe as motivações para abordagem do tema. Este tem início com a exibição dos aspectos favoráveis para utilização da transmissão em corrente contínua, é seguido por uma retrospectiva a respeito da evolução desta tecnologia e por fim são mostrados os dois principais tipos de conversores empregados, que definem dois grandes grupos: CSC e VSC, cada um com características operacionais singulares.

O capítulo dois, como já mencionado, aborda alguns aspectos dos sistemas de transmissão HVDC. Neste são tratadas as topologias dos conversores e das linhas, assim como, é mostrada a relação de custo versus benefício de cada configuração. Em seguida, as estratégias de controle empregadas para manter a potência ativa, reativa e a tensão CC em condições de operação desejadas. E por fim, uma importante condição de operação será analisada, o modo de proteção, que é o comportamento dos conversores mediante um curto-circuito na linha de transmissão. 
O terceiro capítulo trata os conceitos estatísticos necessários à compreensão da aplicação do CCP. Neste documento são mostrados algoritmos simplificados que foram desenvolvidos para abordar estes conceitos. Os algoritmos mostram a dinâmica da simulação de Monte Carlo, para alguns cenários hipotéticos. O capítulo também mostra os resultados expressos através da função de densidade de probabilidade e da densidade acumulada de probabilidade. Além disso, neste capítulo são mostrados resultados de simulações do $\mathrm{CCP}$, desenvolvidas durante esta pesquisa em um programa comercial para um sistema em corrente alternada. Estas simulações foram baseadas no proposto por Mamede (2004) e foram precursoras desta pesquisa.

O quarto capítulo refere-se ao cálculo dos transitórios eletromagnéticos. São tratadas duas formas de executa-los, a primeira, por espaço de estados e a segunda, por equações de diferença. Será justificado o uso de equações de diferença para a construção da biblioteca OEMTP e será mostrado como os elementos elétricos são representados por estas equações. O capítulo também retrata os diferentes modelos de simulação de linhas de transmissão, para que os resultados não sejam prejudicados devido a um modelo pouco representativo. A finalização deste capítulo ocorre com uma seção que descreve precisamente a biblioteca OEMTP.

O capítulo cinco mostra o sistema teste que foi empregado para validação da metodologia proposta e apresenta os resultados obtidos, na forma da função de densidade de probabilidade e da função de distribuição acumulada. Também é medida a correlação entre respostas de simulações realizadas simultaneamente em um programa comercial e no OEMTP, para que suas ações sejam comprovadamente válidas.

Por fim, o capítulo 6 irá apresentar as considerações a respeito das métricas utilizadas e dos resultados obtidos, como também, vislumbrar novas contribuições afim de obter continuidade para este estudo. 


\section{Transmissão de Energia Elétrica Através de Sistemas VSC-HVDC}

Como foi tratado no Capítulo 1, há diferenças operacionais significativas entre projetos de linhas HVDC que empregam conversores CSC e que empregam VSC. Reconhecidas estas diferenças, foi adotado como critério para a metodologia a utilização de um sistema de teste que emprega conversores do tipo VSC, devido as perspectivas para as futuras gerações de linhas de transmissão HVDC.

Embora tenha sido adotado conversores VSC para a metodologia deste estudo, isso não inviabiliza estudos de CCP em sistemas com conversores CSC.

Segundo a $A B B$, que é uma das principais fabricantes desta tecnologia, até 2024 estarão em operação em todo o mundo mais de 60 sistemas VSC-HVDC, além de 44 sistemas com tecnologia convencional, CSC-HVDC (ABB, 2014).

De forma simplificada, estes sistemas compreendem duas estações conversoras, que podem ser interligadas através de linhas de transmissão CC. Estas estações utilizam transistores ${ }^{1}$ como elemento físico de chaveamento. Este tipo de conversor utiliza a modulação do tipo Pulse Width Modulation (PWM) para controlar o chaveamento.

Para os sistemas HVDC, tanto os transistores quanto as linhas CC podem ser arranjados de formas diferentes no circuito, essa diversidade de arranjos é importante para promover sistemas com operações diversificadas. Na seção seguinte serão explorados os arranjos mais comuns de chaves e na sequência, uma outra seção, tratará das topologias de linhas de transmissão.

\footnotetext{
${ }^{1}$ Neste estudo serão tratados VSC baseados em transistores do tipo Insulated Gate Bipolar Transistor (IGBT), embora os Metal Oxide Semiconductor Field Effect Transistor (MOSFET) também possam ser usados como dispositivos de chaveamento.
} 


\subsection{Topologias dos Dispositivos de Chaveamento}

A topologia mais simples de VSCs são conversores conectados ao sistema trifásico que geram sinais com dois níveis de tensão. São constituídos por estações conversoras com seis IGBTs e com diodos anti-paralelo, ver Figura 6. Devido a simplicidade, a topologia de dois níveis gera sinais com elevados níveis de distorção harmônica, pois sintetizam sinais quadrados. Uma possível solução consiste no aumento do número de níveis dos sinais gerados por estes conversores.

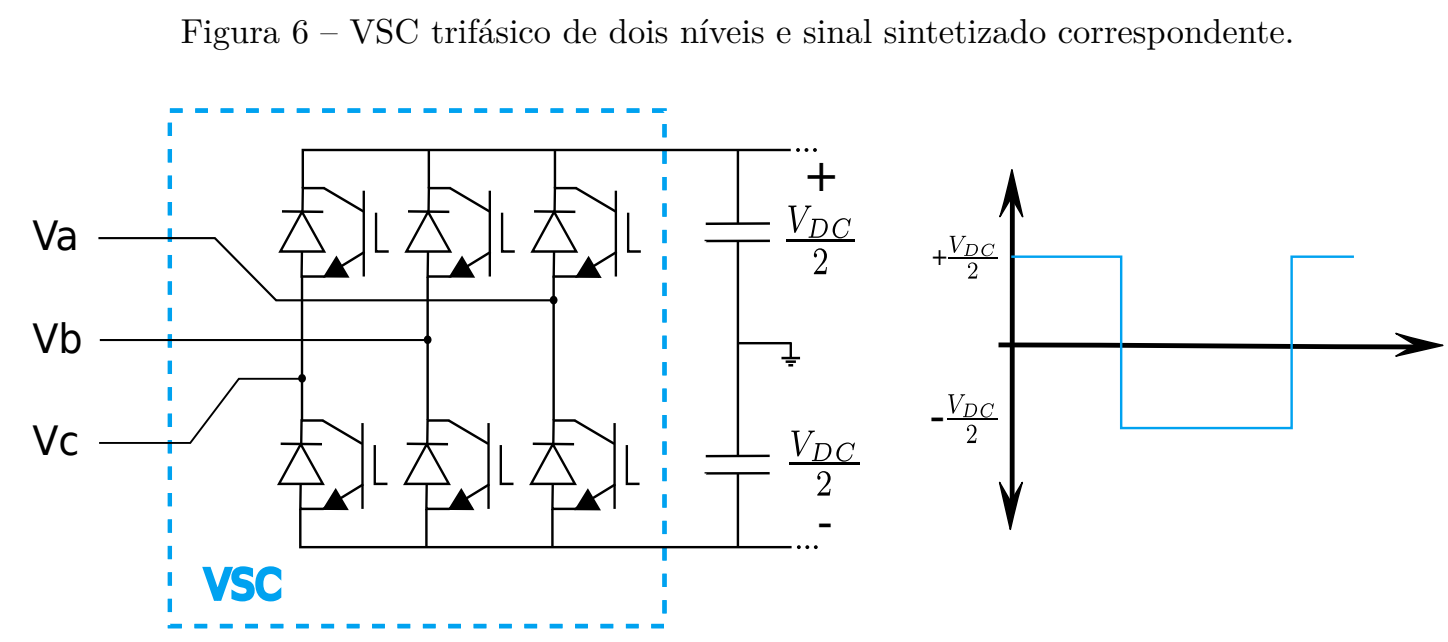

Na Figura 7, há a representação do circuito equivalente de um conversor que sintetiza sinais de três níveis. Esta configuração inclui o nível nulo ao sinal de saída e o princípio de funcionamento é semelhante ao de dois níveis.

Figura 7 - VSC trifásico de três níveis e sinal sintetizado correspondente.

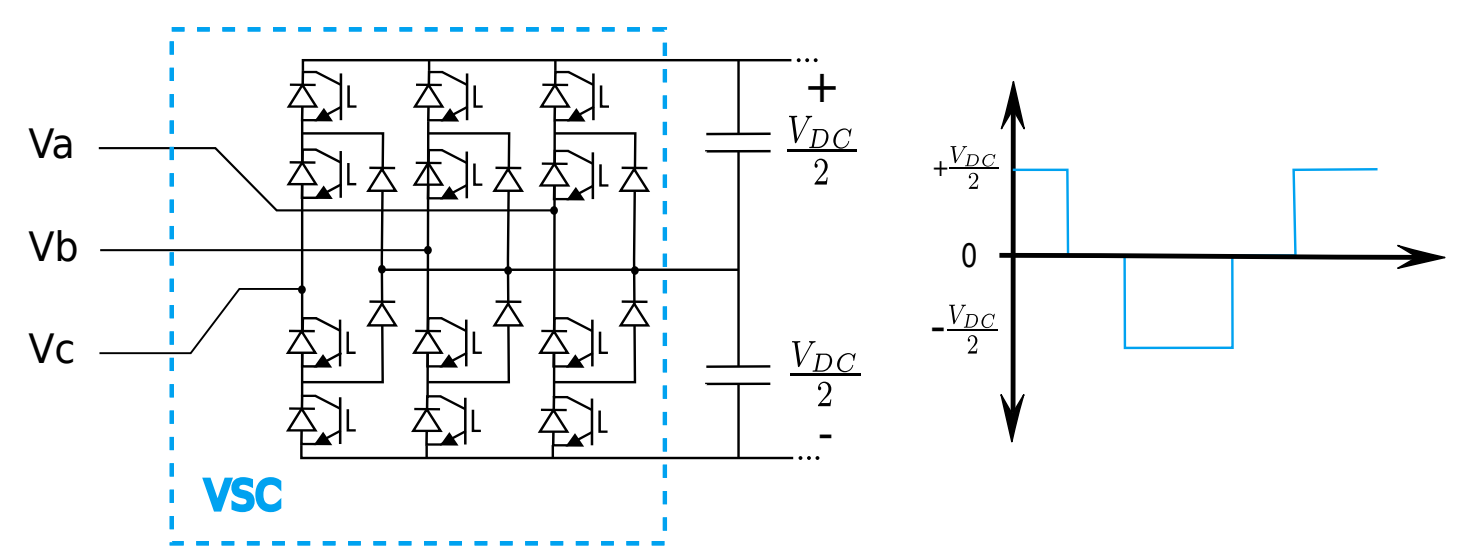

Além de benefícios em relação a redução da injeção de harmônicos, a elevação do número de níveis do conversor reduz as perdas por chaveamento, já que a frequência de operação de cada chave será reduzida. Conversores com mais de dois níveis podem ser denominados Conversores de Multiníveis Modulares. Estes, embora mais eficientes, elevam o investimento, devido ao incremento do número de transistores e diodos. Na Figura 8, 
estão representados os arranjos dos submódulos empregados em topologias multiníveis, onde, cada submódulo é composto por dois IGBTs em paralelo com um capacitor. Cada conjunto de submódulo estará em série com reatores e geram sinais com o número de níveis mais um, determinado conforme o número de submódulos arranjados (CIGRÉ B4, 2011; BARNES; BEDDARD, 2012; FLOURENTZOU; AGELIDIS; DEMETRIADES, 2009).

Figura 8 - Uma fase de um conversor multinível modular, trifásico, de cinco níveis e o sinal sintetizado correspondente.
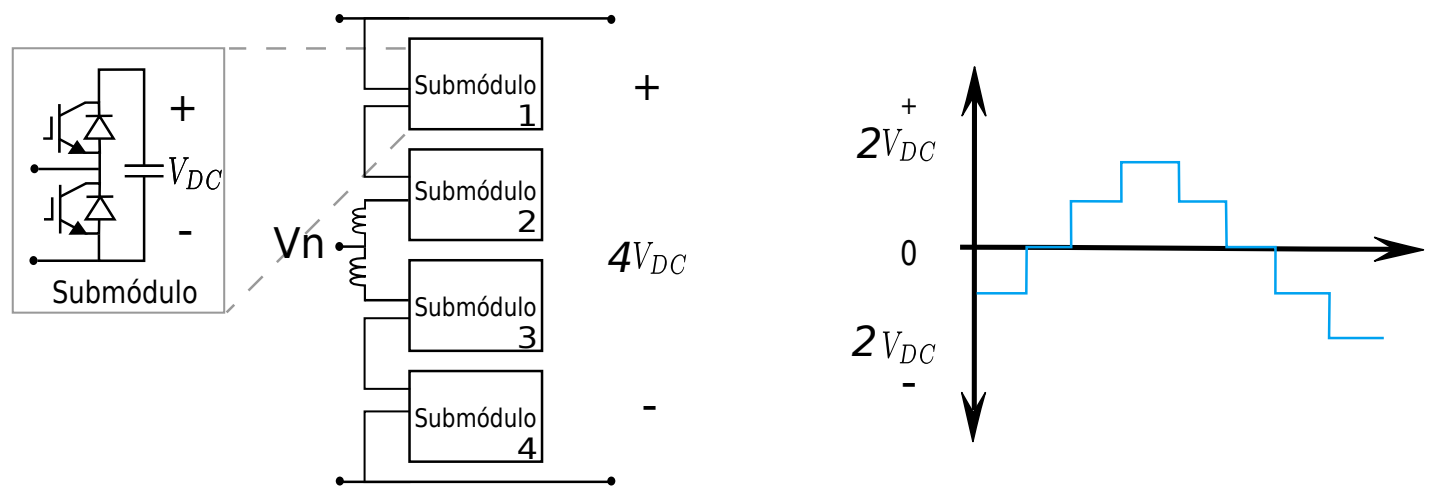

Apesar das vantagens técnicas desempenhadas pelas tecnologias baseadas em conversores multiníveis, as aplicações ainda estão restritas devido ao custo. Em favor dos conversores de dois níveis, além dos menores custos, está o progresso contínuo dos semicondutores, afim de reduzir as perdas por chaveamento, mostrando viabilidade técnica e econômica para as futuras gerações de linhas de transmissão de corrente contínua (PAUCAR, 2014). Devido a estes motivos, um critério para a metodologia deste estudo, foi utilizar conversores trifásicos de dois níveis no sistema teste.

\subsection{Topologias das Linhas de Corrente Contínua}

A literatura dispõe de inúmeras configurações de sistemas HVDC, buscando proporcionar flexibilidade de operação e de custo. Diferentes topologias de linhas, tanto para os sistemas CSCs quanto para os VSCs, são denominadas por back-to-back, monopolar e bipolar. Outras configurações são propostas mediante a combinação destas topologias ou de uma delas em cascata, denominadas de multiterminal.

Quando se trata do tipo back-to-back, refere-se a um arranjo de dois conversores ligados diretamente, sem linha de transmissão, ver Figura 9. Esta topologia é comumente usada na conexão de sistemas assíncronos, onde os dois sistemas possuem frequência ou método de controle distintos.

A topologia monopolar possui uma subclassificação, podendo ser simétrica e assimétrica. A topologia assimétrica envolve dois conversores conectados através de uma única linha de alta tensão. Nesta configuração, frequentemente, o retorno pelo terra é utilizado 
Figura 9 - Topologia back-to-back.

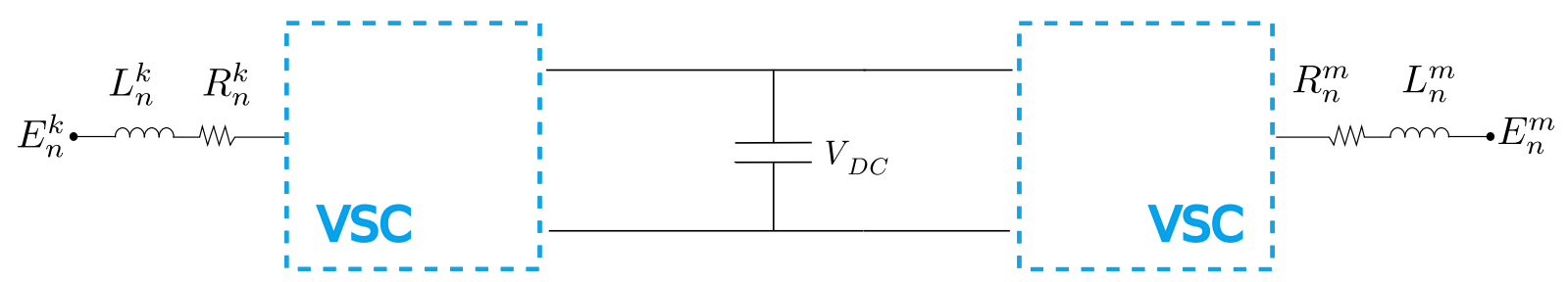

como condutor de retorno ou um condutor de retorno metálico é instalado. Quanto a operação desta topologia, contendo um retorno instalado, apenas o condutor trabalha para manter a tensão nominal do sistema. Em caso de ocorrência de um curto-circuito, é inevitável que o sistema deixe de operar. Esta topologia é ilustrada na Figura 10.

Figura 10 - Topologia monopolar assimétrica.

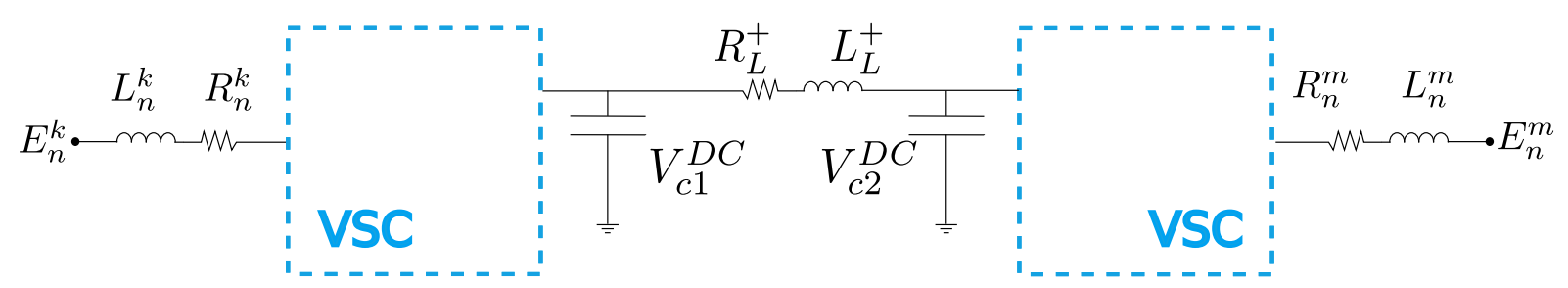

A topologia simétrica é constituída por dois conversores interligados através de duas linhas de alta tensão com polaridades opostas sendo a referência provida através do aterramento do filtro capacitivo, como ilustrado na Figura 11. Apesar desta topologia possuir duas linhas de transmissão, caso uma linha esteja em curto-circuito a outra linha não poderá manter-se operando através do retorno pelo terra.

Figura 11 - Topologia monopolar simétrica.

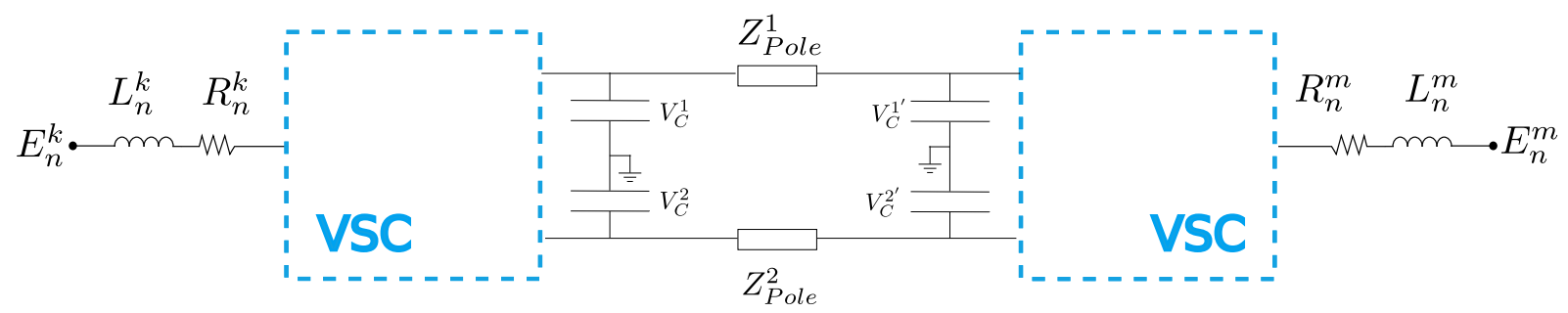

A topologia bipolar configura dois sistemas monopolares assimétricos combinados, sendo um polo positivo e o outro negativo. Embora em operação convencional os polos possuem a mesma tensão com polaridade oposta. Neste caso, é possível a operação independente dos polos, devido a existência de quatro conversores e do retorno pelo terra, ver Figura 12 (CIGRÉ B4, 2013).

Os sistemas multiterminais agrupam todas as demais topologias, ou algumas delas, em uma única rede. Ilustrado na Figura 13 (VRANA, 2014), está o sistema multiterminal de teste proposto pelo Comitê Internacional de Produção e Transmissão de Energia Elé- 
Figura 12 - Topologia bipolar.

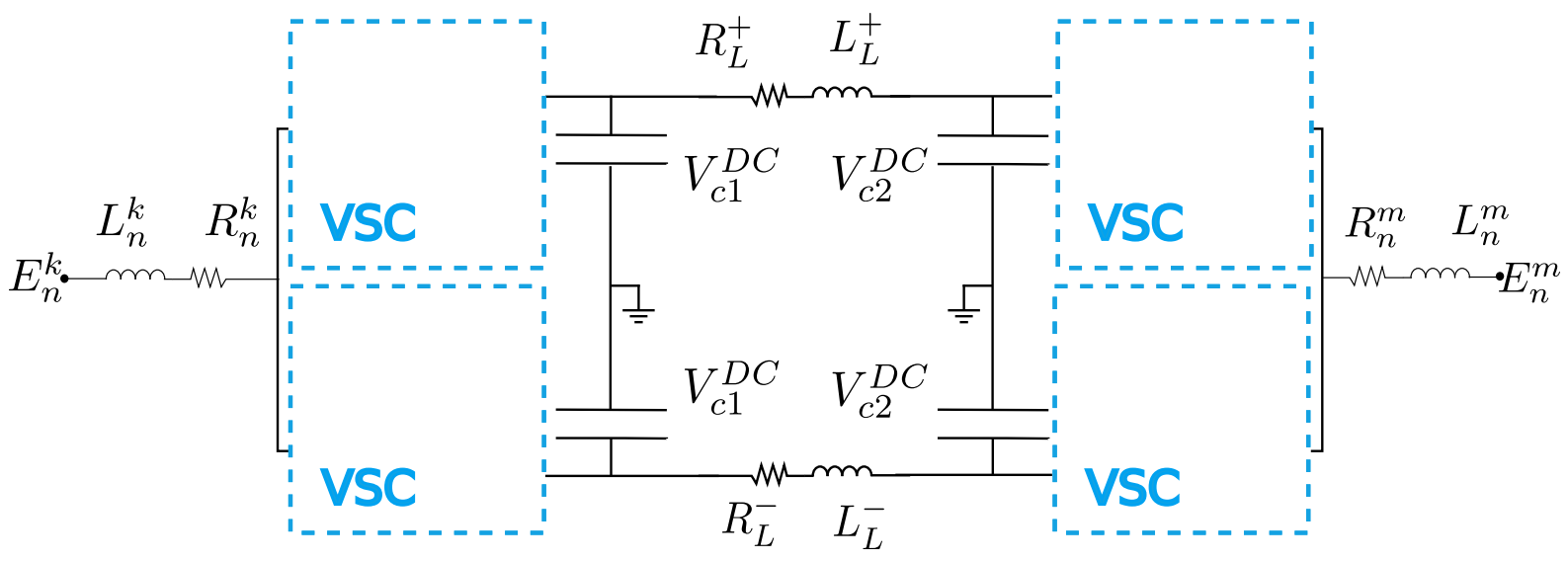

trica, da língua francesa Conseil International des Grands Réseaux Électriques (CIGRÉ). Este se configura como um bom exemplo de sistema multiterminal, pois apresenta além da interligação entre sistemas alternados e contínuos, trechos monopolares simétricos e bipolares.

Figura 13 - Topologia multiterminal.

^ચి Estação de Conversão AC-DC $\triangleq$ Estação de Conversão DC-DC - Cabo Aéreo - - Cabo Não-Aéreo
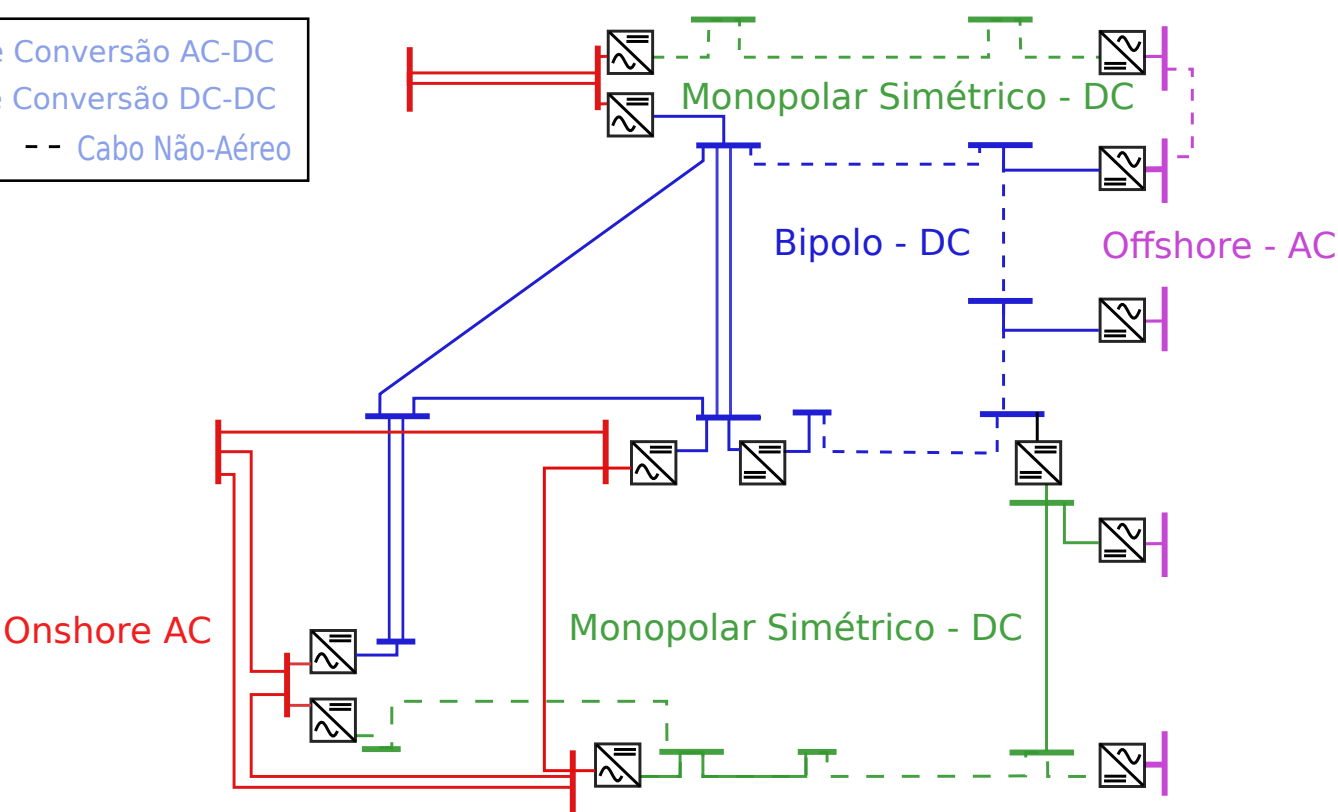

Esta seção descreveu as topologias definidas pelos arranjos dos transistores e das linhas de alta tensão. Esses arranjos associam flexibilidade de custo e de operação, além do gerenciamento dos níveis harmônicos. 


\subsection{Técnica de Controle dos Conversores VSC}

O sistema de controle empregado no chaveamento dos conversores do tipo VSC, regula o fluxo de energia entre os terminais da linha de transmissão. Este controle atua de maneira desacoplada para efetuar o controle da potência ativa, reativa e tensão CC. Com este fim, diferentes estratégias de controle podem ser empregadas, sendo a mais comum delas o Método de Controle Vetorial (MCV) (BAJRACHARYA, 2008). Este método utiliza a Transformação de Park para converter os vetores do sistema alternado (tensão e corrente) em vetores contínuos. Esta medida permite que, através de um controlador Proporcional Integral (PI) o erro em regime permanente seja minimizado.

A transformada de Park consiste na criação de vetores de referência $(d-q-0)$ para o sistema trifásico $(a-b-c)$, através de vetores ortogonais girando em sincronismo com a frequência da rede alternada. O circuito de sincronismo, do inglês Phase Locked Loop (PLL), é fundamental, uma vez que os vetores (d-q) necessitam acompanhar os vetores do sistema alternado (a-b-c), com mesma frequência e com ângulo conhecido. Este circuito irá gerar um sinal sincronizado com a componente fundamental do sistema alternado (corrente ou tensão), disponibilizando as grandezas frequência e ângulo de fase, em regime permanente ou durante transitórios eletromagnéticos.

Para estes novos vetores de referência o eixo direto $d$ estará em fase com a fase $a$ do sistema alternado, o eixo em quadratura $q$ estará formando $90^{\circ}$ com o eixo direto e a componente homopolar 0 é nula para sistemas alternados com três fios.

\subsubsection{Fluxo de Potência}

O controle do chaveamento dos IGBTs dos VSCs permitem o gerenciamento do fluxo de potência, tanto ativa, quanto reativa. Este controle ocorre mediante o ajuste da tensão $\dot{V}_{n}$, ver Figura 14. A tensão do sistema Corrente Alternada (CA) é $\dot{E}_{n}$, a tensão no terminal do conversor é $\dot{V}_{n}$ e $X_{n}$ é a reatância de filtro.

Figura 14 - Tensões de referência para o controle do fluxo de potência.

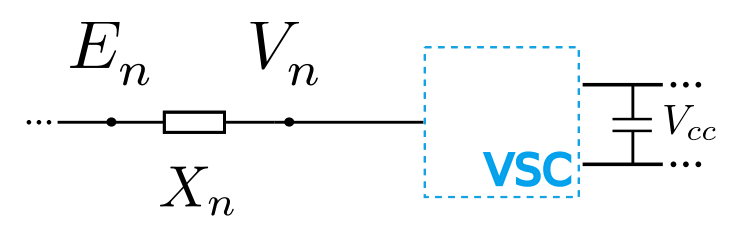

Os fasores $\dot{E}_{n}$ e $\dot{V}_{n}$ estão representados na Figura 15. Para estes conversores o fluxo de potência é ajustado através do controle, que determina o valor de $\dot{V}_{n}$. Permitindo a operação nos quatro quadrantes do plano $P-Q$.

As potências ativa $P$ e reativa $Q$, podem ser calculadas através da Equação 1 e da Equação 2, respectivamente (CIGRÉ B4, 2005; FLOURENTZOU; AGELIDIS; DEMETRIADES, 
Figura 15 - Defasagem relativa entre $\dot{E}_{n}$ e $\dot{V}_{n}$.

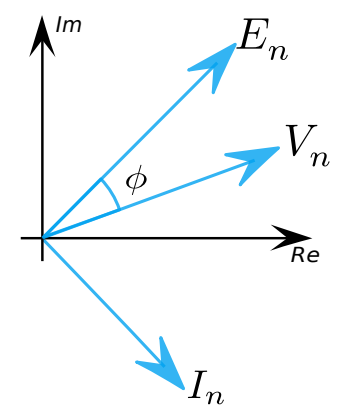

2009). Nestas equações a tensão do sistema alternado $\dot{E}_{n}$ e a tensão do conversor $\dot{V}_{n}$, além do ângulo $\phi$, que associa as duas, são relacionados com a reatância $X_{n}$.

$$
\begin{gathered}
P=\frac{V_{n} \operatorname{sen} \phi}{X_{n}} E_{n} \\
Q=\frac{V_{n} \cos \phi-E_{n}}{X_{n}} E_{n}
\end{gathered}
$$

O controle da potência é uma das vantagens da utilização de VSC em transmissão HVDC, uma vez que esta flexibiliza o gerenciamento da energia. Este aspecto é ainda mais importante, quando se trata de conexões entre mais de duas estações HVDC.

\subsubsection{Blocos de Controle}

Cada VSC do sistema deve controlar, diretamente, duas variáveis, $P$ e $Q$ ou $V_{c c}$ e $Q$. Assim, cada VSC possui uma malha para cada variável a ser controlada ${ }^{2}$.

A Figura 16 mostra um esquema de controle típico, com duas malhas, que compreendem o $P I_{1}$ e $P I_{2}$, respectivamente, o controle da corrente $I_{d}$ e da potência P. A primeira instância da figura compreende o $P I_{2}$, que ajusta a potência $P$ e gera a referência $I_{d, r e f}$ para a malha de controle de corrente. Tanto a medida de $\mathrm{P}$ quanto de $\mathrm{Q}$ são obtidas do produto entre $\dot{V}_{p u}$ e $\dot{I}_{p u}$ do circuito, que são medidas nos terminais da fonte de tensão CA.

Figura 16 - Malha de controles da potência ativa P.

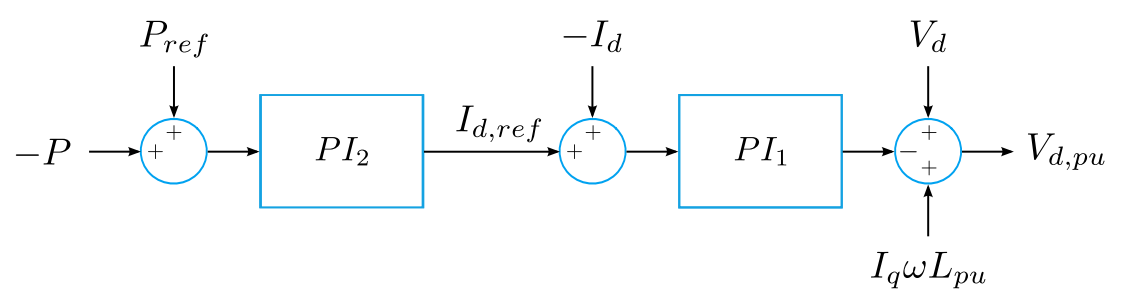

De forma análoga ao controle de $\mathrm{P}$, o controle de Q irá gerar referência para a malha de corrente, sendo neste caso, referência para corrente em quadratura $I_{q, r e f}$, ver Figura 17.

\footnotetext{
${ }^{2} \mathrm{Na}$ etapa de controle todas as variáveis foram tratadas em p.u. e estão no domínio da transformada de Park.
} 
Figura 17 - Malha de controles da potência reativa Q.

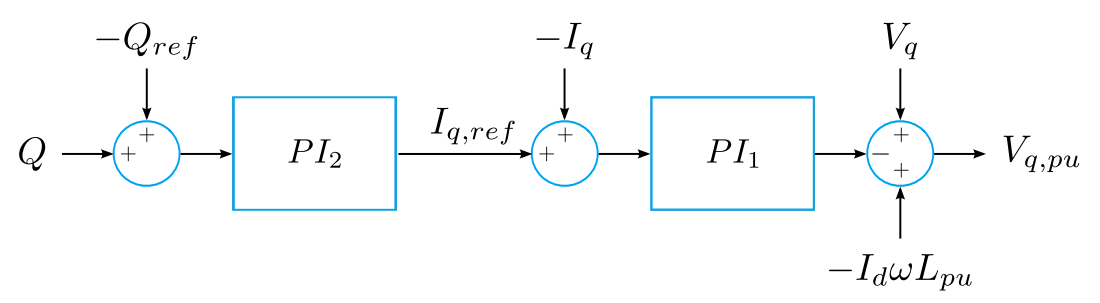

Quanto ao controle de $V_{c c}$, a adição de uma malha intermediária $P I_{3}$, que controla $\mathrm{P}$, é sugerida para melhorar a performance das respostas geradas por este esquema. Dependendo das características do sistema essa malha intermediária pode ser ignorada e a malha $P I_{2}$ gerar referência diretamente para a malha $P I_{1}$.

Figura 18 - Malha de controles de $V_{c c}$.

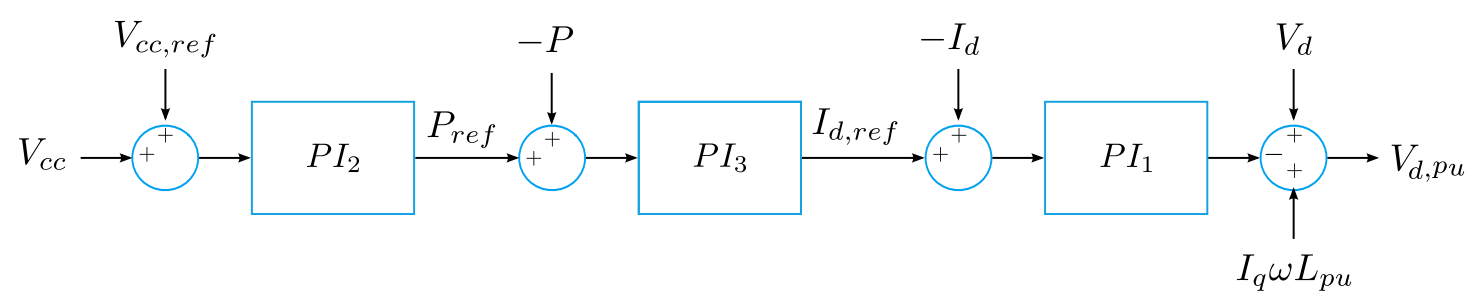

As malhas de controle de corrente são implementadas tanto para $I_{d}$ quanto para $I_{q}$. Estas malhas regulam o sinal de corrente através do controlador $P I_{1}$. A saída de $P I_{1}$ é o sinal de tensão $V_{d}$ ou $V_{q}$, que após passarem pela transformada de $d$ - $q$ - 0 para $a$ - $b$ $c$, serão as senoides, $V_{a, r e f} V_{b, r e f}$ e $V_{c, r e f}$, de referência para o PWM, como mostrado na Figura 19. Esta figura mostra os sinais resultantes do controle de um VSC no circuito que será descrito na Seção 5.6. Por hora, é importante observar a forma de onda da portadora, os sinais de referência $V_{a, r e f} V_{b, r e f}$ e $V_{c, r e f}$, resultado da transformação $d-q-0$ para $a-b-c$ e o sinal de controle do IGBT que é gerado a partir da comparação. Cada $V_{n, r e f}$ (n é a fase da tensão) gera referência para dois $\operatorname{IGBTs}^{3}$, um sinal de referência direta e um sinal complementar. A referência direta ligado a fase $a$, controla o $I G B T_{a}^{+}$, como mostra a figura.

No circuito que gerou os sinais mostrados na Figura 19, uma falta foi inserida na linha de transmissão em $t=0.15 \mathrm{~s}$, de forma que pode ser observado, logo após a ocorrência da falta, o estado de bloqueio do IGBT. Na próxima seção detalhes a respeito deste modo de operação serão tratados.

O ajuste da tensão $\dot{V}_{n}$ (tensão nos terminais do conversor) é dado através do chaveamento dos IGBTs, que ocorre através da modulação PWM, abordada nessa seção. A modulação deste tipo, emprega as senoides de referência $V_{a, r e f} V_{b, r e f}$ e $V_{c, r e f}$ na comparação com um sinal da portadora, que é uma onda triangular de frequência elevada. Esta técnica é vantajosa em termos das componentes harmônicas geradas no sinal sintetizado

\footnotetext{
${ }^{3}$ Considerando um sistema monopolar simétrico de dois níveis.
} 
Figura 19 - Portadora, referência por fase e saída do PWM implementado.

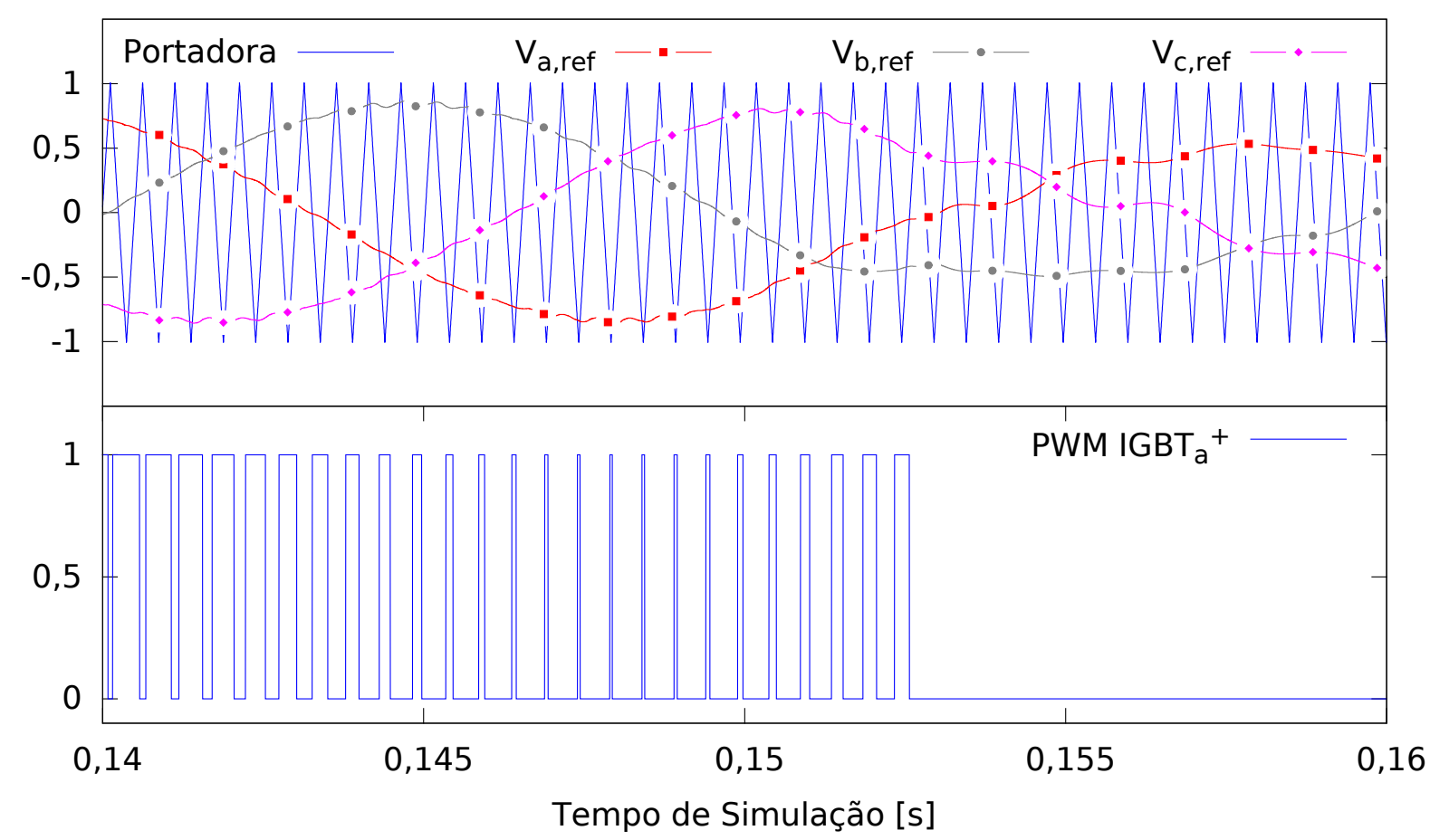

estarem em torno da frequência fundamental de chaveamento e suas múltiplas, facilitando o projeto de filtros para sua eliminação (DANIEL, 2011).

\subsection{Modo de Proteção dos Conversores}

Os conversores CSCs naturalmente proporcionam maior resistência a correntes de curtos-circuitos na parcela CC do sistema, devido aos indutores no circuito em corrente contínua, bem como limitam as correntes durante tais condições. Já os VSCs, são mais vulneráveis a essas correntes. De forma a compensar essa fragilidade, novos equipamentos de proteção estão sendo desenvolvidos, além de configurações de cabos que minimizem a ocorrência de defeitos (FLOURENTZOU; AGELIDIS; DEMETRIADES, 2009).

Embora seja fundamental para a maior aceitação e confiabilidade das redes HVDC, a disponibilidade dos disjuntores é limitada e a sua aplicação não está consolidada. Estas restrições ocorrem devido a diferença dos requisitos de operação dos sistemas CC, ou seja, devido à ausência de correntes que naturalmente assumam valor nulo. Assim, os disjuntores CC necessitam interromper as correntes de curto-circuito rapidamente e precisam dissipar a energia que é armazenada na indutância no sistema (FRANCK, 2011). Por vezes, os disjuntores para sistemas CC disponíveis, atendem a baixa e média tensão, e os que atendem a alta tensão, apenas compreendem diferentes conexões de disjuntores clássicos ou dispositivos armazenadores de energia, sendo que, nenhum destes atendem todos os requisitos necessários a abertura e dissipação de energia conveniente aos circuitos HVDC (FRANCK, 2011). 
Dessa forma, as condições de curto-circuito nas linhas CC são cenários desfavoráveis aos VSCs. Como forma de proteção contra os efeitos danosos devido a exposição aos altos valores das correntes, os transistores passam a operar no modo de proteção quando a corrente ultrapassa $2 \mathrm{pu}$, onde estes param de chavear e expõem os diodos reversos às correntes de curto-circuito (RTE, 2012).

No modo de proteção, os VSCs passam a operar como retificadores não controlados, como ilustrados na Figura 20.

Figura 20 - Circuito equivalente mediante bloqueio dos IGBTs.

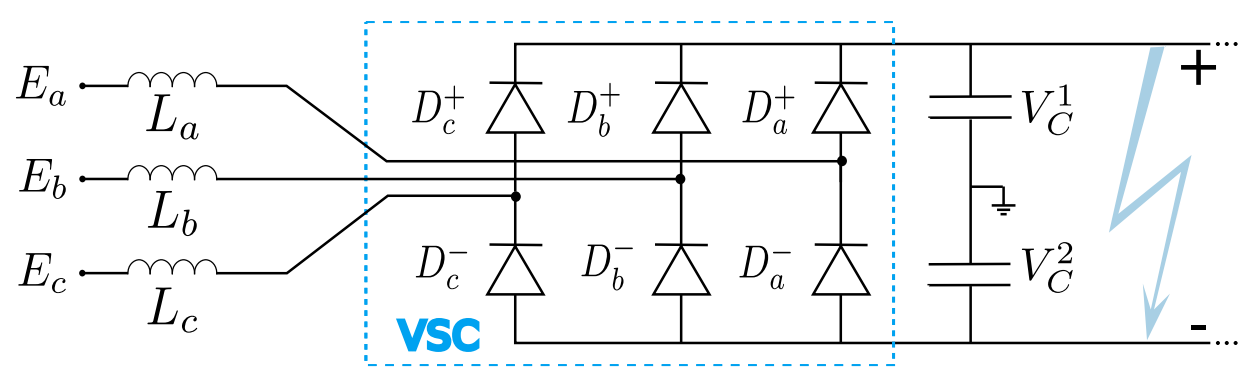

O modo de proteção dos conversores garante a integridade física dos semicondutores e evita o estresse nos quais estes seriam submetidos caso percorridos por correntes de curto-circuito. Para detectarem cenários desfavoráveis à operação, os IGBTs utilizam o valor médio instantâneo das correntes das fases do circuito de CA, onde o valor absoluto da corrente das três fases é comparado com um valor limiar predeterminado. No instante em que a corrente de uma das fases supera o limiar de 2 pu, os IGBTs passam a operar em modo de proteção (LU; SHARMA, 2008).

\subsection{Modelo do Sistema Utilizado}

A partir das considerações que foram feitas neste capítulo, um modelo de sistema foi usado para validar a metodologia deste estudo. Este modelo é mostrado na Figura 21. O sistema modelo adota os seguintes parâmetros ${ }^{4}$ :

$\square$ Tipo de conversor: VSC;

Número de níveis: Dois;

$\square$ Tipo da linha: Topologia monopolar simétrica;

$\square$ Tipo de controle utilizado: Método de Controle Vetorial (MCV);

\footnotetext{
${ }^{4}$ Os demais parâmetros, que não foram tratados nesta seção, serão posteriormente abordados.
} 
Figura 21 - Modelo do sistema em estudo.

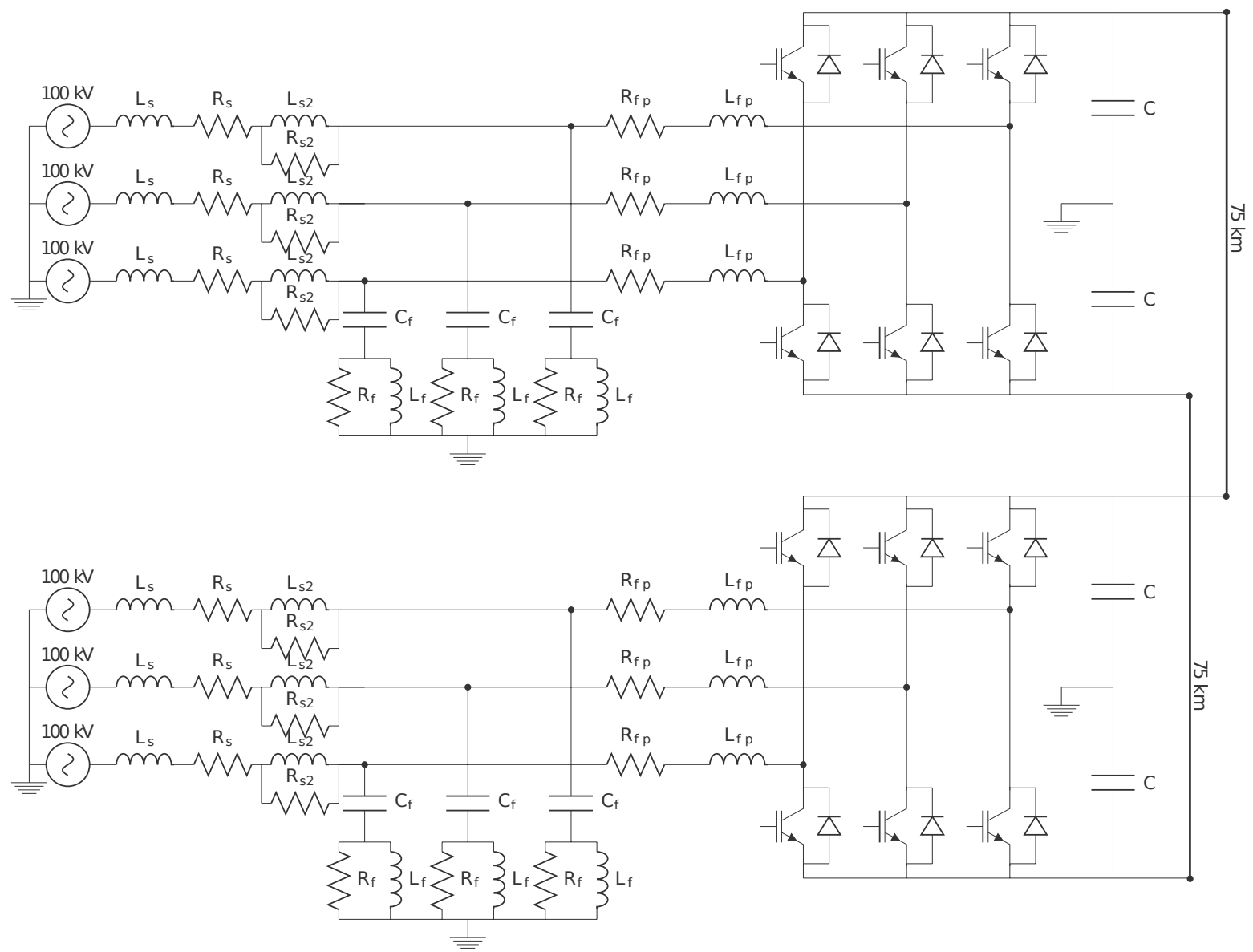

\subsection{Considerações}

Neste capítulo foram abordadas as topologias das estações VSC, onde foram mostrados diversos arranjos de transistores e diodos, para proporcionar uma diversidade maior de características operacionais aos sistema VSC-HVDC. Também foram tratados os diversos tipos de configurações das linhas CC, que possibilita uma avaliação custo-beneficio, sobre possíveis redundâncias no sistema, que são os casos de falta em uma das linhas pode existir outra linha que continuará a operar, mantendo o sistema estável.

Ainda neste capítulo, foram tratadas as condições de operação dos conversores. Estas são definidas pela relação entre a tensão do barramento alternado $\dot{E}_{n}$ e a tensão nos terminais do conversor, $\dot{V}_{n}$. Esta relação define o fornecimento ou consumo de potência ativa e reativa em cada conversor. Na sequência foi mostrada a estrategia de controle utilizada e as malhas de cada variável controlada.

Para finalizar o capítulo, foi abordado a operação em modo de proteção, que consiste no mecanismo de defesa dos transistores ao se depararem com situações de curto-circuito e a sua consequente operação como retificador não controlado. 


\section{Curto-Circuito Probabilístico em Sistemas Elétricos de Potência}

No Capítulo 1 foram contextualizadas as aplicações dos sistemas em corrente contínua e a motivação para aplicação de técnicas estatísticas nestes. No Capítulo 2, foi possível conhecer a respeito das topologias de sistemas HVDC. Propondo a integração das temáticas já tratadas neste estudo, este capítulo irá apresentar a teoria estatística inerente aos CCP, bem como seus princípios. O mesmo ainda se propõe a explanar o estado da arte do CCP de sistemas em corrente alternada.

Todos os casos e algoritmos mostrados neste capítulo, são situações hipotéticas que os autores simularam através do programa Matlab. Estes foram criados com objetivo de auxiliar o leitor quanto a compreensão dos conceitos estatísticos ligados ao CCP. A teoria necessária para o desenvolvimento dos mesmos foi baseada em Dantas (2008), Bisquerra, Sarriera e Matínez (2007).

\subsection{Conceitos Inerentes aos Fenômenos Estocásticos}

Situações as quais gerem incertezas quanto a consequência, como por exemplo o lançamento de um dado ou o placar de uma partida de futebol, são eventos ditos aleatórios, pois, se repetidos nas mesmas condições, não produzirão, impreterivelmente, o mesmo resultado. Para alguns eventos aleatórios, como é o caso dos exemplos citados, uma forma de definir sua consequência é atribuir um valor numérico a este. Sendo estes eventos aleatórios, cada realização destes, acarretará em variações do valor numérico atribuído. No caso do lançamento de um dado, as possíveis consequências serão limitadas pelo número de faces deste. Estas consequências definem o espaço amostral deste evento. Neste exemplo é intuitivo atribuir a cada face do dado o valor nela descrita, no caso de um dado de seis faces, o espaço amostral pode ser descrito pela Equação 3.

$$
C: S \rightarrow\{1,2,3,4,5,6\}
$$


Quando uma função associa elementos do espaço amostral a valores numéricos, esta é denominada de Variável Aleatória (VA) (DANTAS, 2008). Existem duas formas de classificar VAs, são elas: contínuas ou discretas. Quando contínuas, assumem qualquer valor do conjunto de números reais e quando discretas, são numericamente parte do conjunto dos números naturais.

Para melhor representar os conceitos inerentes aos processos aleatórios, foram desenvolvidos neste estudo os ensaios dos eventos $A$ e $B$. Nestes ensaios, foi realizada a Simulação de Monte Carlo (SMC) no programa Matlab, para descrever os fenômenos ligados ao lançamento de dados.

O Algoritmo 1, descreve o ensaio do evento A. Supondo que o evento consiste em realizar $N$ lançamentos de um dado de seis faces, que o espaço amostral foi descrito na Equação 3. Pode-se considerar que, as faces possuem probabilidade igual de serem sorteadas, no pressuposto que nenhum fenômeno físico age sobre este objeto para priorizar determinada face. Assim, a VA deste evento é caracterizada por uma função de distribuição uniforme. A função rand retorna um único número aleatório distribuído uniformemente entre 0 e 1 . O produto de rand $* 6$ atribuirá os valores da função rand ao intervalo definido pelo espaço amostral.

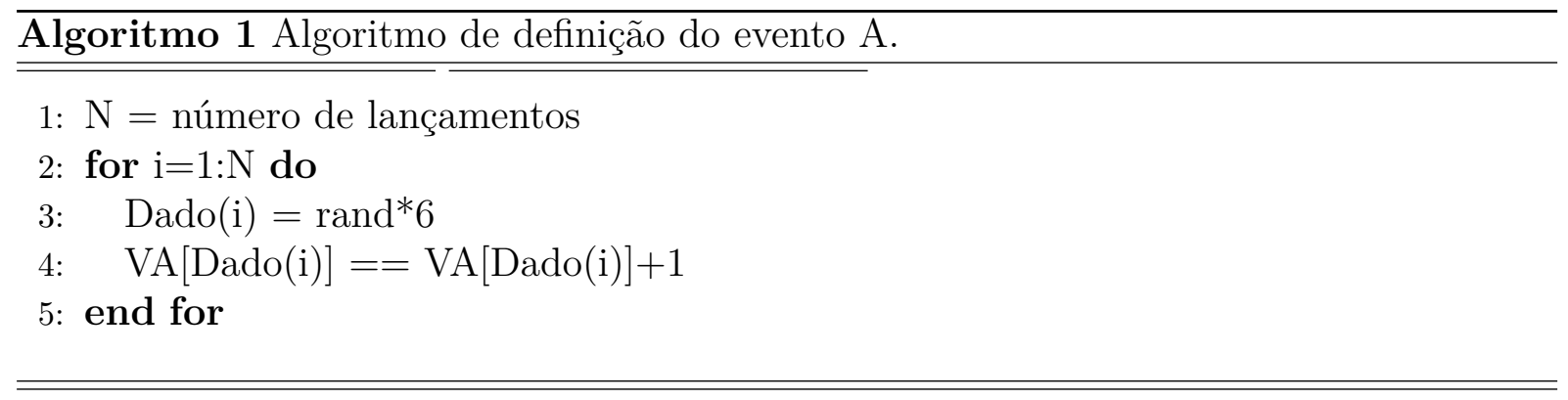

Ao final das iterações um vetor VA foi gerado, com a frequência de ocorrência de cada face do dado. Quando os $N$ lançamentos são distribuídos em suas respectivas faces sorteadas, ocorre o equivalente a distribuir as consequências entre os elemento do espaço amostral, ou seja, construir a Função de Densidade de Probabilidade (FDP) da VA. Quando no evento $A, N=1 E 3$, a FDP pode ser ilustrada pela Figura 22.

No caso do número de lançamentos aumentar para $N=10 E 3$, a função aproxima-se ainda mais de uma reta, apontando que o fenômeno tem como característica uma distribuição uniforme, ver Figura 23. Esses resultados também apontam que quando $N$ cresce, o tipo de distribuição do evento torna-se mais notório, entretanto esse aumento satura ao passo que se atinge a representatividade estatística (BISQUERRA; SARRIERA; MATÍNEZ, 2007) da amostra, assim, mais lançamentos não alterarão a distribuição descrita.

Um novo evento é proposto $(\mathbf{B})$ que consiste em realizar $N$ lançamentos, sendo desta vez considerado o lançamento de dois dados simultaneamente. As faces destes continuam possuindo probabilidade igual de serem sorteadas, embora para construir a FDP deste 
Figura $22-$ FDP do evento A, com $N=1 E 3$.

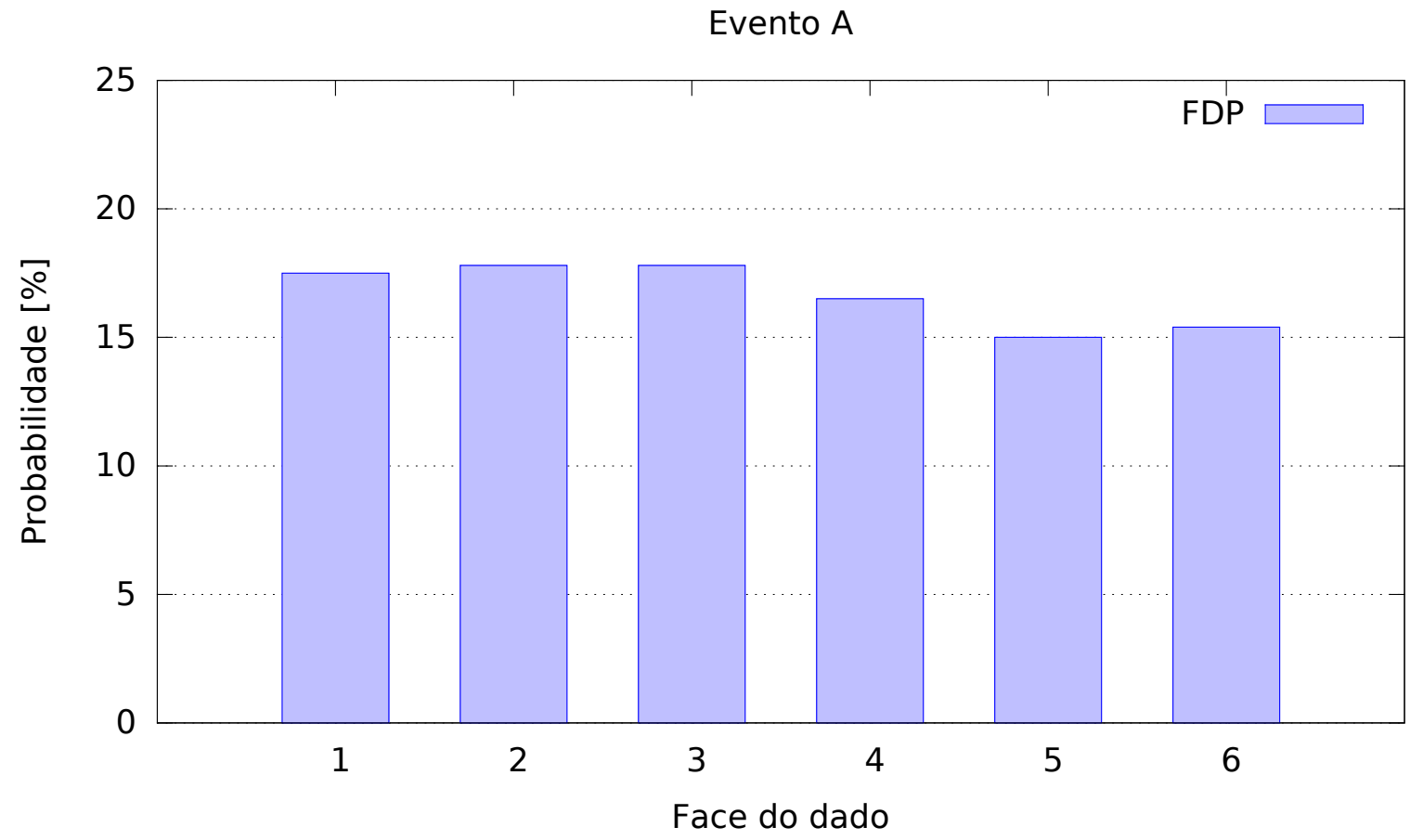

Figura 23 - FDP do evento A, com $N=10 E 3$.

Evento A

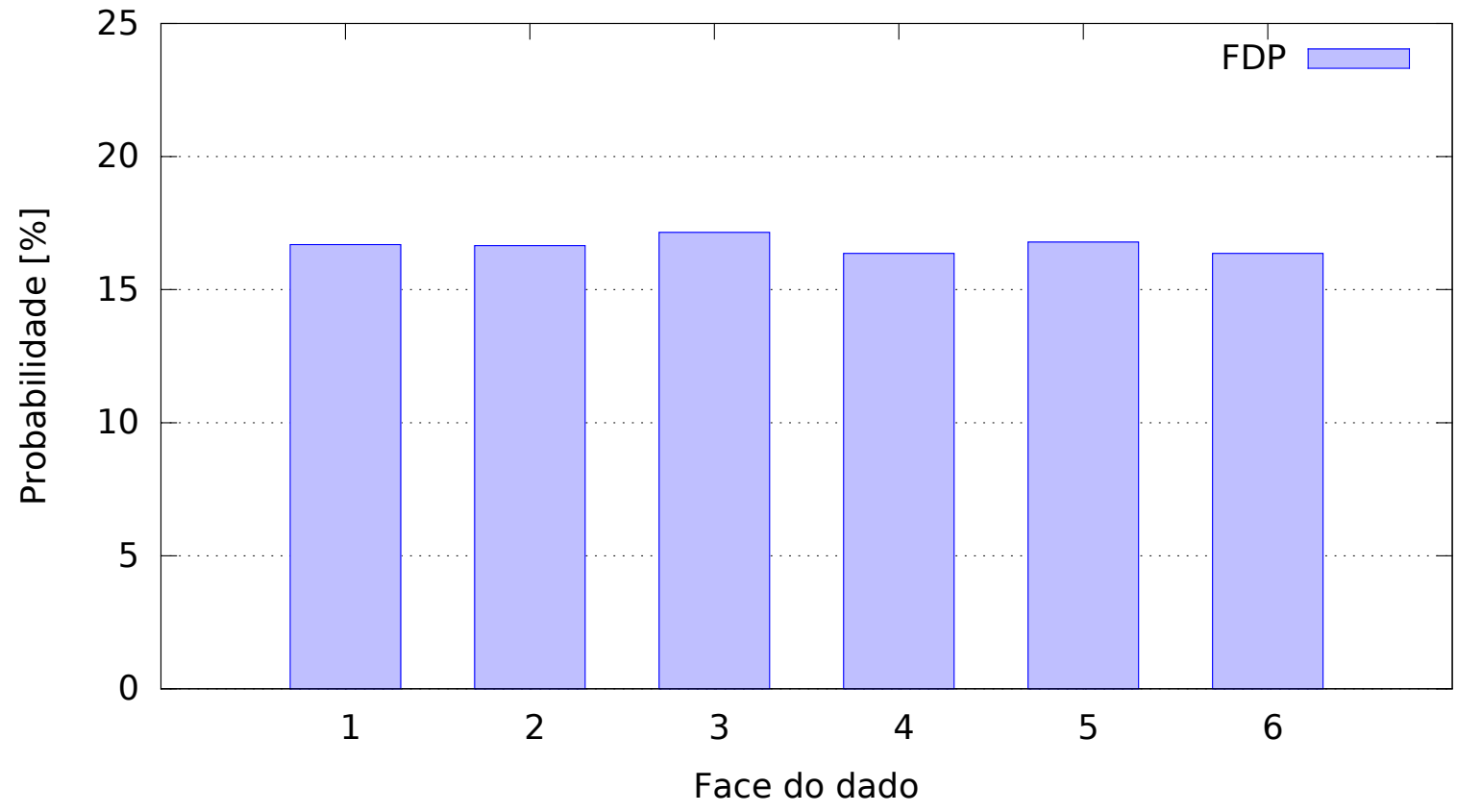

evento sugere-se que a cada lançamento seja somado o valor expresso na face de cada dado. Um novo espaço amostral representará este evento, apresentado na Equação 4.

$$
C: S \rightarrow\{2,3,4, . ., 12\}
$$


Este novo espaço amostral terá seus limites definidos pelo máximo e o mínimo valor resultado da soma dos valores das faces dos dados. Onde, o mínimo é quando os dois dados lançados mostrem a face unitária, sendo a soma igual a dois e o máximo é quando os dois dados mostram a face de valor seis, onde a soma é igual a doze, como descrito pelo espaço amostral. Este evento foi criado através do Algoritmo 2.

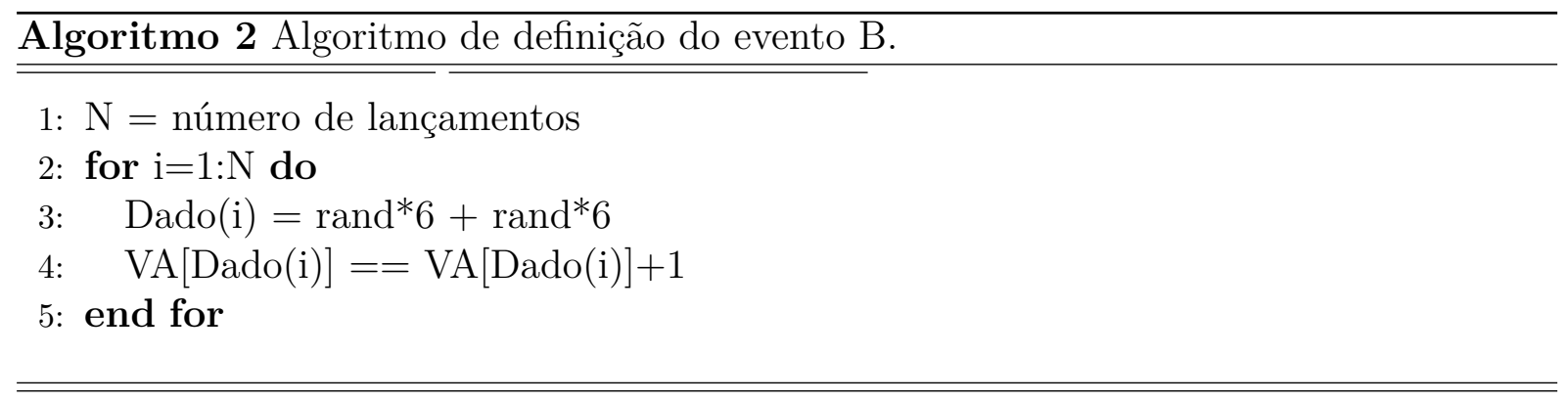

Para o evento $B$, a Figura 24 mostra a FDP para $N=1 E 3$ e a Figura 25 para $N=10 E 3$. Ao se deparar com tais resultados, percebe-se que o comportamento não é mais descrito através de uma função uniforme, e sim através de uma função normal. Isso porque, se analisado o fenômeno $\mathbf{B}$, existem muitas possibilidades do somatório das faces resultarem no valor sete enquanto que uma única forma de resultar no valor dois. A ocorrência do fenômeno B implica que a VA descreve uma função denominada do tipo normal ou gaussiana. A literatura descreve outros tipos de distribuição de probabilidade (SCHWAAB, 2003), entretanto, este estudo, se limitará aos tipos já descritos: uniforme e normal.

Da mesma forma que o evento A, o evento B mostra uma função ainda mais próxima a gaussiana perfeita, quando o número de eventos aumenta.

\subsection{Número de Amostras}

Embora que o número de lançamentos nos evento A e B sejam suficientes para descrever o tipo de função desempenhada por cada fenômeno, este consiste em uma questão com bastante relevância no escopo do CCP. Como já foi descrito, quanto mais amostras, melhor um fenômeno é representado, até o ponto que o crescimento do número de amostras não alterara a função descrita. Uma forma de quantificar a alteração da função é calcular a distância euclidiana entre os histogramas de um mesmo evento, com número de amostras diferentes. Primeiramente, a distância euclidiana entre dois pontos, $\alpha=\alpha_{1}, \alpha_{2}, \ldots, \alpha_{n}$ e $\beta=\beta_{1}, \beta_{2}, \ldots, \beta_{n}$ pode ser dada pela Equação 5 .

$$
\text { Euclidiana }=\sqrt{\left(\alpha_{1}-\beta_{1}\right)^{2}+\left(\alpha_{2}-\beta_{2}\right)^{2}+\ldots+\left(\alpha_{n}-\beta_{n}\right)^{2}}
$$

Dessa forma, define-se o evento A: $\alpha$ equivale ao histograma com $N=5 E 3$ e $\beta$ equivale a um histograma com $N=10 E 3$, onde $\alpha_{1}$ e $\beta_{1}$ equivale ao percentual descrito 
Figura $24-$ FDP do evento B, com $N=1 E 3$.

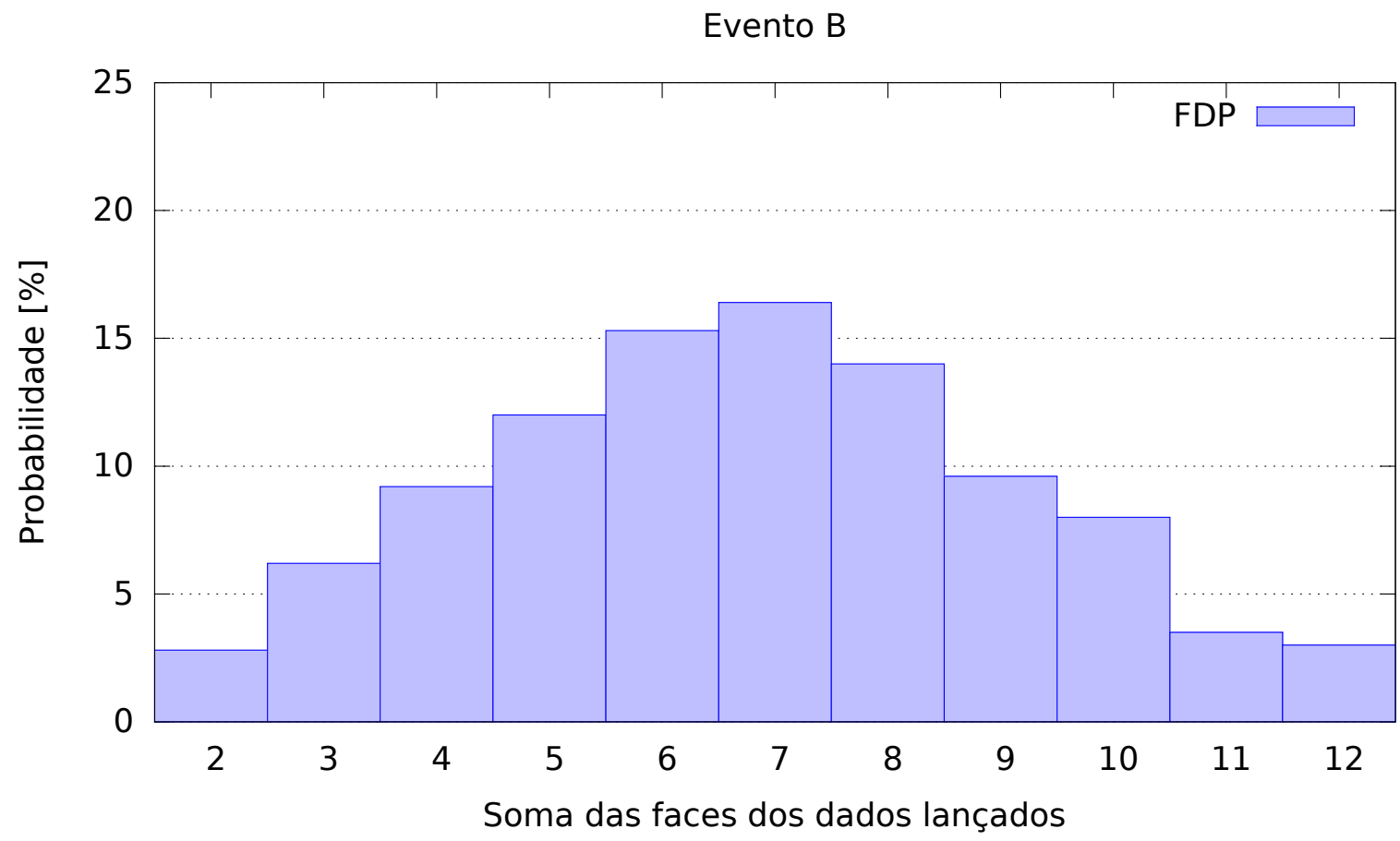

Figura 25 - FDP do evento B, com $N=10 E 3$.

Evento B

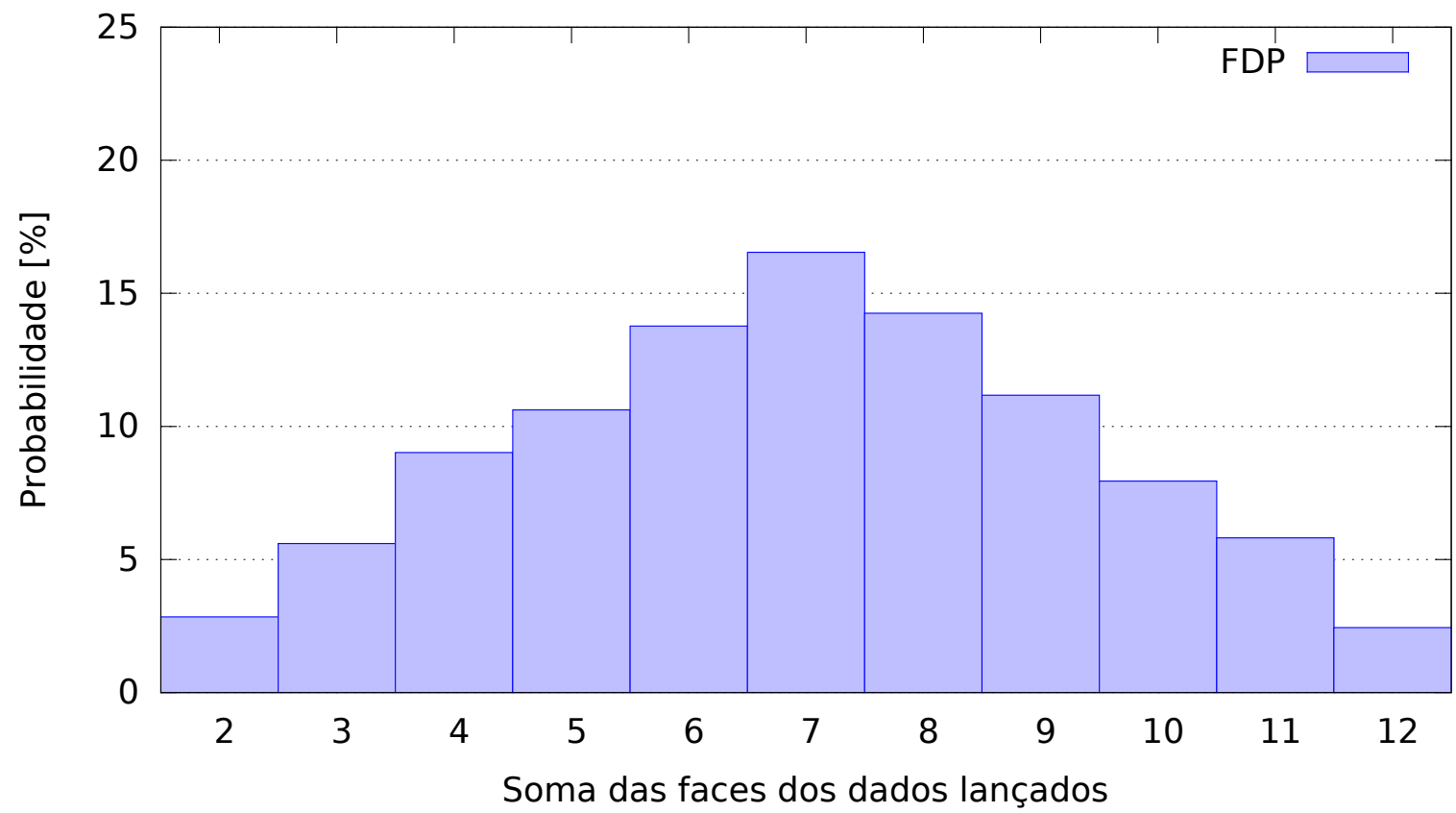

pela primeira barra de cada histograma, e assim sucessivamente até a barra de número $n$. Dessa forma a Equação 5 irá imprimir a distância normalizada entre o histograma $\alpha$ e $\beta$ do evento A, na variável D1, ver Figura 26. Foram gerados novos histogramas $n s[k]$, incrementando o número de simulações, em relação ao histograma atual, com o passo de $p s=5 E 3$, como definido na Equação 6, até que o número de simulações seja igual a 
$n s=50 E 3$.

$$
n s[k]=n s[k-1]+p s
$$

Para cada novo histograma $n s[k]$ foi medida a sua distância para o histograma $n s[k-1]$, assim obtendo a distância euclidiana normalizada entre histogramas consecutivos, como mostra o Algoritmo 3. A distância euclidiana $D_{i}$ obtida para os consecutivos histogramas é mostarda na Figura 26.

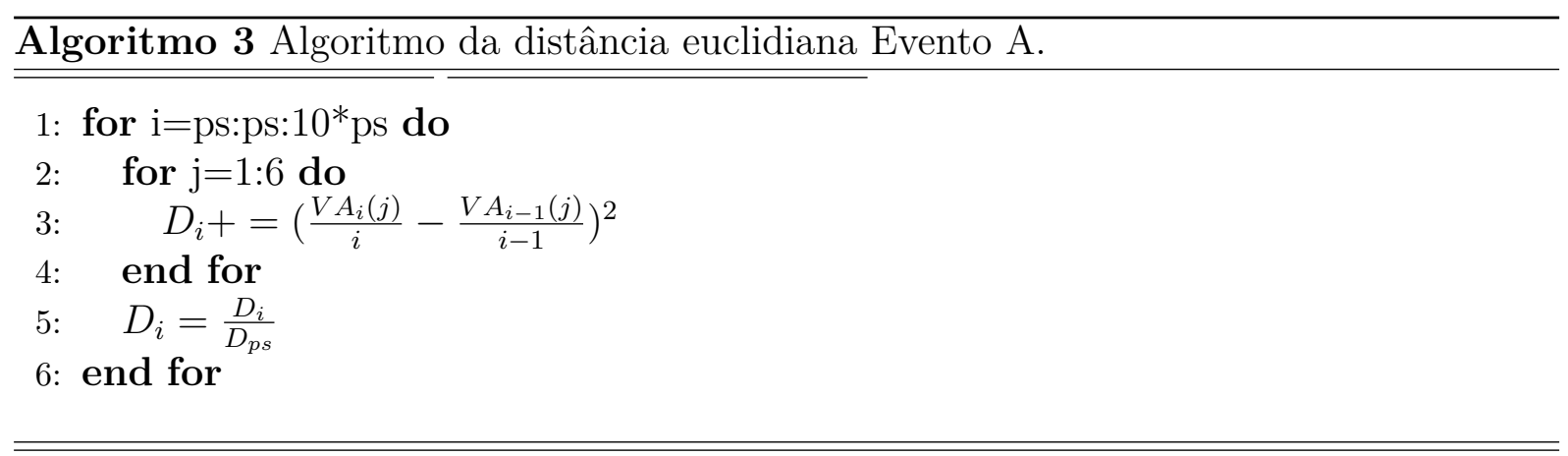

Figura 26 - Distância euclidiana normalizada, entre histogramas com um número crescente de simulações.

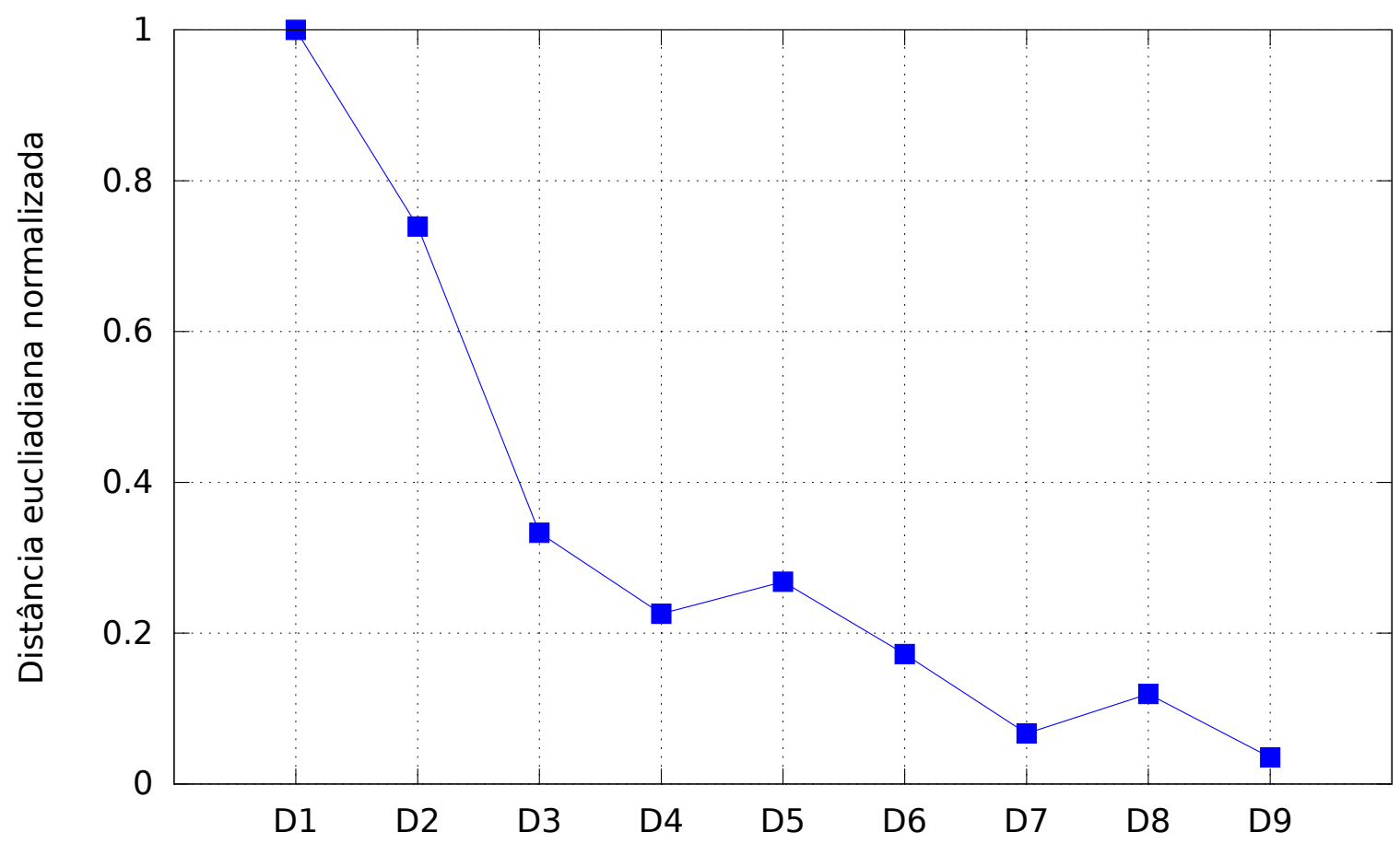

Como pode-se notar, a distância euclidiana diminui conforme o número de simulações cresce, isso implica que não haverão grandes alterações nos histogramas gerados com mais simulações, pois a distância tende a zero. Portanto, conclui-se que é possível escolher, considerando a relação custo computacional versus benefício, um número otimizado de simulações que represente adequadamente esse fenômeno. 


\subsection{Densidade Acumulada de Probabilidade}

Uma vez definida a FDP de um evento, pode-se considerar atrativo determinar a probabilidade de um conjunto de soluções, ou seja, uma parcela de interesse específica do espaço amostral. Como exemplo, para o fenômeno A, um jogador poderá desejar conhecer a probabilidade de que o lançamento de um dado resulte em valores $\leq 4$. A informação de interesse do jogador pode ser extraída da Densidade Acumulada de Probabilidade (DAP), esta função pode ser construída como descrito no Algoritmo 4. Neste, o vetor VA (que já foi determinado pela FDP), acumulará em cada posição o valor da posição anterior, ao ponto que todos os lançamentos estarão expressos ao se alcançar o último intervalo.

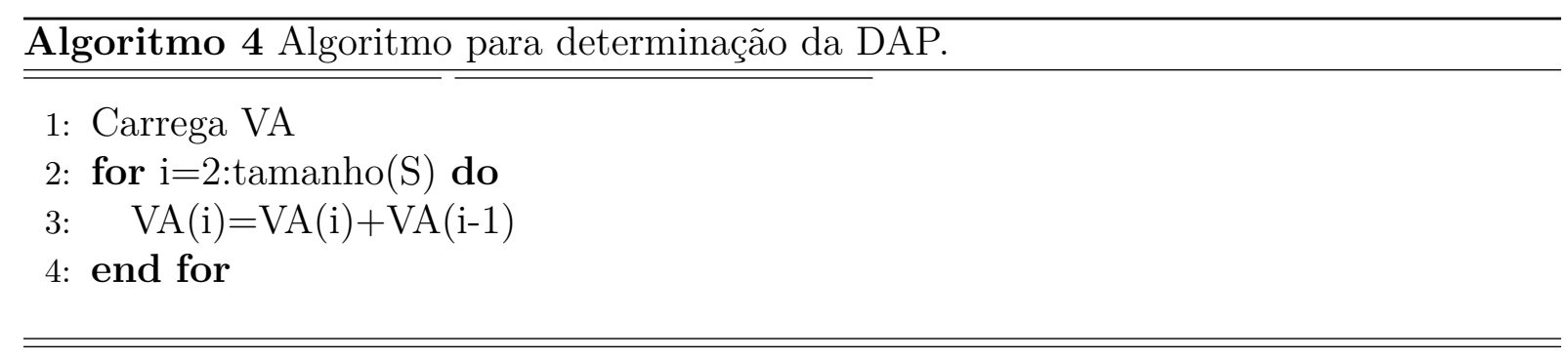

A Figura 27, mostra a DAP do evento $A$ e a Figura 28 mostra a DAP do evento $B$, ambos com $N=10 E 3$.

A partir da DAP é possível responder ao jogador que a probabilidade de valores menores e iguais a quatro serem sorteados é de 66,6\%. Esta conclusão é listada na Tabela 2, para todos os valores do espaço amostral do evento A, e na Tabela 3, para todos os valores do espaço amostral do evento B.

Tabela 2 - Probabilidade de intervalos do evento A.

\begin{tabular}{ccccccc}
\hline Face & $\leq 1$ & $\leq 2$ & $\leq 3$ & $\leq 4$ & $\leq 5$ & $\leq 6$ \\
Probabilidade & $16,6 \%$ & $33,3 \%$ & $50,0 \%$ & $66,6 \%$ & $83,3 \%$ & $100 \%$ \\
\hline Face & $\geq 1$ & $\geq 2$ & $\geq 3$ & $\geq 4$ & $\geq 5$ & $\geq 6$ \\
Probabilidade & $83,4 \%$ & $66,7 \%$ & $50,0 \%$ & $33,4 \%$ & $16,7 \%$ & $0 \%$ \\
\hline
\end{tabular}

Tabela 3 - Probabilidade de intervalos do evento B.

\begin{tabular}{cccccccccccc}
\hline Face & $\leq 2$ & $\leq 3$ & $\leq 4$ & $\leq 5$ & $\leq 6$ & $\leq 7$ & $\leq 8$ & $\leq 9$ & $\leq 10$ & $\leq 11$ & $\leq 12$ \\
Probabilidade & $2 \%$ & $8 \%$ & $16 \%$ & $28 \%$ & $42 \%$ & $58 \%$ & $72 \%$ & $83 \%$ & $91 \%$ & $96 \%$ & $100 \%$ \\
\hline Face & $\geq 2$ & $\geq 3$ & $\geq 4$ & $\geq 5$ & $\geq 6$ & $\geq 7$ & $\geq 8$ & $\geq 9$ & $\geq 10$ & $\geq 11$ & $\geq 12$ \\
Probabilidade & $98 \%$ & $92 \%$ & $84 \%$ & $72 \%$ & $58 \%$ & $42 \%$ & $28 \%$ & $17 \%$ & $9 \%$ & $4 \%$ & $0 \%$ \\
\hline
\end{tabular}

A Tabela 2 e a Tabela 3, são a tradução do que foi mostrado através das DAPs de cada evento. Como exemplo, pode-se apontar a probabilidade do evento $B$ gerar um resultado igual ou maior que 10, que é de $9 \%$. Em suma, é possível observar que, se o interesse for por todos os eventos que um fenômeno possa resultar (todo o espaço amostral) a DAP resultará na soma de cada ponto descrito na função FDP. Ou seja, se todas as soluções 
Figura 27 - DAP do evento A, com $N=10 E 3$.

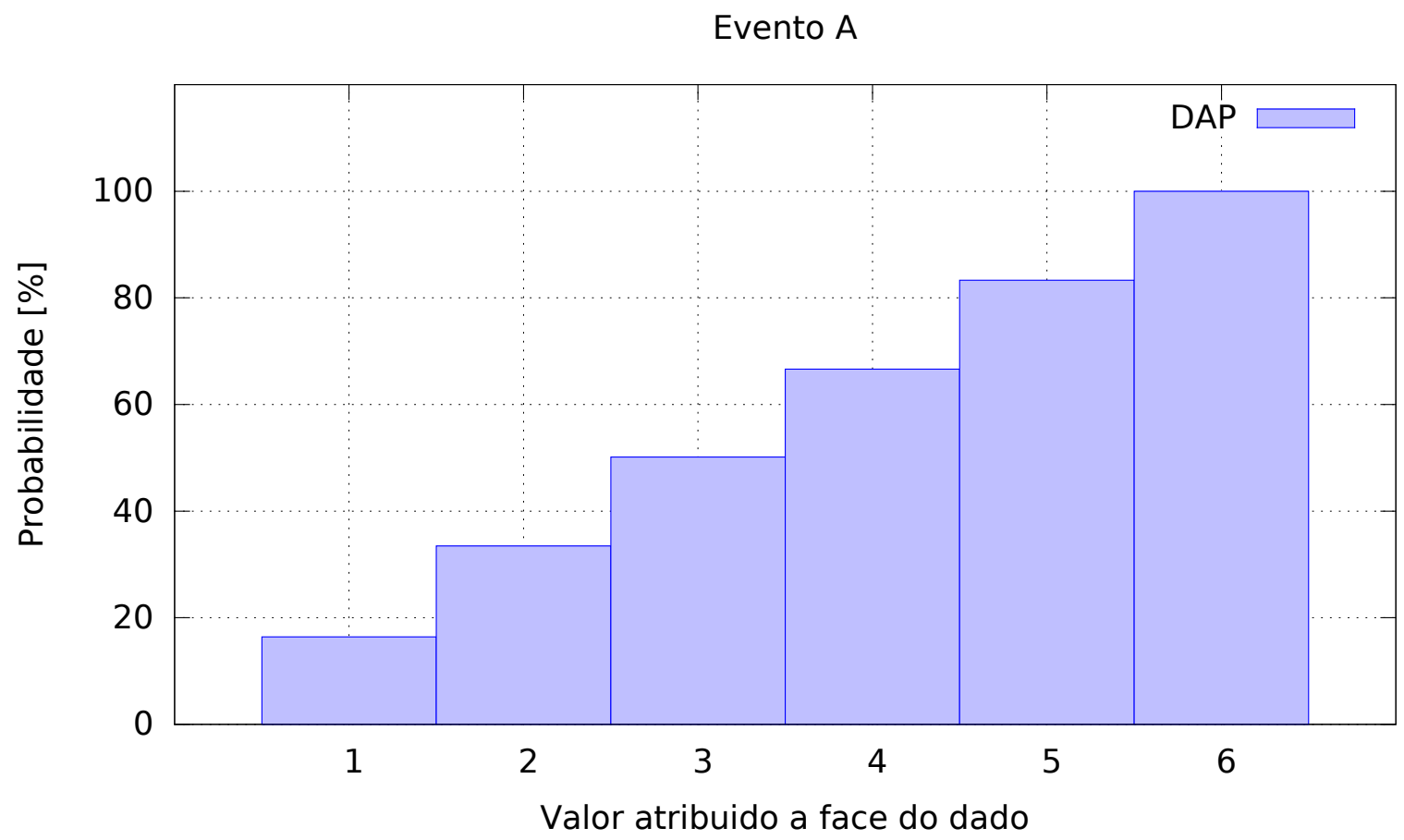

Figura 28 - DAP do evento B, com $N=10 E 3$.

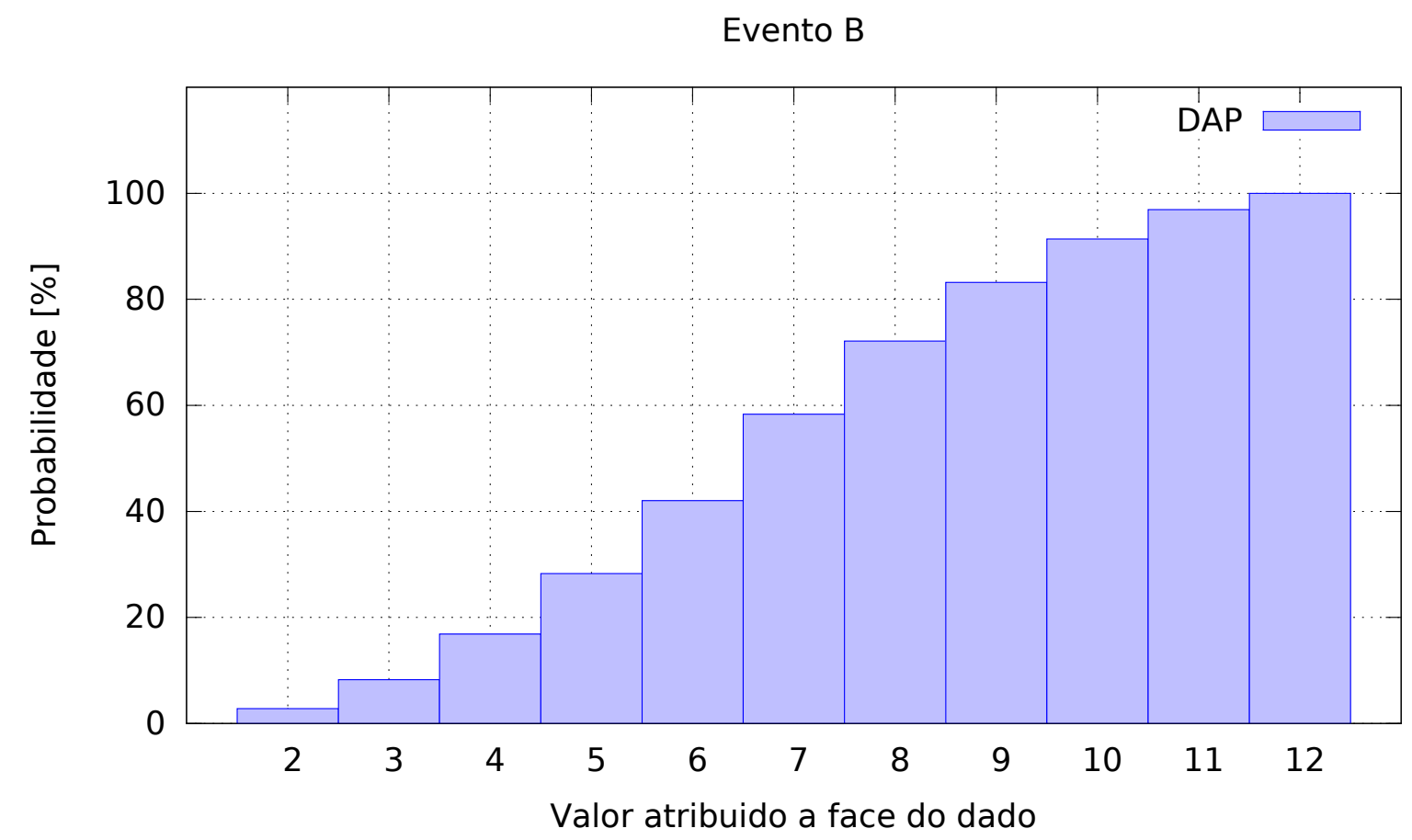

estão descritas no espaço amostral $S$, Equação 7, a DAP deste fenômeno poderá ser representado através da Equação 8 (BRAGA, 2010), isto é, o somatório das probabilidades de $k_{1}, k_{2}, \ldots, k_{n}$.

$$
X: S \rightarrow\left\{k_{1}, k_{2}, \ldots, k_{n}\right\}
$$




$$
\sum_{X=k_{1}}^{k_{n}} P(X)=100 \%
$$

Se em um fenômeno, as soluções possuem igual probabilidade de ocorrer, como é o caso do evento A, este desempenhará uma função do tipo uniforme e cada solução terá a probabilidade igual de ocorrer, como mostra a Equação 9, onde $n$ é o número de soluções.

$$
P(X=k)=\frac{1}{k_{n}}
$$

\subsection{Correlação entre Sinais}

A estatística também provê ferramentas para medir a similaridade entre sinais, estas serão úteis no decorrer deste estudo para medir a similaridade entre sinais gerados em ferramentas distintas. A similaridade é medida obtendo a correlação entre sinais e se refere a busca da existência de relação, isto é, conhecer se as alterações sofridas por uma das variáveis são acompanhadas por alterações nas outras. O termo significa relação em dois sentidos e é usado em estatística para designar a semelhança entre dois conjuntos de valores.

A verificação da existência e do grau de relação entre sinais é o objeto de estudo da correlação. Na Equação 10 é medida a correlação entre os sinais digitais $x=x_{1}, x_{2}, \ldots, x_{n}$ e $y=y_{1}, y_{2}, \ldots, y_{n}$, cada um com $n$ amostras e $i$ é um contador de amostras.

$$
r=\frac{\sum_{i=1}^{n} x_{i} y_{i}-\frac{\sum_{i=1}^{n} x_{i} \sum_{i=1}^{n} y_{i}}{n}}{\sqrt{\sum_{i=1}^{n} x_{i}^{2}-\frac{\left(\sum_{i=1}^{n} x_{i}\right)^{2}}{n}} \sqrt{\sum_{i=1}^{n} y_{i}^{2}-\frac{\left(\sum_{i=1}^{n} y_{i}\right)^{2}}{n}}}
$$

\subsection{Contexto da Simulação de Monte Carlo}

Técnicas de simulações são empregadas com sucesso em diversos problemas de engenharia. As simulações são estratégias numéricas computacionais que pretendem reproduzir algum sistema real. Essa reprodução é obtida através de modelos que são utilizados para analisar uma decisão envolvendo o comportamento de um ou mais fatores que não são conhecidos com exatidão.

Toda simulação requer a construção de um modelo, definido por um conjunto de relações lógicas e matemáticas. Dependendo do problema a ser abordado, o modelo criado para este pode gerar uma simulação do tipo determinística ou do tipo probabilística (BOUZADA, 2013; LAW AVERILL M, 1991). De forma simplificada, um modelo de simulação 
determinístico é aquele que não contêm nenhum elemento aleatório. Um sistema complexo de equações diferenciais que descrevam uma reação química pode ser um exemplo deste tipo de modelo. Em um modelo determinístico a saída é obtida quando se define o conjunto de entradas e suas relações, através do modelo proposto. Entretanto, alguns sistemas devem ser modelados com componentes de entradas aleatórias, e são essas entradas aleatórias que dão origem ao modelo probabilístico. Os modelos de simulação probabilístico produzem saídas de natureza também aleatória. Por isso, devem ser tradadas como uma estimação das características reais do modelo(LAW AVERILL M, 1991).

No contexto das simulações que buscam reproduzir o comportamento de processos que dependem de fatores aleatórios, um método estatístico que vem ao longo dos anos obtendo sucesso é da Simulação de Monte Carlo (SMC)(ECKHARD, 1987). Este método permite essencialmente gerar uma avaliação interativa de um modelo, podendo ser ele determinístico ou probabilístico, usando números aleatórios como entradas. No caso probabilístico, o método consiste em gerar números aleatórios, escolhidos de maneira que simulam diretamente os processos aleatórios físicos do problema original para inferir a solução desejada a partir do comportamento destes números aleatórios. Caso o problema seja determinístico, o método consiste em tratá-lo mediante uma analogia probabilística.

No passado, as aplicações da SMC eram limitadas devido ao esforços computacionais necessários, dado o número elevado de simulações para descrever adequadamente um modelo. Este problema foi superado na atualidade devido a ampliação da capacidade dos computadores modernos. Atrelado aos conceitos abordados na Seção 3.1 o objetivo da SMC é descrever as características das VAs e das funções a esta relacionadas.

A geração de números puramente aleatórios através de computadores é um desafio, já que nas máquinas, todos os eventos são programados através de algoritmos. Na realidade, grande parte dos números aleatórios gerados por computador são obtidos de forma previsível, através de uma fórmula matemática. Os números aleatórios gerados neste estudo, para as simulações em linguagem C++, utilizam o gerador gsl_rng_mt19937 cujo núcleo de geração possui um período de aproximadamente $10^{6 E 3}$ e foi desenvolvido por Makoto Matsumoto and Takuji Nishimura (GSL, 2015). O período é a quantidade de números gerados, até que o algoritmo fique previsível. Como neste estudo foram gerado no máximo um milhão de números aleatórios, este algoritmo mostra-se eficiente para o propósito deste estudo.

\subsection{O Sistema Elétrico de Potência e as Aplicações da Teoria de Curto-Circuito Probabilístico}

O primeiro trabalho relevante no campo dos estudos probabilísticos em sistemas de energia elétrica foi datado do ano de 1961 (ANDERSON, 1961), onde se buscava analisar, utilizando a SMC, a performance das linhas de transmissão de um sistema elétrico 
de potência, mediante a ocorrência de descargas atmosféricas. Este método associado ao CCP começou a ter expressão em 1986 (BALOUKTSIS; TSANAKAS; VACHTSEVANOS, 1986), onde se afirma que a distribuição de probabilidade das correntes de curto-circuito fornecem informações importantes ao planejamento, confiabilidade e avaliação de risco. Posteriormente, muitas outras temáticas do sistema elétrico de potência têm sido abordadas através de métodos probabilísticos, com destaque para a SMC (VICENTE; CAIRE; HADJSAID, 2012; MAMEDE, 2004).

No tocante a transmissão através de sistemas HVDC, os primeiros registros relevantes no campo da estatística ocorreram em 1993 e propõem um modelo probabilístico de análise do desequilíbrio de tensão e variações de carga do conversor, como também o comportamento aleatório dos harmônicos do sistema (WANG; PIERRAT, 1993). Em 1994 técnicas de análise de confiabilidade por Billinton e Sankarakrishnan (1994) e em 2011 foram simulados por Greiner et al. (2011) eventos de curto-circuito em um sistema multiterminal utilizando disjuntores CC para que fossem estimados dados de mantenabilidade do sistema.

\subsection{Cálculo de Curto-Circuito Probabilístico em Li- nhas de Transmissão em Corrente Alternada}

No decorrer desta seção é discutida a teoria de CCP em sistemas CA, como proposto por Mamede (2004), e serão avaliados os resultados das simulações de CCP-CA desenvolvidas nesta pesquisa. Por fim, um paralelo entre as características físicas e operacionais entre sistemas CA e CC será criado.

Segundo Mamede (2004), duas frentes de estudo dão margem ao CCP. A primeira delas descreve um método analítico, e a segunda através da SMC. Com o advento da tecnologia, o custo computacional não se configura como problema ao SMC, fazendo desta, uma alternativa conveniente e adequada. Este método, promove a geração de números aleatórios a partir de uma dada função de distribuição e seu resultado é expresso através da FDP das correntes de curto-circuito.

Para contemplar a teoria do CCP-CA, será considerada a ocorrência de um curtocircuito trifásico na linha de transmissão de corrente alternada, ilustrada na Figura 29.

Figura 29 - Sistema em corrente alternada.

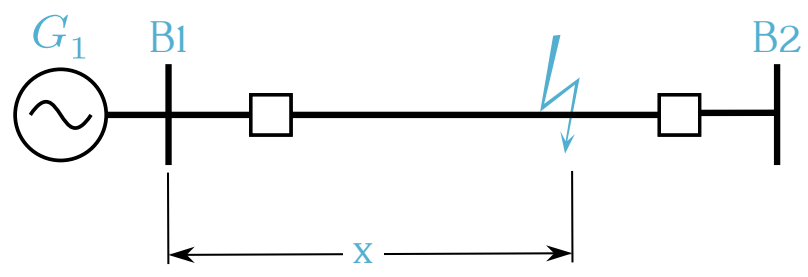


A corrente de curto-circuito trifásica poderá ser calculada através da Equação 11, para o sistema ilustrado na Figura 29, mediante a ocorrência de um curto-circuito a uma distância $x$ da Barra $B 1$. Esta equação foi obtida através da análise do sistema representado em componentes simétricas, onde os diagramas de sequências de fase são acoplados convenientemente de acordo com o tipo de curto-circuito (JÚNIOR, 2003; STEVENSON, 1978).

$$
I_{3 \phi}=\frac{E}{z_{s}+z_{l} * x}
$$

onde $z_{s}$ é a impedância de sequência positiva da fonte, $z_{l}$ é a impedância de sequência positiva da linha de transmissão, em $\frac{\Omega}{k m}$, enquanto que $x$ indica a posição em que a falta ocorre na linha, em km. A tensão defase imposta pelo gerador $G_{1}$ é $E$. Essa equação permite determinar a intensidade da corrente de curto-circuito, $I_{3 \phi}$, em relação a posição em que ocorre, $x$. Apesar disto, esta não é suficiente para expressar a probabilidade de ocorrência de uma corrente de amplitude $I_{f}$. Para alcançar este objetivo é necessário notar que $x$ possui característica aleatória, pois o curto-circuito pode ocorrer em qualquer ponto da linha. Como consequência, a corrente de curto-circuito obtida adquire natureza aleatória.

Para determinar a FDP da posição $x$, é suficiente pressupor que não há fenômeno que priorize trechos da linha de transmissão. Definiu-se a VA como o conjunto de todas as possibilidades que um processo aleatório pode assumir. No caso das linhas de transmissão, a VA $x$, que define a posição da falta, se restringe a qualquer valor entre o comprimento mínimo $\left(l_{\min }\right)$ e o comprimento máximo $\left(l_{\max }\right)$ da linha. Supondo uma linha de transmissão com dez unidades de comprimento, $u$, o curto-circuito poderá ocorrer em qualquer uma das dez unidades de comprimento, tendo cada unidade a mesma probabilidade de ser contemplada com o curto-circuito. Neste caso a probabilidade de cada unidade de comprimento será $\frac{1}{10}$. Portanto uma linha de comprimento $l$ implicará em uma função de distribuição uniforme de probabilidade igual a $P(x)$, como descrito na Equação 12. Que aponta a distribuição de probabilidade uniforme de $x$, para qualquer ponto da linha e está associado a função de probabilidade que a define, cujo valor é o inverso do comprimento total da linha.

$$
P(x)=\frac{1}{l}
$$

Rearranjando a Equação 11, para isolar a variável da posição, x, é obtida a Equação 13.

$$
x=\frac{E}{z_{l} I_{3 \phi}}-\frac{z_{s}}{z_{l}}
$$

Derivando a Equação 13 em relação a corrente de curto-circuito trifásico $I_{3 \phi}$, gera-se a Equação 14. Onde é relacionada a variação da posição com a variação da corrente de 
curto-circuito trifásico, $I_{3 \phi}$.

$$
\frac{d x}{d I_{3 \phi}}=-\frac{E}{z_{l} I_{3 \phi}^{2}}
$$

O produto da função de distribuição $P(x)$, com a derivada em relação a $I_{3 \phi}$ reproduz a FDP de $I_{3 \phi}$, Equação 15 (MAMEDE, 2004). O sinal negativo da função de distribuição foi omitido já que a FDP é uma grandeza que não assume valores negativos.

$$
F D P\left(I_{3 \phi}\right)=\frac{1}{l} \frac{d x}{d I_{3 \phi}}
$$

No sistema elétrico outras variáveis aleatórias influenciam no valor da corrente, como a impedância e o tipo de curto-circuito. Em casos nos quais o tipo de curto-circuito seja considerado como variável aleatória, estes poderão ser obtidos através de uma função descrita pela frequência de ocorrência de cada tipo, disponíveis em dados históricos. A Figura 30 expressa uma típica função de distribuição da ocorrência de curtos-circuitos de sistemas alternados (CABRAL, 2010; MAMEDE, 2004; SIVANAGARAJU; REDDY, 2007).

Figura 30 - Função de distribuição de probabilidade do tipo do curto-circuito de sistemas de transmissão trifásico alternado.

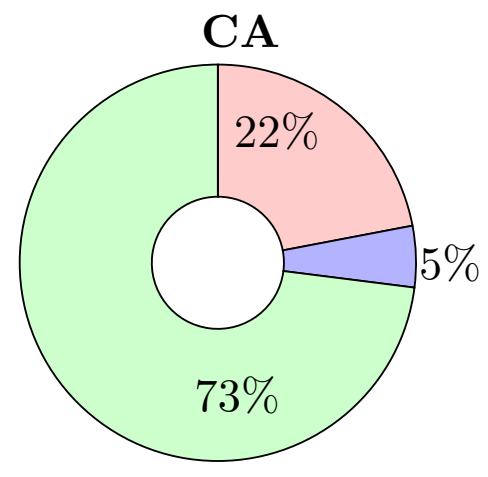

CA

Trifásica

Fase-fase

Fase-terra

Outra variável aleatória é a impedância de falta. A Equação 16 descreve a função de distribuição uniforme que descreve $z_{f}$. Considerando que todas as possíveis impedância de falta terão a mesma probabilidade de ocorrer e sendo esta definida entre o máximo e mínimo valor possível.

$$
P\left(z_{f}\right)=\frac{1}{z_{\max }}
$$

O CCP-CA foi desenvolvido nessa pesquisa, com as métricas baseadas no proposto por Cabral (2010) e Mamede (2004), embora o sistema elétrico utilizado seja distinto, como também o ambiente de simulação. O algoritmo de simulação desenvolvido neste estudo, está ilustrado na Figura 31. Como pode-se observar, em uma primeira instância, obtêm-se os parâmetros nominais do sistema elétrico, define-se o número de simulações e, posteriormente, determina-se os parâmetros de natureza aleatória, utilizando a SMC. 
Esta define a posição, impedância e o tipo de curto-circuito. Definidos os parâmetros é possível calcular a corrente de curto-circuito do cenário criado. Até que se atinja o número de simulações determinado, este laço será repetido e a saída de cada iteração armazenada com o objetivo de construir a FDP e a DAP.

Figura 31 - Algoritmo do curto-circuito probabilístico para linhas de transmissão em corrente alternada.

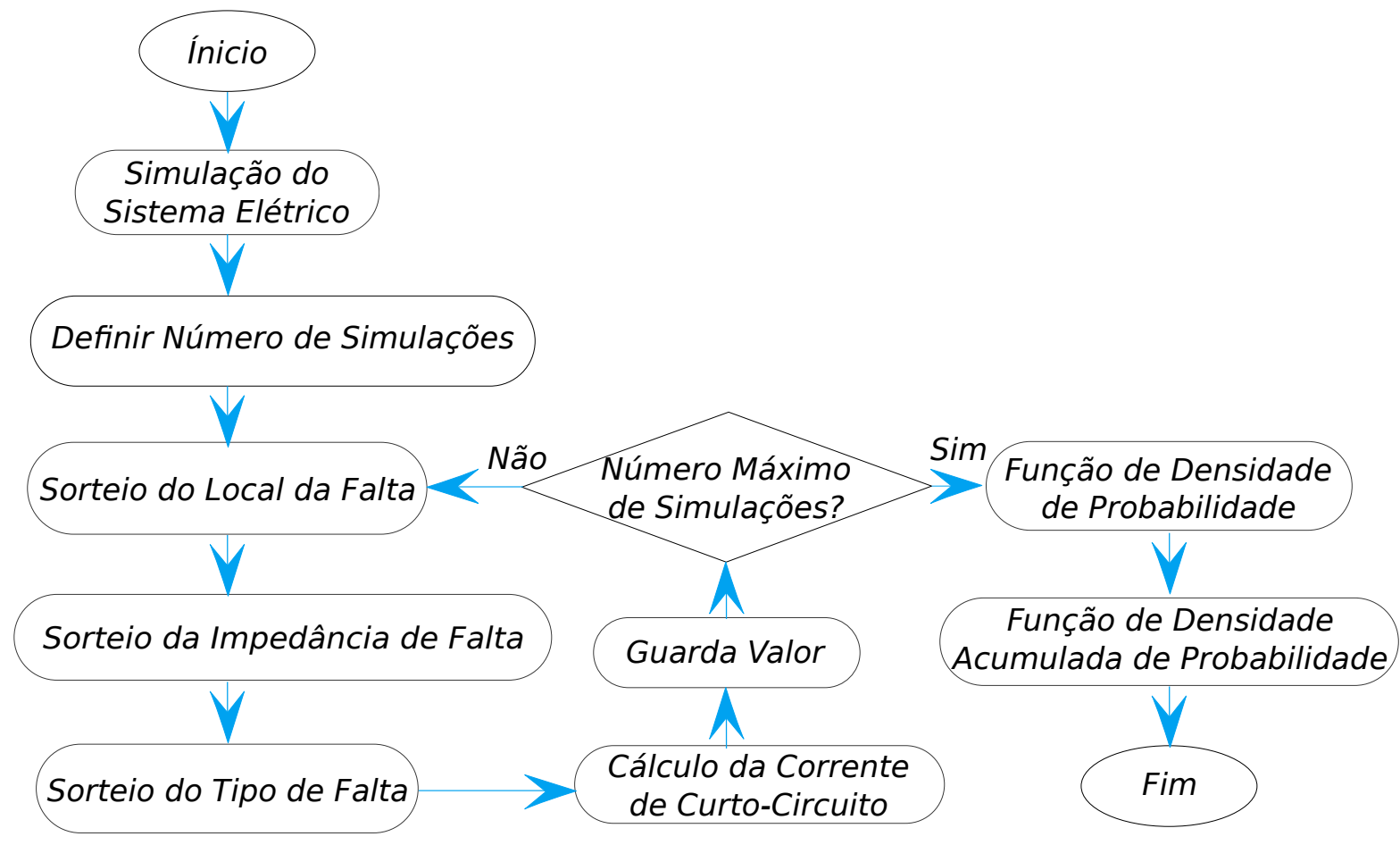

O sistema de transmissão simulado, possui $75 \mathrm{~km}$ de linha, a tensão da fonte igual a $13.8 \mathrm{kV}$, as impedâncias em PU de sequência positiva, negativa e zero do gerador são iguais a $z_{s 1}=0.2 i, z_{s 2}=0.14 i$ e $z_{s 0}=0.06 i$, respectivamente. Para o transformador as impedâncias de sequência positiva, negativa e zero são iguais a $z_{t 1}=0.2 i, z_{t 2}=0.2 i$ e $z_{t 0}=0.2 i$, respectivamente. As impedâncias da linha de transmissão por unidade de comprimento são: sequência positiva, $z_{l 1}=0.0197+0.0441 i$, sequência negativa $z_{l 2}=$ $0.0197+0.0441 i$ e sequência zero, $z_{l 0}=0.0383+0.1972 i$. A impedância de falta $z_{f}$ varia entre 0 e $100 \Omega$. Foram simulados $25 \mathrm{E} 3$ curtos-circuitos por $\mathrm{km}$ de linha, como proposto por Mamede (2004).

O CCP do sistema descrito mostra a FDP da corrente de curto-circuito na linha de transmissão, Figura 32, onde é proeminente a probabilidade de faltas com amplitude em torno de $0.5 k A^{1}$. Nesta figura, a faixa entre 0 e 0,4 equivale a faixa de corrente da operação nominal do circuito.

A DAP resultante para a FDP do sistema modelo CA é mostrada na Figura 33. Através desta, pode-se definir os intervalos de confiabilidade da Tabela 4. Como exemplo,

\footnotetext{
${ }^{1} \mathrm{O}$ eixo $\mathrm{x}$ do gráfico foi alterado de forma a ressaltar as informações que estão entre $0 k A$ e $3 k A$, que
} contem a maior parte das informações. Entre $3 k A$ até $45 k A$ foi aumentada a escala. 
Figura 32 - FDP do sistema modelo em corrente alternada.

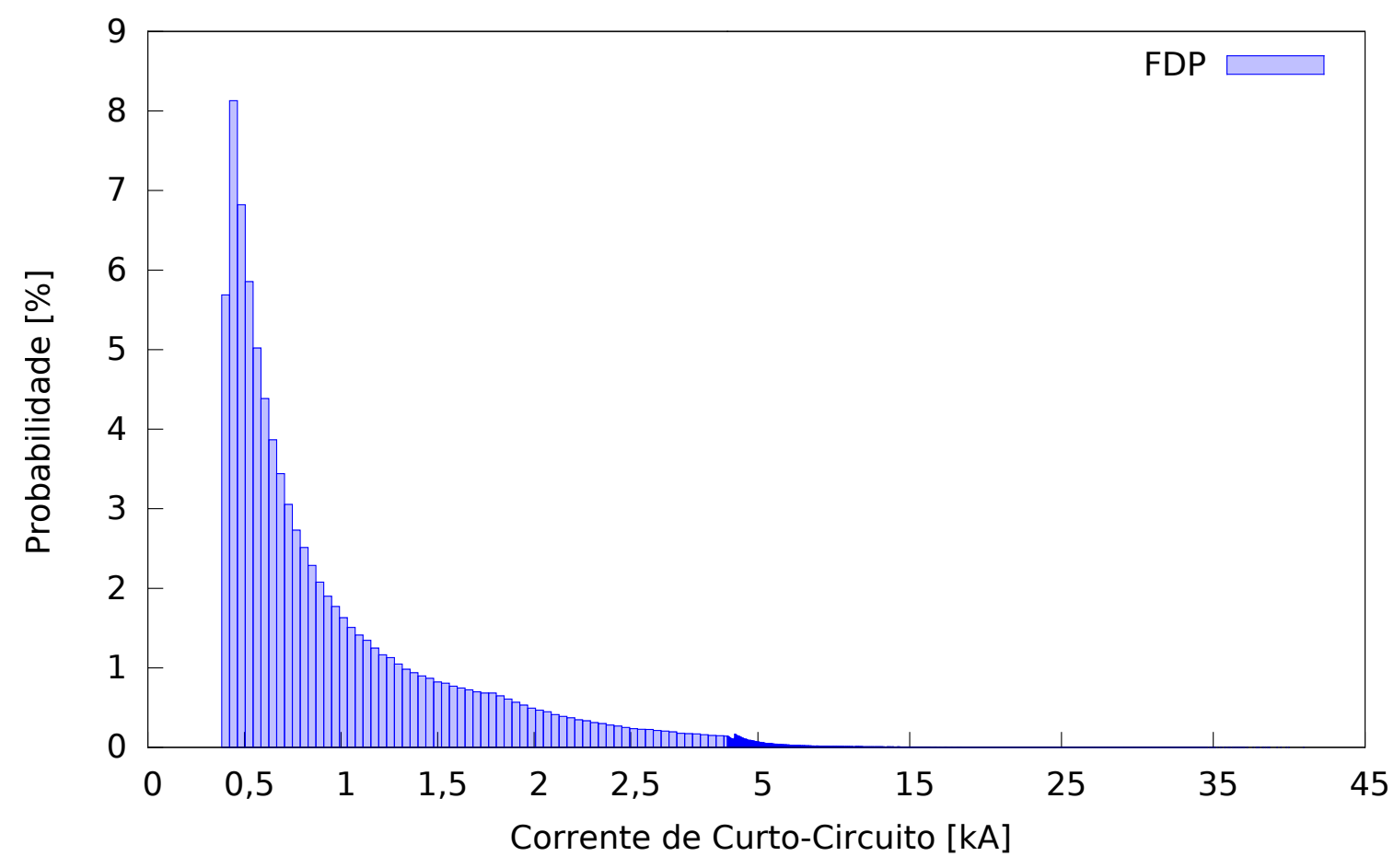

pode-se observar a probabilidade de ocorrerem faltas com corrente que superem $5 \mathrm{kA}$ $(>5)$ é de 5,89\%. Portanto, esta tabela define intervalos de confiabilidade que pode ser utilizado em, por exemplo, equipamentos como disjuntores, projetados para atuar com correntes menores que $30 k A$ garante um intervalo de confiabilidade de $99,87 \%$.

Tabela 4 - Probabilidade para intervalos de correntes de curto-circuito do sistema modelo CA.

\begin{tabular}{ccccc}
\hline $\mathrm{kA}$ & $<5$ & $<15$ & $<25$ & $<30$ \\
Probabilidade & $94,11 \%$ & $98,90 \%$ & $99,69 \%$ & $99,87 \%$ \\
\hline $\mathrm{kA}$ & $>5$ & $>15$ & $>25$ & $>30$ \\
Probabilidade & $5,89 \%$ & $1,10 \%$ & $0,31 \%$ & $0,13 \%$ \\
\hline
\end{tabular}

A definição do número de barras ${ }^{2}$ de um histograma tem grande influência na função que será mostrada pela FDP. Muitos estudos se dedicam a determinar um número otimizado para essas barras (MACIEJEWSKI, 2011), mais detalhes serão mostrados na Seção 5.8. Nesta ocasião, para $n=1875 E 3$ simulações, foi definido o número de barras como $k=1,5 E 3$, através da regra da raiz quadrada.

\footnotetext{
${ }^{2}$ Barras ou classes fazem referência ao agrupamento de dados de um histograma, em forma de retângulos com bases iguais e alturas que variam conforme a quantidade de dados contidos.
} 
Figura 33 - DAP do sistema modelo CA.

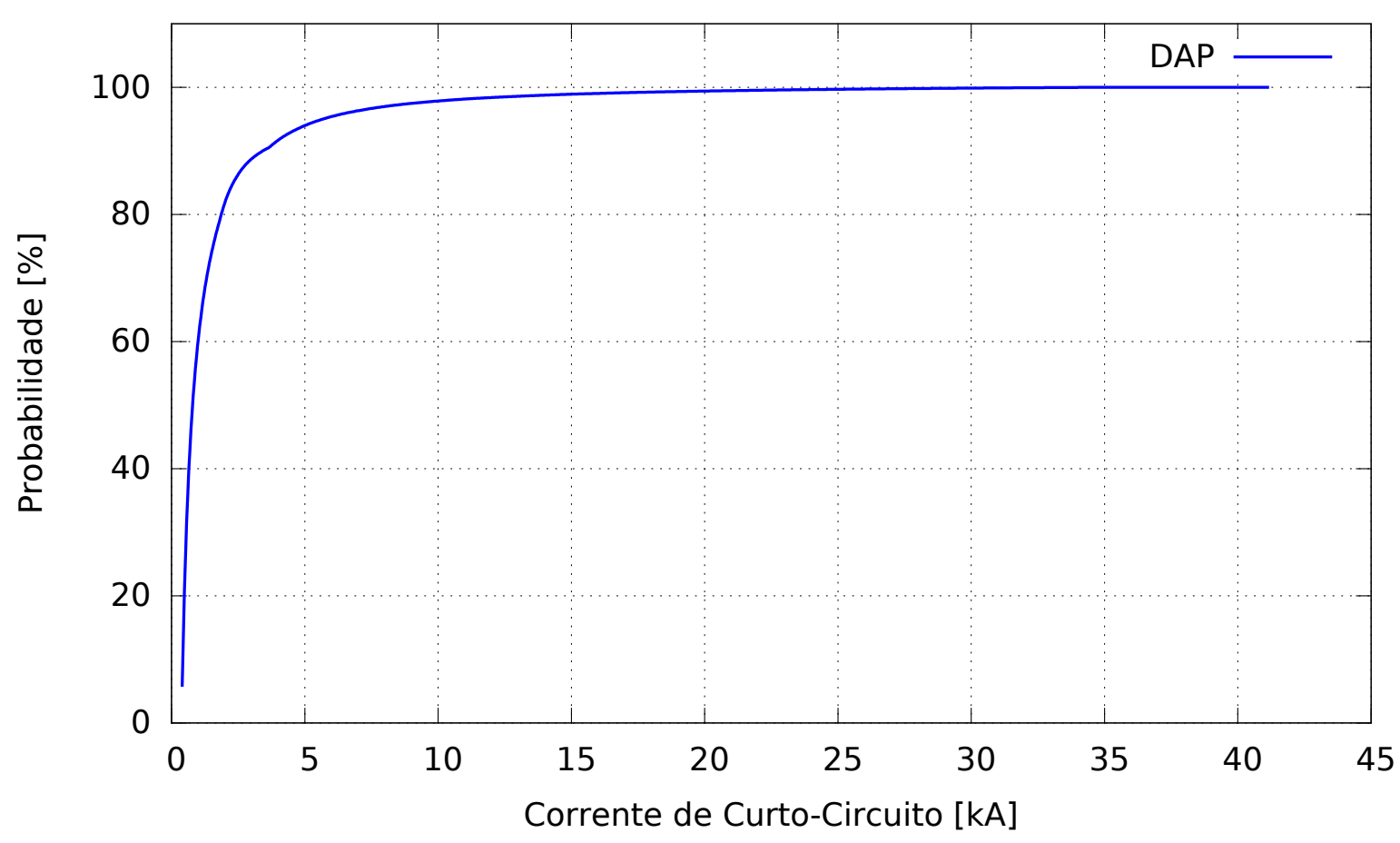

\subsection{Cálculo de Curto-Circuito Probabilístico em Li- nhas de Transmissão em Corrente Contínua Atra- vés da Simulação de Monte Carlo}

Distinto das linhas de transmissão CA, o equacionamento para obter as correntes de curto-circuito das linhas CC não é trivial (YANG, 2012). A métrica de componentes simétricas, muito frequente para cálculo de curto-circuito em sistemas CA, não se aplica aos sinais CC devido a não possuir representação fasorial. Como solução, esta pesquisa utiliza um método de simulação de transitórios eletromagnéticos para obter as correntes de curto-circuito. Este método será abordado no Capítulo 4.

Independente do modelo adotado do circuito elétrico, alguns dos parâmetros necessários ao CCP nos sistemas CC são análogos as linhas de transmissão em corrente alternada. Nas torres de transmissão, que são mostradas na Figura 34, para um mesmo nível de tensão, a distância entre linhas de transmissão e solo é igual para sistemas CA e sistemas CC.

Se considerado o sistema CC, mostrado na Figura 21, os parâmetros do CCP são determinados em analogia as linhas de transmissão CA, como já justificado. Dessa forma foram consideradas as probabilidades de faltas fase para terra CA proporcionais as faltas de polo a terra (CC). O percentual excedente é atribuído as faltas entre polos. A Equação 17 mostra como foi calculada a proporcionalidade de faltas do tipo polo a terra. A 
Figura 34 - Torre CA e torre CC, para um mesmo nível de tensão (100 kV) e relação entre dimensões.

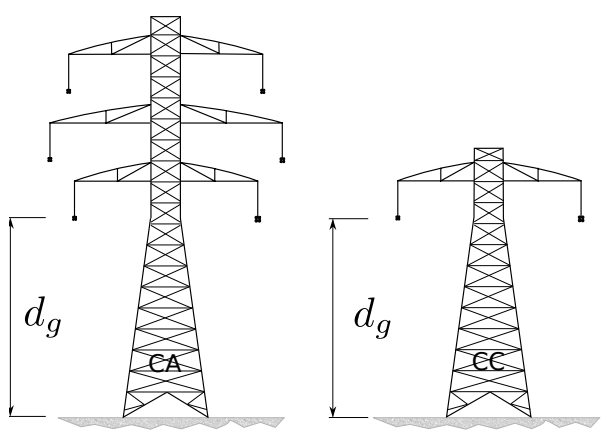

Figura 35 mostra o resultado final da redistribuição dos percentuais de falta.

Dado a probabilidade de cada tipo de falta $\mathrm{CA}$, as probabilidades equivalentes para os sistemas CC foram obtidas através da Equação 17 e da Equação 18, onde a probabilidade de faltas trifásicas CA foram removidas. Essa consideração é feita devido a não existência de um tipo de falta semelhante a este, nos sistemas CC. Assim a probabilidade total foi redistribuída entre faltas de polo a polo e de polo a terra.

$$
\begin{aligned}
& \text { polo a terra }(\%)=\frac{\text { fase }- \text { terra }(\%)}{100 \%-\text { trifásicas }(\%)} \\
& \text { polo a polo }(\%)=100 \%-\text { polo a terra }(\%)
\end{aligned}
$$

Figura 35 - Função de distribuição de probabilidade do tipo de curto-circuito CA e a probabilidade equivalente de cada tipo CC.

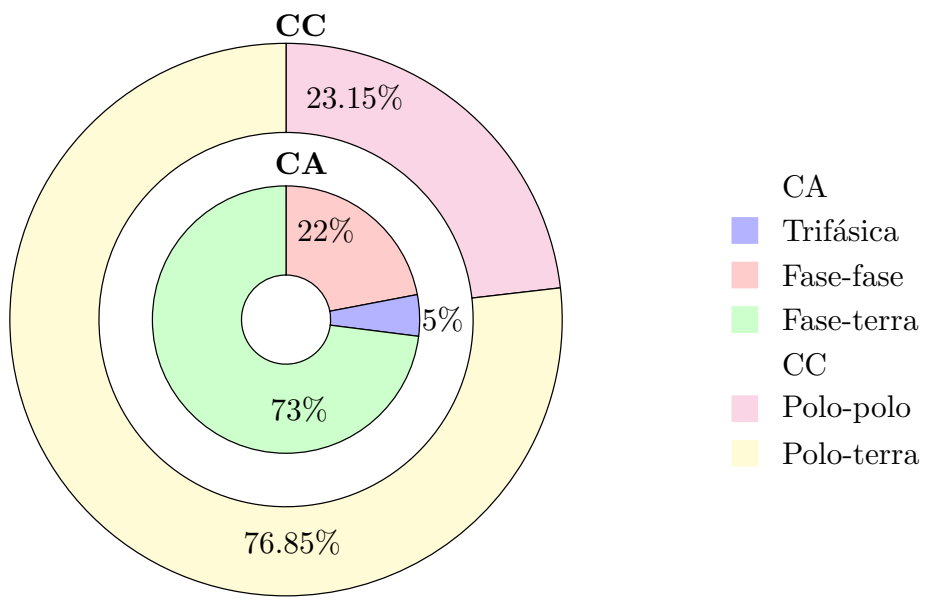

A função de distribuição da posição e da impedância da falta na linha de transmissão CC, também foi considerada uniforme, semelhante as faltas CA (Equação 12 e Equação 16).

Para ilustrar como a SMC sorteia a posição e impedância de falta, foram realizadas 300 simulações, como descrito no Algoritmo 5. Cada laço de simulação sorteia aleatoriamente uma posição na linha de transmissão $(0 \mathrm{~km} \leq x \leq 75 \mathrm{~km})$ e um valor de impedância de 
falta $\left(0 \Omega \leq z_{f} \leq 100 \Omega\right)$. O resultado destas consecutivas simulações mostra a função de distribuição da posição e da impedância das faltas nos sistemas CC.

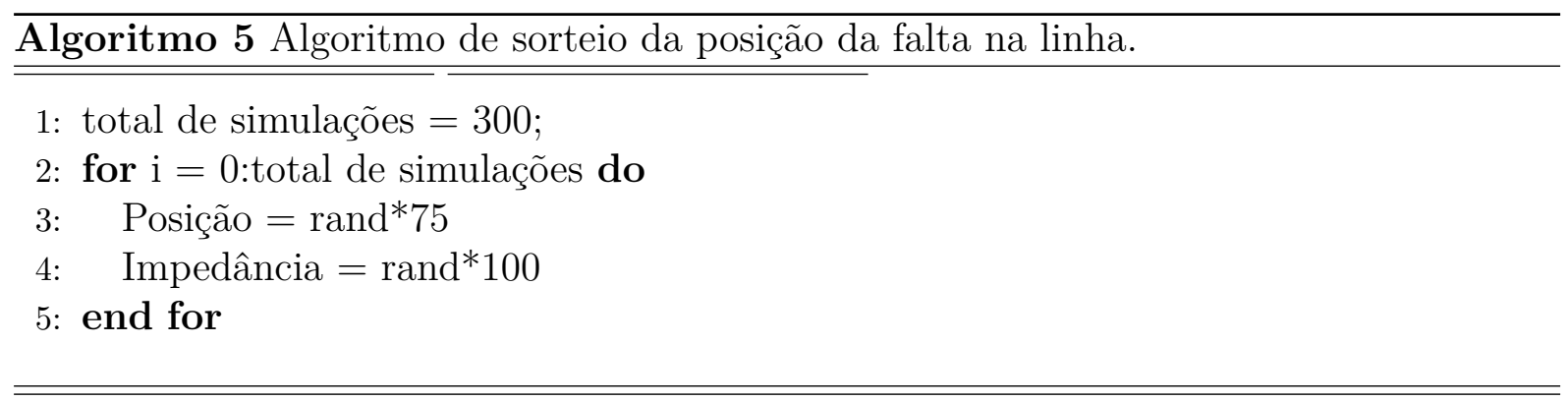

A Figura 36(a) e 36(b), mostra o resultado das 300 simulações de Monte Carlo. Na Figura 36(a), representa-se o valor da impedância, que compreende valores entre $0 \Omega$ e $100 \Omega$, em relação a probabilidade de cada valor de impedância $\left(\frac{1}{100} * 100 \%\right)$. É considerada impedância de falta para as faltas de polo a terra. Já para as faltas entre polos sua impedância é considerada nula. Na Figura 36(b) tem-se a relação entre a posição que o curto-circuito ocorre na linha de comprimento $75 \mathrm{~km}$, e no eixo ordenado expressa-se a probabilidade de cada posição $\left(\frac{1}{75} * 100 \%\right)$. Como pode ser visto, a probabilidade é uniforme e igual ao inverso do comprimento da linha.

Para o sistema CC, além da posição e impedância, também foi considerada como variável aleatória, o ponto de operação do sistema, porque entende-se que uma falta pode ocorrer quando o sistema esteja submetido a qualquer condição de carregamento. $\mathrm{O}$ carregamento do sistema implica na quantidade de potência o sistema CC está consumindo ou injetando no sistema CA. Os limites são definidos através da Equação 1 e Equação 2, mostradas no Capítulo 2.

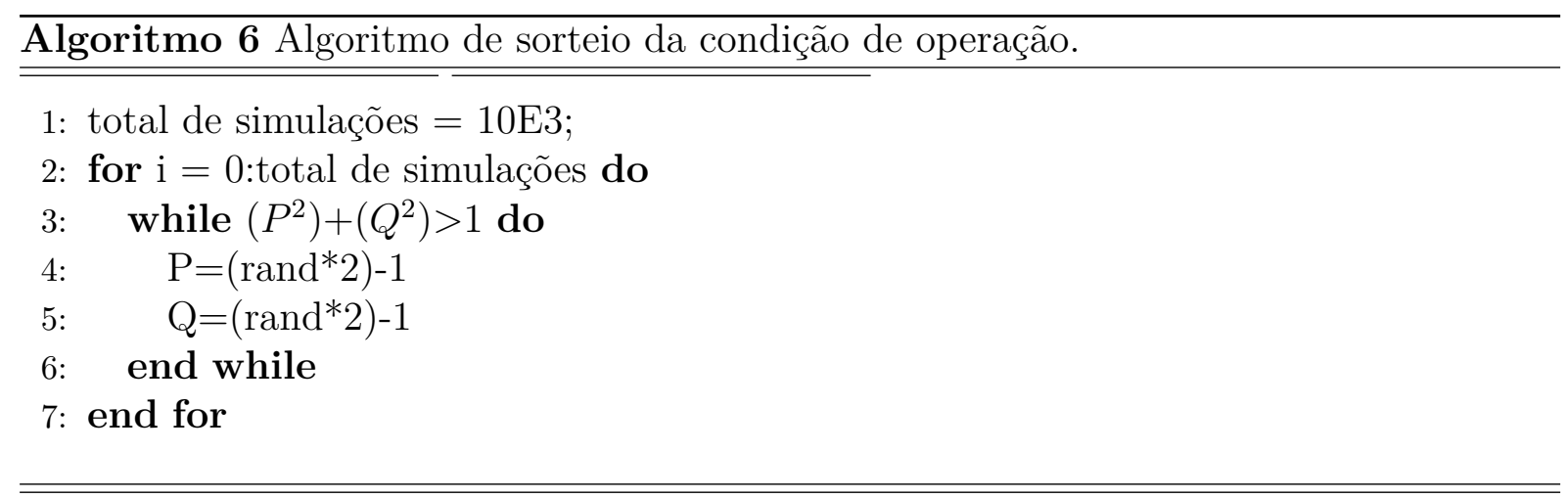

Um exemplo de como o SMC sorteia os dados de P e Q foi simulado através do Algoritmo 6. Onde P e Q são sorteados aleatoriamente, com valores entre $-1 \leq$ Potência $\leq 1$, até que seja obedecida a relação $\left(P^{2}\right)+\left(Q^{2}\right)<1$, que garante que os valores estarão contidos em um circulo com raio unitário. A Figura 37 mostra o resultado da SMC, onde cada ponto relaciona um P e um Q sorteado. 
3.8. Cálculo de Curto-Circuito Probabilístico em Linhas de Transmissão em Corrente Contínua Através da Simulação de Monte Carlo

Figura 36 - Função de distribuição de probabilidade real para impedância e posição da falta.

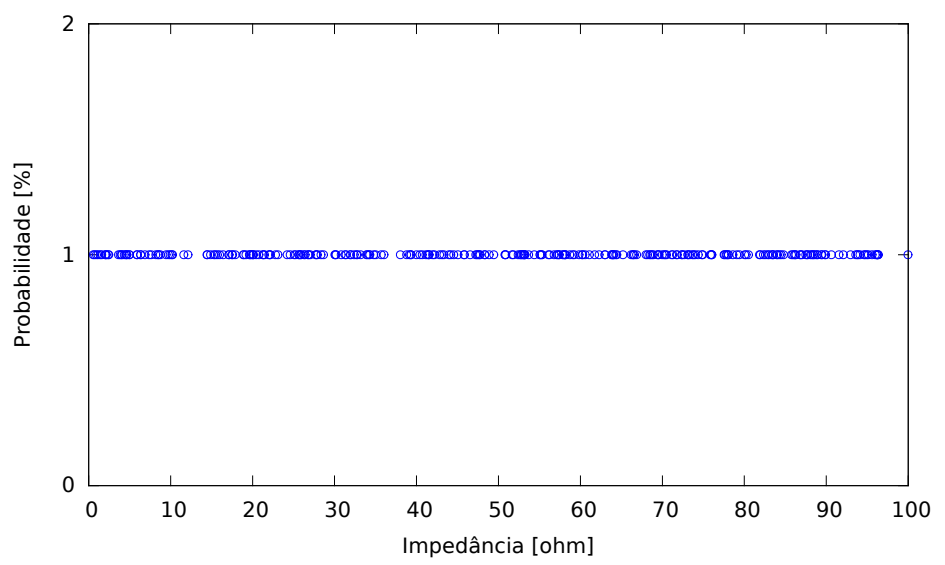

(a) Distribuição para impedância.

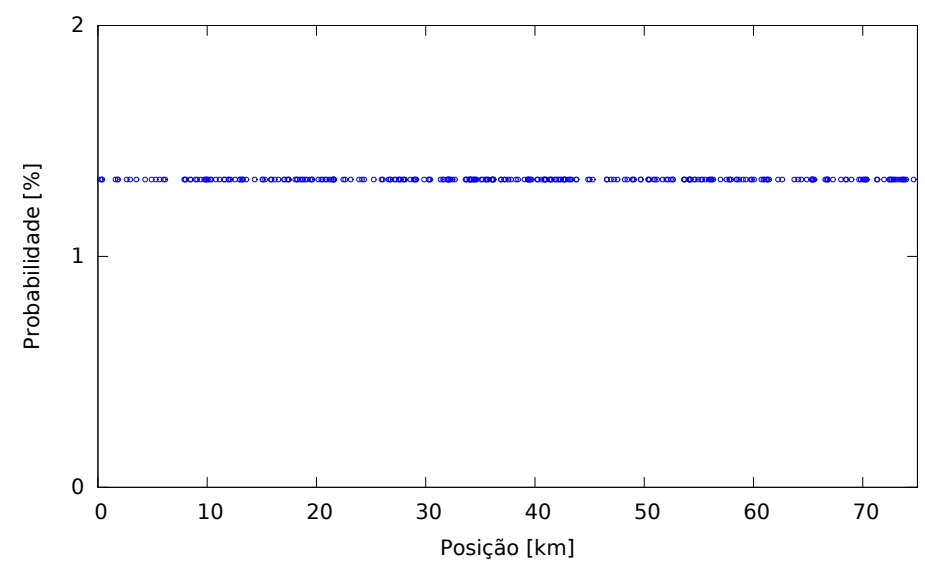

(b) Distribuição para posição.

Figura 37 - Função de distribuição da operação de um conversor (valores de P e Q).

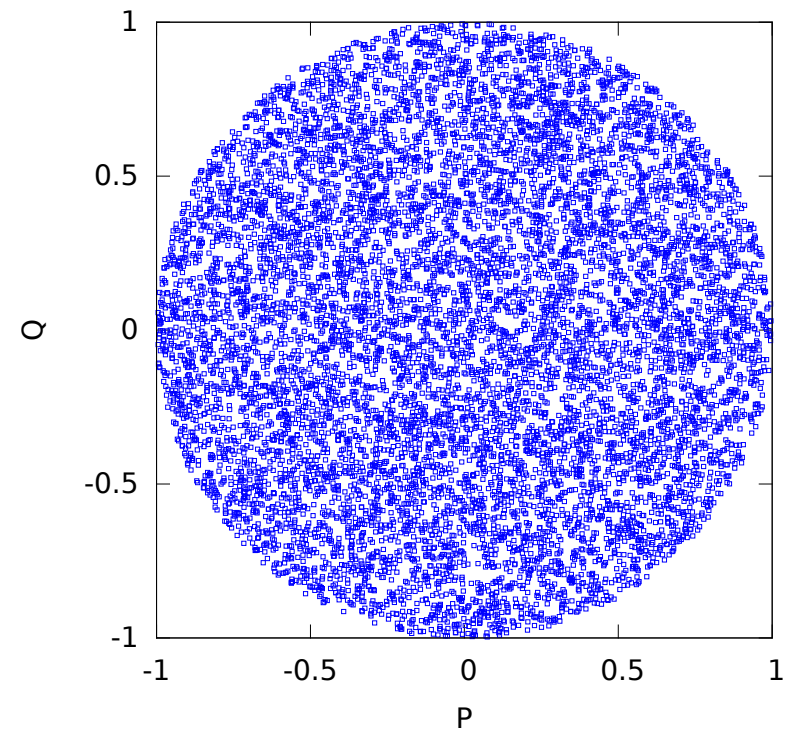




\subsection{Considerações}

Neste capítulo foram contemplados os conceitos probabilísticos necessários a compreensão da metodologia de CCP. Esta metodologia permite mostrar as máximas correntes de curto-circuito em linhas de transmissão e é amplamente empregado para o aprimoramento da parcela do SEP que configura os sistemas CA, no que diz respeito a qualidade da energia, proteção do sistema, manutenção dos equipamentos e análise de risco.

O algoritmo desenvolvido para realizar o CCP-CA, gerou resultados concordantes com o proposto por Mamede (2004), sendo essenciais para a evolução deste estudo.

Em função do desenvolvimento até então realizado, espera-se que as informações contidas neste capítulo, principalmente no que diz respeito aos conceitos estatísticos, esclareçam e aprimorem a aplicação do CCP em sistemas HVDC e promovam o desenvolvimento dos equipamentos e técnicas de proteção destes sistemas. 


\section{Cálculo de Transitórios Eletromagnéticos em Sistemas de Energia Elétrica}

Transitórios são fenômenos eletromagnéticos oriundos de alteração súbitas nas condições operacionais de um circuito ou sistema de energia elétrica (JÚNIOR, 2003). O primeiro passo para o desenvolvimento do cálculo de transitórios é construir um modelo adequado e que agrupe as características necessárias à descrição o mais próximo possível ao sistema real. Simulação de transitórios eletromagnéticos são capazes de descrever os fenômenos de troca súbita de energia no sistema elétrico (WATSON; ARRILLAGA; ENGINEERS, 2003).

Para solução de transitórios eletromagnéticos no SEP, as equações diferenciais, baseadas nas leis de Kirchhoff, são capazes de descrever o comportamento de circuitos na forma $R L C$, para excitações específicas. Essa representação é naturalmente analógica, enquanto que as simulações tratam sinais na forma digital. Assim, na tarefa de desenvolver simulações adequadas para solução, deve-se considerar a discretização destas equações.

No contexto das simulações digitais de equações diferenciais no domínio do tempo, duas estratégias são vastamente utilizadas para obter a representação das funções, são elas: a representação em espaço de estados e a representação através de equações de diferença. Esta última é a base do método implementado por Dommel. Ambas são discretizadas através de métodos de integração numérica. A representação por espaço de estados pode ser solucionada analiticamente. Já as equações de diferença, tem dependência com o valor do passo de integração, sendo solucionadas através de métodos sistemáticos.

É neste contexto que este capítulo tratará ambas as estratégias e descreverá a formulação adequada dos elementos elétricos para calcular transitórios eletromagnéticos no domínio do tempo. 


\subsection{Espaço de Estados}

Nesta seção será apresentada a representação por espaço de estados de circuitos. Esta representação trata as equações diferenciais ordinárias na forma matricial. As equações descrevem o comportamento do sistema através dos seus estados, relacionado às entradas e saídas. A excitação e um estado inicial das variáveis devem ser conhecidos, pois estas condições de contorno compreendem os vetores de estados que descreverão o comportamento do sistema ao longo do tempo.

O arranjo matricial de equações diferenciais de primeira ordem, de sistemas lineares, é descrito na Equação 19 e Equação 20. Em que $A, B, C$ e $D$ são matrizes constantes, $x$ é vetor de estados, que agrupa as variáveis de estados $x_{i}, y$ é o vetor de saídas e $u$ o vetor de excitações do sistema, as entradas.

$$
\begin{aligned}
& \dot{x}=A x+B u \\
& y=C x+D u
\end{aligned}
$$

Foi desenvolvido nesse estudo um programa de simulação usando linguagem $\mathrm{C}++$, para solucionar transitórios eletromagnéticos através de espaço de estados. Neste programa foi simulado um circuito simplificado, com uma linha de transmissão com parâmetros concentrados ligando uma estação VSC, operando em modo de retificador não-controlado, a uma fonte de tensão CC constante, ver Figura 38. O mesmo circuito foi simulado no programa Spice/Gnucap para validar o programa desenvolvido.

Figura 38 - Sistema simplificado simulado através de espaço de estados.

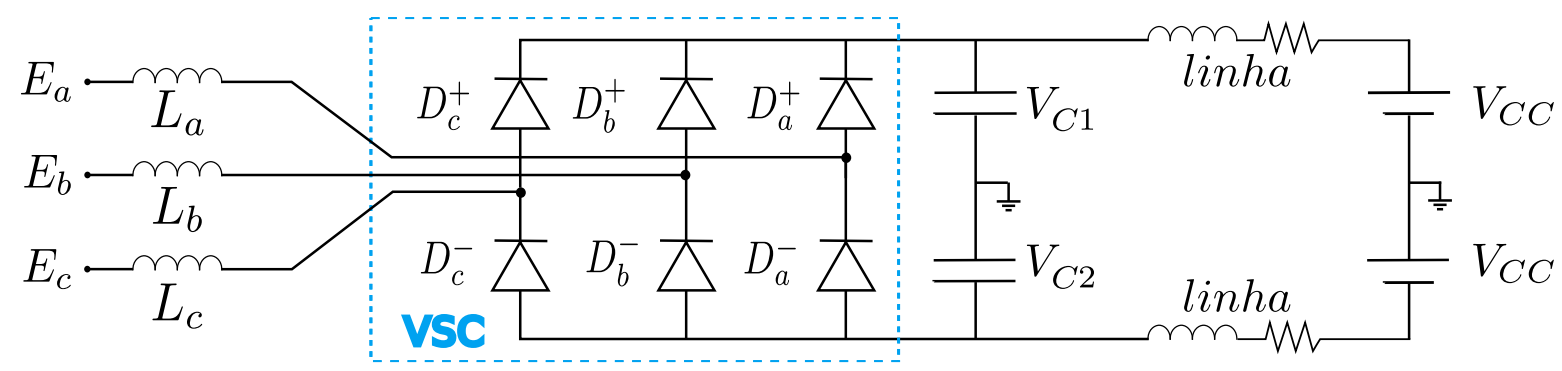

O resultado dessa validação está ilustrado na Figura 39, onde os sinais de tensão $V_{C 1}$ e $V_{C 2}$ dos capacitores são impressos para a simulação no Gnucap e por espaço de estados. Nota-se no gráfico que no intervalo de 0.01 e 0.02 segundos existe uma condição não modelada pelos estados, o que inviabiliza prosseguir com tal abordagem.

Para a solução de sistemas não-lineares é necessário conhecer os instantes de alteração da topologia do sistema, para rearranjar a matriz $A$ a cada nova transição. No caso do circuito simulado, conhecer a condição de chaveamento dos diodos . Outra dificuldade é 
Figura 39 - Tensão do filtro capacitivo $\left(V_{C 1}\right.$ e $\left.V_{C 2}\right)$ do sistema simulado no Gnucap e em linguagem $\mathrm{C}++$, por espaço de estados (edo).

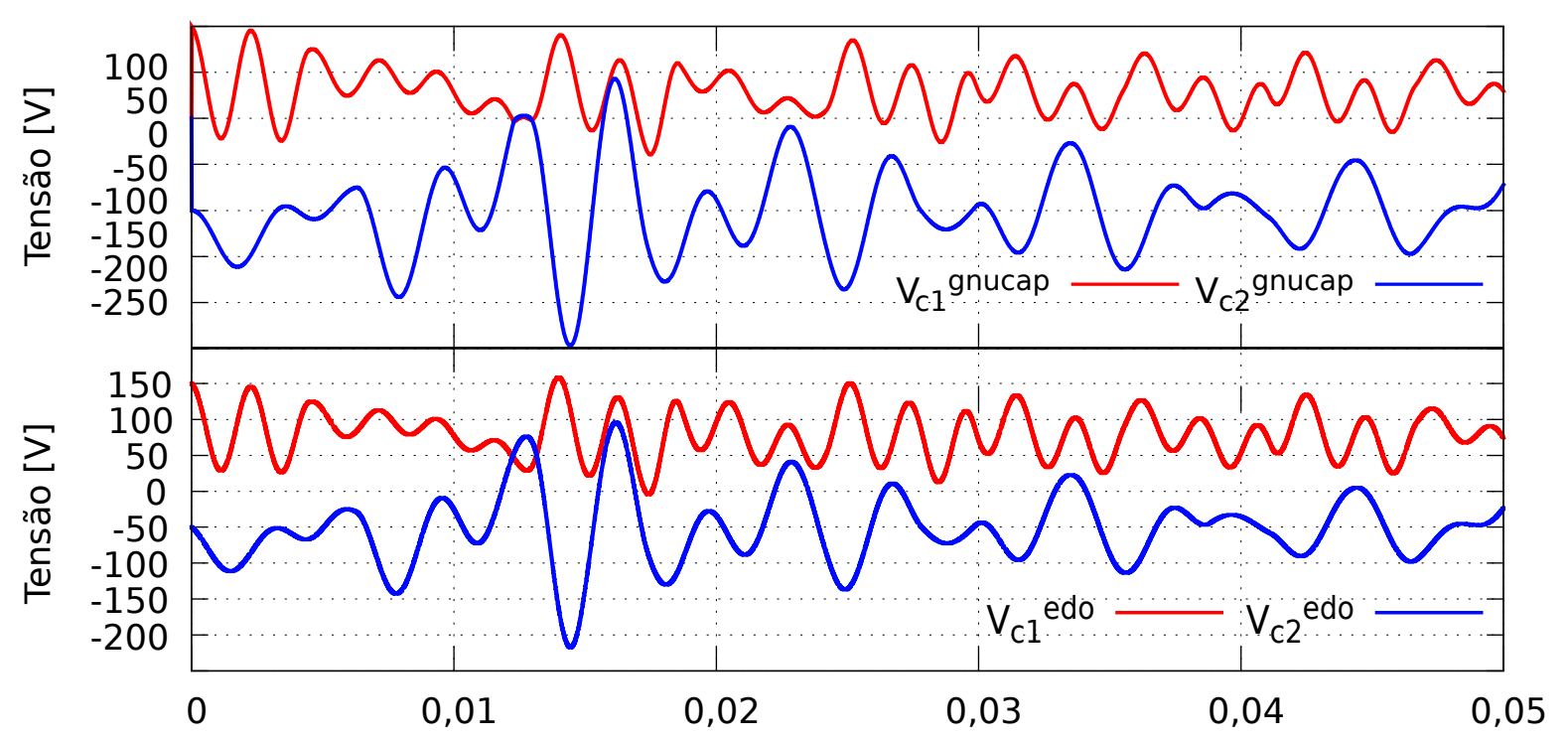

Tempo de Simulação [s]

determinar todos os estados que o sistema pode assumir. Uma abordagem mais detalhada sobre a representação em espaço de estados poderá ser encontrada em (JÚNIOR, 2003).

\subsection{Equações de Diferença}

A representação através de equações de diferença é baseada na discretização de sistemas elétricos, onde o passo de integração é combinado com a solução da tensão nodal. Dessa forma, elementos do circuito são representados através das relações entre corrente e tensão nodal. Neste estudo, a integração numérica é do tipo trapezoidal, devido a simplicidade, estabilidade e precisão, em grande parte das circunstâncias. Entretanto, por ser baseada no truncamento da série de Taylor, a integração trapezoidal pode causar oscilações numéricas diante de algumas condições, nesta uma solução por Euler é utilizada. Esta substituição equivale a diminuir o passo de integração de $\Delta t$ para $\frac{\Delta t}{2}$, em tais condições.

A proposta de solução de transitórios eletromagnéticos, abordada neste estudo, discretiza as equações diferenciais advindas da teoria de sinais e sistemas para representar os elementos dos circuitos elétricos a partir das equações de diferença do circuito. Este estudo trata do método desenvolvido por H. W. Dommel que se baseou no método de integração trapezoidal por meio da análise nodal. Este método permitiu o desenvolvimento de algoritmos eficientes que sofreram sucessivas evoluções e, atualmente, são conheci- 
dos como Electromagnetic Transients Program (EMTP), possuindo diversas aplicações comerciais (ARAUJO; NEVES, 2005; DOMMEL, 1969; S. FÁBIO Y.; PISSOLATO, 2007).

De forma genérica as relações de tensão e corrente dos circuitos, na forma de análise nodal, devem ser representadas como disposto na Equação 21, onde $i$ são as correntes instantâneas, $I$ são as correntes históricas, $v$ as tensões nos nós e $G$ a matriz de condutância do sistema.

$$
i(t)+I(t)=G v(t)
$$

O programa de cálculo de transitório eletromagnético desenvolvido neste estudo foi reescrito, utilizando a teoria de equações de diferença. Os elementos elétricos são representados como descrito na próxima subseção.

\subsubsection{Representação dos Componentes Elementares}

Para se representar os componentes elementares dos circuitos elétricos através de equações diferenciais, deve-se obter as equações dos bipolos sobre cada elemento, ver Figura $40^{1}$. Onde a indutância $L$ é submetida a diferença de potencial de $v_{k}(t)-v_{m}(t)$ e esta diferença de potencial propicia a passagem da corrente elétrica $i_{k m}^{L}(t)$ através do elemento indutivo.

De forma análoga, o capacitor $C$ e o resistor $R$ também estão submetidos a uma diferença de potencial $v_{k}(t)-v_{m}(t)$ e a uma corrente $i_{k m}^{C}(t)$ e $i_{k m}^{R}(t)$ flui através deles, respectivamente.

Figura 40 - Representação do bipolo sobre o indutor L, o resistor R e o capacitor C.
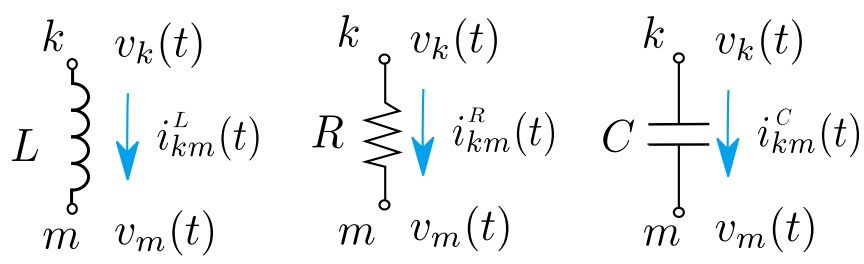

A equação diferencial, para o indutor $L$ e para capacitor $C$, são respectivamente a Equação 22 e a Equação 23. Para o resistor $R$, como este não é um elemento armazenador de energia, a sua corrente não é determinada por equação diferencial e sim, apenas pela diferença de potencial sobre ele, em relação com sua resistência, ver Equação 24.

$$
\begin{gathered}
v_{k}(t)-v_{m}(t)=L \frac{d}{d t} i_{k m}^{L}(t) \\
i_{k m}^{C}(t)=C \frac{d}{d t}\left(v_{k}(t)-v_{m}(t)\right)
\end{gathered}
$$

\footnotetext{
${ }^{1}$ Os elementos elétricos ilustrados nesta dissertação estão de acordo com a norma (IEEE. .., 1993).
} 


$$
i_{k m}^{R}(t)=\frac{v_{k}(t)-v_{m}(t)}{R}
$$

Com a discretização trapezoidal das equações diferenciais, para o indutor são obtidas equações da corrente em função do instante atual e da corrente histórica armazenada no elemento (Equação 25). Desta equação, as dependências do termo $(t-\Delta t)$ equivalem a parcela da corrente histórica, que é isolada e mostrada na Equação 26.

$$
\begin{gathered}
i_{k m}^{L}(t)=i_{k m}^{L}(t-\triangle t)+\frac{\triangle t}{2 L}\left[\left(v_{k}(t)-v_{m}(t)\right)+\left(v_{k}(t-\triangle t)-v_{m}(t-\triangle t)\right)\right] \\
I_{k m}^{L}(t-\triangle t)=i_{k m}^{L}(t-\triangle t)+\frac{\triangle t}{2 L}\left[v_{k}(t-\triangle t)-v_{m}(t-\triangle t)\right]
\end{gathered}
$$

De forma análoga às equações descritas para o indutor, o capacitor tem sua corrente expressa pela Equação 27, e isolando os termos dependentes de $(t-\Delta t)$, descrevemos a componente histórica da corrente, Equação 28.

$$
\begin{gathered}
i_{k m}^{C}(t)=\frac{2 C}{\triangle t}\left(v_{k}(t)-v_{m}(t)\right)-i_{k m}^{C}(t-\triangle t)-\frac{2 C}{\triangle t}\left(v_{k}(t-\triangle t)-v_{m}(t-\triangle t)\right) \\
I_{k m}^{C}(t-\triangle t)=-i_{k m}^{C}(t-\triangle t)-\frac{2 C}{\triangle t}\left[v_{k}(t-\triangle t)-v_{m}(t-\triangle t)\right]
\end{gathered}
$$

A integração trapezoidal das equações diferenciais, gerou equações que podem ser representadas por circuitos equivalentes de Norton, como mostra a Figura 41.

Figura 41 - Equivalentes de Norton do induto L, resistor R e capacitor C.

$$
I_{k m}^{L}(t-\Delta t) \sum_{m}^{k} v_{m}^{v_{k}(t)}
$$

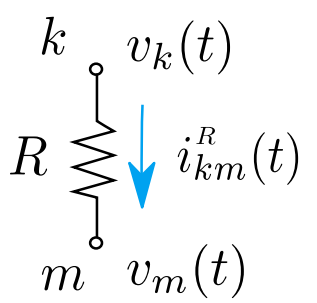

$$
I_{k m}^{C}(t-\Delta t) \underbrace{k}_{m} v_{m}^{\frac{\Delta t}{2 C} \sum_{j}^{i} i_{k m}^{C}(t)}
$$

\subsection{Modelo de Simulação para as Linhas de Trans- missão}

Para uma consideração adequada do cálculo de transitórios eletromecânicos é importante considerar as diferentes condições do sistema para as quais existe um modelo de linha de transmissão que melhor se aplica. Os modelos existentes são classificados como modelo com parâmetros concentrados, com parâmetros distribuídos e com parâmetros dependentes da frequência. O uso adequado de cada modelo pode ser determinado como 
Figura 42 - Algoritmo para seleção adequada do modelo de linha para simulação.

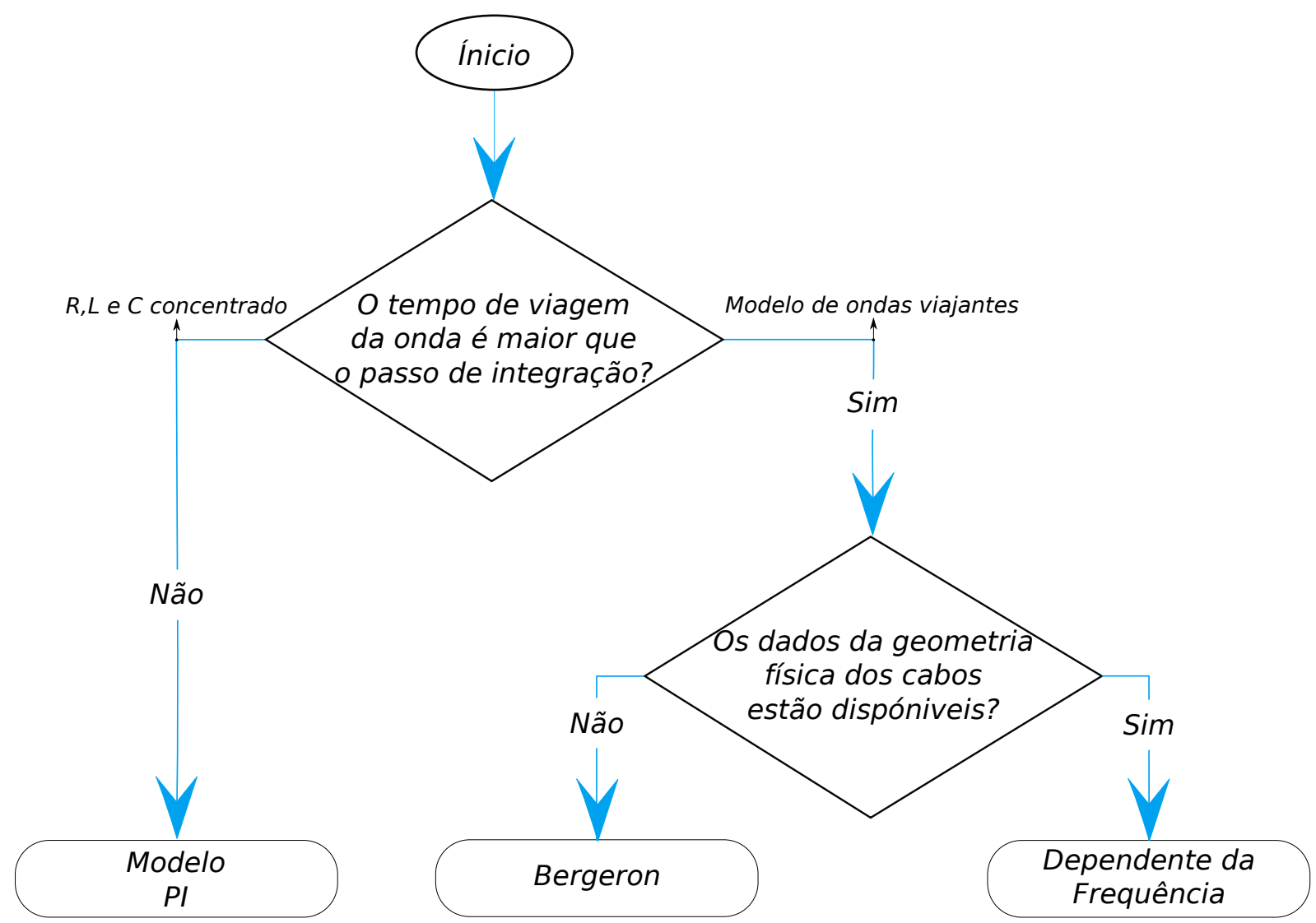

mostra a Figura 42 (WATSON; ARRILLAGA; ENGINEERS, 2003). Neste algoritmo o primeiro passo é definir o tempo de propagação $\tau$ dos sinais na linha de transmissão, esse tempo pode ser definido através da Equação 29, onde $l$ é o comprimento da linha em $\mathrm{km}$ e $L C$ é o produto da capacitância e indutância por $\mathrm{km}$ de linha. Se o tempo de viagem da onda é maior que o passo de simulação adotado, o modelo Pi não é indicado, em vez deste, pode ser utilizado um modelo baseado na teoria de ondas viajantes.

$$
\tau=l \sqrt{L C}
$$

\subsubsection{Modelo Pi}

Este modelo pode ser representado de forma monofásica e trifásica. Este último para considerar o acoplamento entre as fases. Para este modelo uma seção $\pi$ representa a linha de transmissão monofásica, com R, L e C escalares. No caso da representação trifásica $\mathrm{R}$, L e C são matrizes na forma $\left[R_{x y}\right]+j \omega\left[L_{x y}\right]$, onde, para $x=y$ representa a impedância própria da fase e $x \neq y$ representa a impedância mutua entre as fases $x$ e $y$. As capacitâncias são representadas por uma matriz diagonal $C_{x y}$, onde $x=y$ e é calculada pela soma das capacitâncias no terminal da fase. 
Neste estudo, para simular a linha monofásica HVDC com parâmetros concentrados, as capacitâncias puderam ser desconsideradas, uma vez que as capacitâncias dos filtros do VSC possuem valores muito superiores. Assim a linha pode ser modelada como ilustra a Figura 43. Os parâmetros concentrados da linha foram tratados, como um equivalente de Norton, já apresentado neste capítulo.

Figura 43 - Modelo de linha de transmissão com parâmetros concentrados.

$$
\begin{aligned}
& v_{k}(t) \stackrel{\mathrm{a}^{\prime}}{\stackrel{i_{k m}(t)}{\longrightarrow}} \mathrm{m}^{m} v_{m}(t) \\
& \frac{L}{k m} \quad \frac{R}{k m}
\end{aligned}
$$

\subsubsection{Modelo Bergeron}

Este modelo simula uma linha sem perdas e os parâmetros das linhas são constantes com a frequência. Para adicionar as perdas uma resistência concentrada é inserida. Este modelo é baseado na teoria de ondas viajantes (FUCHS, 1979). Este estudo aborda essa teoria com intuito de obter o equivalente de Norton da linha de transmissão (WATSON; ARRILLAGA; ENGINEERS, 2003).

Seja a linha de transmissão, ilustrada na Figura 43, onde um sinal se propaga do terminal $k$ para o terminal $m$. Considerando resistência, indutância e capacitância da linha distribuídos ao londo do seu comprimento total $l$, um novo modelo pode ser observado na Figura 44, que mostra o circuito equivalente no modelo Bergeron. A Equação 30 define a corrente $i_{k m}(t)$ e a Equação 31 define a sua parcela histórica $I_{k}$. Na Figura 44, o termo $\frac{R}{4}$ equivale as perdas e $z_{c}$ é a impedância característica da linha.

Quando os computadores digitais ainda não possuíam os recursos que são disponíveis hoje, grande parte dos cálculos de transitórios no SEP eram feitos na forma monofásica, isso porque o cálculo polifásico necessitava de grande esforço computacional (HEDMAN et al., 1983). Esta estratégia desconsidera o desequilíbrio elétrico e magnético existente em sistemas polifásicos (FUCHS, 1979). Devido ao recorrente interesse dos pesquisadores em desenvolver técnicas de análise polifásica de transitórios eletromagnéticos, estratégias matemáticas foram aplicadas a este problema, para o tornar computacionalmente praticável e mesmo com os recursos computacionais que são disponíveis na atualidade, essas técnicas ainda são uma boa estratégia para simulações de redes polifásicas.

Na modelagem de linhas polifásicas é necessário considerar o acoplamento entre as fases. Dependendo do número de fases, essa consideração torna-se muito complexa. Dessa forma, usa-se quantidades modais, o que poderia ser considerado equivalente a decompor um sistema de $n$ fases em $n$ sistemas monofásicos, facilitando a resolução. Ao final do estudo efetua-se o processo inverso e determina-se as quantidades por fases novamente. Cada um dos três sistemas monofásicos pode ser tratado pela forma definida pela mode- 
lagem monofásica: considerando as perdas ou não. Neste estudo não serão consideradas linhas acopladas.

Figura 44 - Modelo Bergeron de linha de transmissão com perdas.
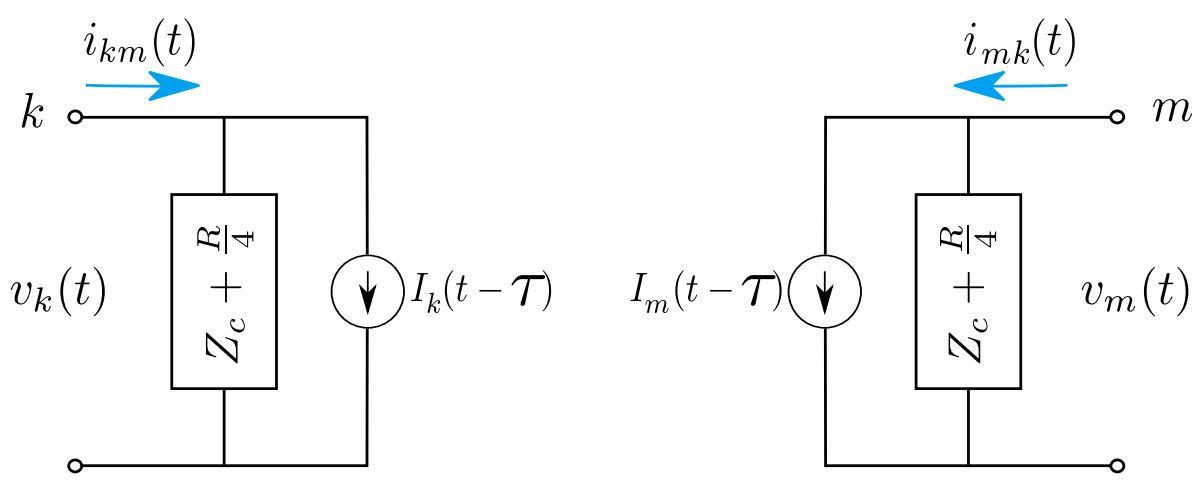

$$
\begin{gathered}
i_{k m}(t)=\frac{1}{z_{c}+\frac{R}{4}} v_{k}(t)+I_{k}(t-\tau) \\
I_{k}(t-\tau)=\frac{-z_{c}}{\left(z_{c}+\frac{R}{4}\right)^{2}}\left[v_{m}(t-\tau)+i_{m k}(t-\tau)\left(z_{c}-\frac{R}{4}\right)\right] \\
+\frac{-\frac{R}{4}}{\left(z_{c}+\frac{R}{4}\right)^{2}}\left[v_{k}(t-\tau)+i_{k m}(t-\tau)\left(z_{c}-\frac{R}{4}\right)\right]
\end{gathered}
$$

\subsection{Biblioteca de Código Livre para Simulação dos Transitórios Eletromagnéticos}

Uma vez que a simulação de Monte Carlo requer muitas simulações e programas comerciais não disponibilizam o acesso da informações ainda em memória, o custo temporal para desempenhar o processo de leitura e escrita em arquivo seria elevado. Devido a isso, optou-se pelo desenvolvimento de um programa em linguagem $\mathrm{C}++$, afim de obter acesso as informações ainda em memória. O programa desenvolvido no decorrer deste estudo foi intitulado de Open Electromagnetic Transients Program (OEMTP).

A biblioteca, que compõe o programa, descreve os elementos básicos constituintes do sistema elétrico, tais como resistores, indutores, capacitores, chaves, fontes e linhas de transmissão. Já o programa, faz uso destes elementos, afim de simular o comportamento do sistema em função do tempo. Uma vez detectada a dificuldade em prever os estados de operação do circuito HVDC, uma solução através de equações de espaço de estados foi inviabilizada e, como alternativa, optou-se por uma solução através do método de equações de diferença.

O OEMTP integra todos os elementos fundamentais de sistemas elétricos de potência à análise de transitórios eletromagnéticos na forma de código livre. Dessa forma, a sua 
aplicação se estende a outros estudos que necessitem deste tipo de abordagem. Este, também permite a integração com estratégias de proteção e controle desenvolvidas na Open Relay, biblioteca que fornece suporte ao desenvolvimento e implementação de algoritmos de proteção (MONARO et al., 2012).

\subsubsection{Estrutura do OEMTP}

O programa OEMTP pode ser descrito através de suas três camadas principais, que são mostradas na Figura 45. A primeira camada consiste na descrição dos elementos elétricos: resistores, capacitores, indutores, fontes e linhas, como mostrado na Seção 4.2 e na Seção 4.3. Na camada 2 o circuito é construído, isto é, os elementos são conectados, possibilitando que a matriz de condutância do sistema seja formada. Por último, a camada 3 executa a dinâmica do circuito em relação ao tempo, compondo a equação $i(t)+I(t)=$ $G v(t)$. Quando tarefas de controle são necessárias, a camada 3 interage com a biblioteca Open Relay para prover ferramentas como: PLLs, PWMs, relés de sobrecorrente, filtros, transformadas, portas lógicas, controles da família PID, entre outras funções.

Figura 45 - Camadas do programa OEMTP.

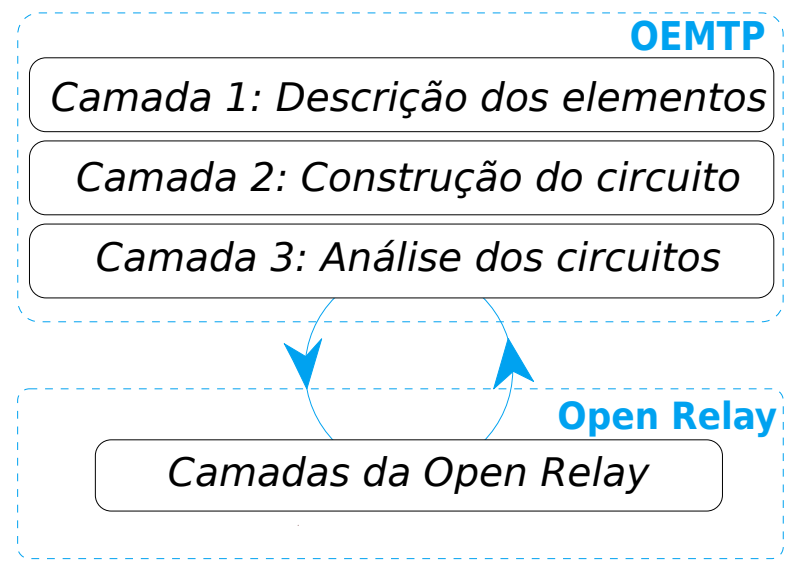

O circuito completo (Figura 21) usado neste estudo para validar a metodologia foi simulado no OEMTP. Alguns trechos do código podem ser vistos no Algoritmo 7, que mostra elementos descritos na camada 2. A primeira linha é uma fonte alternada, denominada de Vas1. Os argumentos entre parentes são respectivamente: nó de origem, nó de destino, tensão de fase, frequência, ângulo de defasagem, impedância interna e passo de integração. A segunda linha do algoritmo mostra como um resistor é descrito. Os parâmetros são respectivamente: nó de origem, nó de destino e valor de impedância. A terceira linha mostra a inclusão de uma linha de transmissão do modelo Bergeron, com os seguintes parâmetros: nó de origem, nó de destino, comprimento em quilômetro, indutância por quilômetro, capacitância por quilômetro, impedância por quilômetro e passo de integração. A descrição do circuito completo da Figura 21, pode ser visto no Algoritmo 9 do Anexo A, que equivale a camada 2 do OEMTP. 


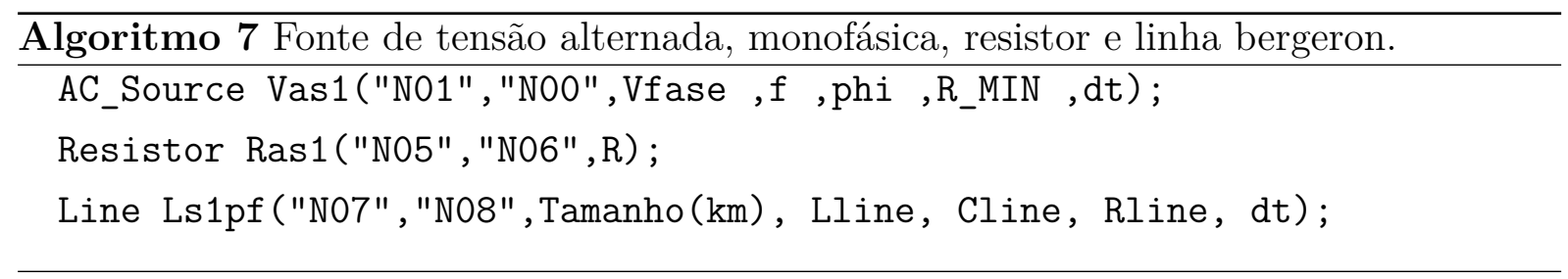

A partir da simulação do circuito modelo (Figura 21) no OEMTP, alguns resultados são obtidos. Os resultados são medidas de sinais do circuito, como corrente e tensão nos polos. Os seguintes parâmetros foram considerados: $P=1$ p.u., $Q=0$ p.u., $V_{\text {linha, fonte }}=100 \mathrm{kV}$ e $C=280 E-6 F$. Demais parâmetros do circuito podem ser encontrados no Anexo A. As técnicas de controle implementadas são as técnicas mostradas na Seção 2.3. Os sinais foram obtidos para uma simulação com duração de $t=0.6 \mathrm{~s}$ e não foram aplicadas faltas neste situação. A duração da simulação permite contemplar tanto o transitório, como o estágio de regime permanente dos sinais.

Para ler os sinais de corrente nos polos, amperímetros foram incluídos no circuito, entre o VSC e os polos, e para ler os sinais de tensão, voltímetros foram ligados do mesmo nó ao terra. Já para a corrente nos IGBTs, foi incluído um amperímetro no braço do conversor, correspondente a fase A. Na Figura 46 mostram-se os detalhes dos medidores no circuito.

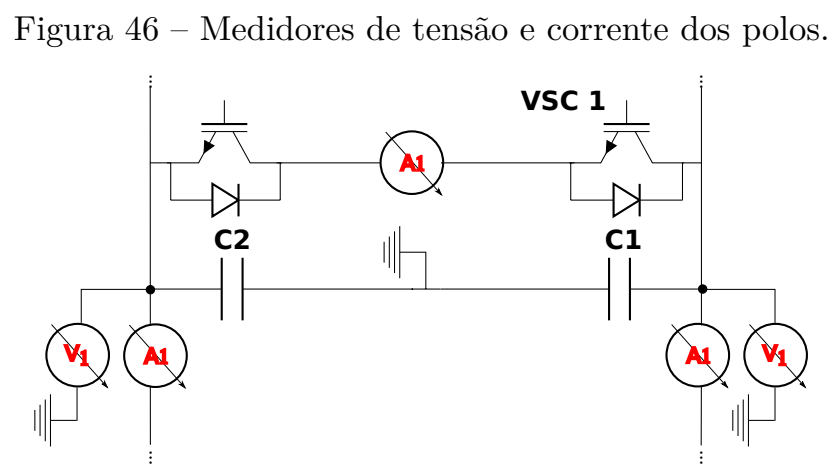

Assim, as correntes dos dois polos são mostradas na Figura 47, onde pode-se observar o comportamento dual esperado para esta grandeza. Igualmente a Figura 48 mostra a tensão nos polos. Já na Figura 49 é mostrada a medida da corrente na fase A do VSC e na Figura 50 é mostrada a tensão por unidade, gerada pelo controle para a referência do PWM.

As tensões de referência do PWM, para controle do VSC 1, são obtidas depois da transformação de d-q-0 para a-b-c, dos sinais gerados no controle. Neste caso é a transformação do sinal de saída é mostrada na Figura 16 e Figura 17. 
Figura 47 - Corrente no polo positivo e no polo negativo.

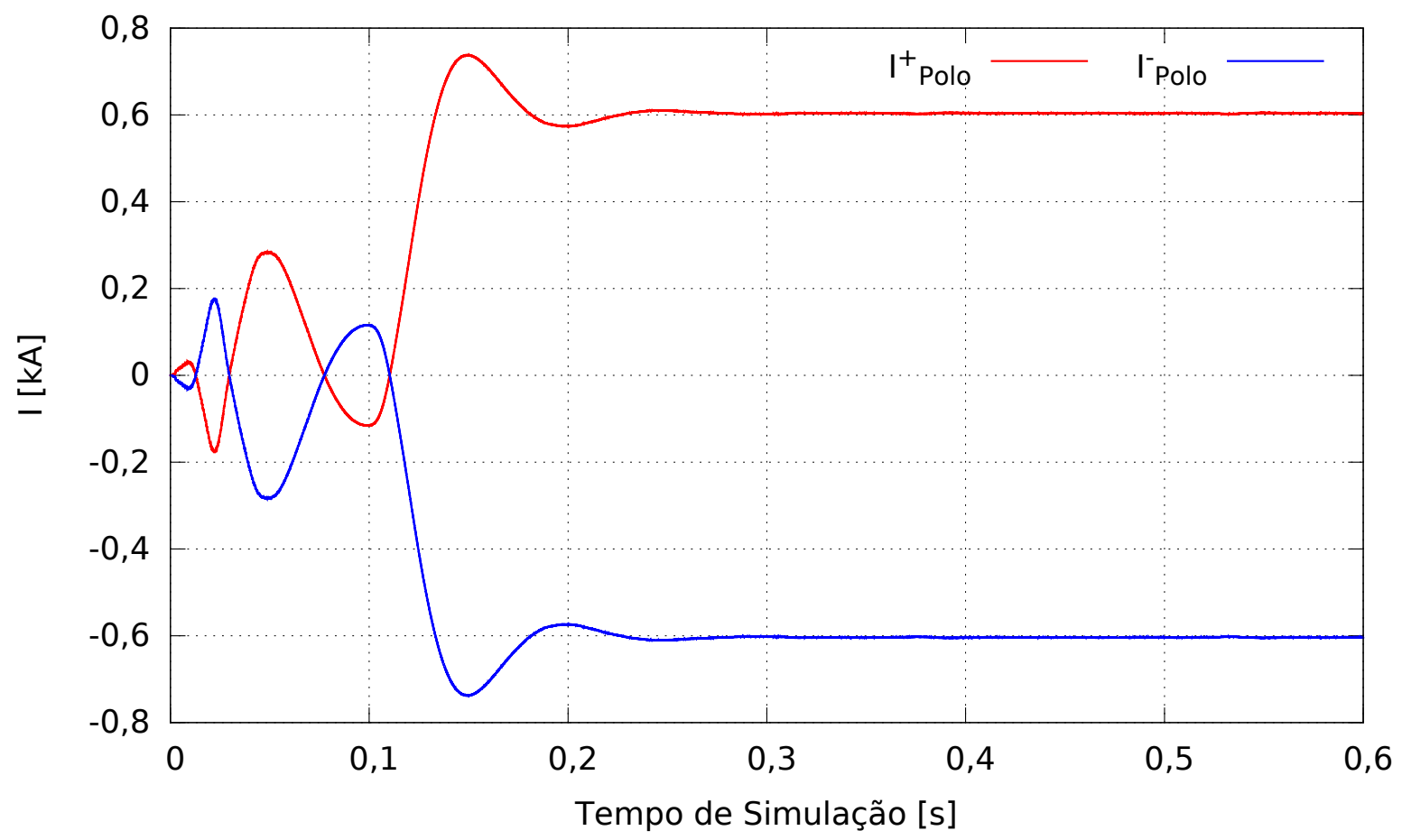

Figura 48 - Tensão no polo positivo e no polo negativo.

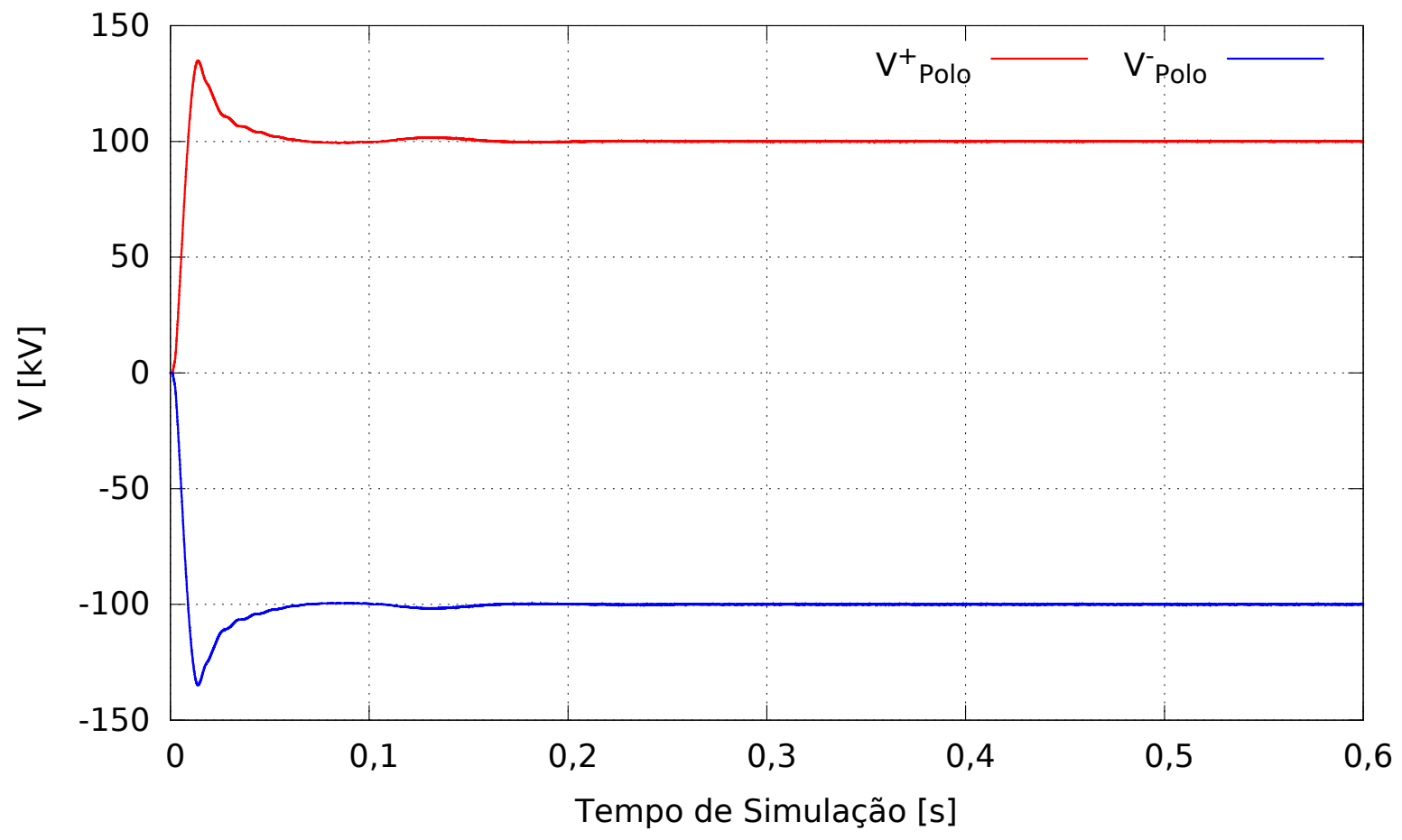


Figura 49 - Corrente no braço do VSC da fase A.

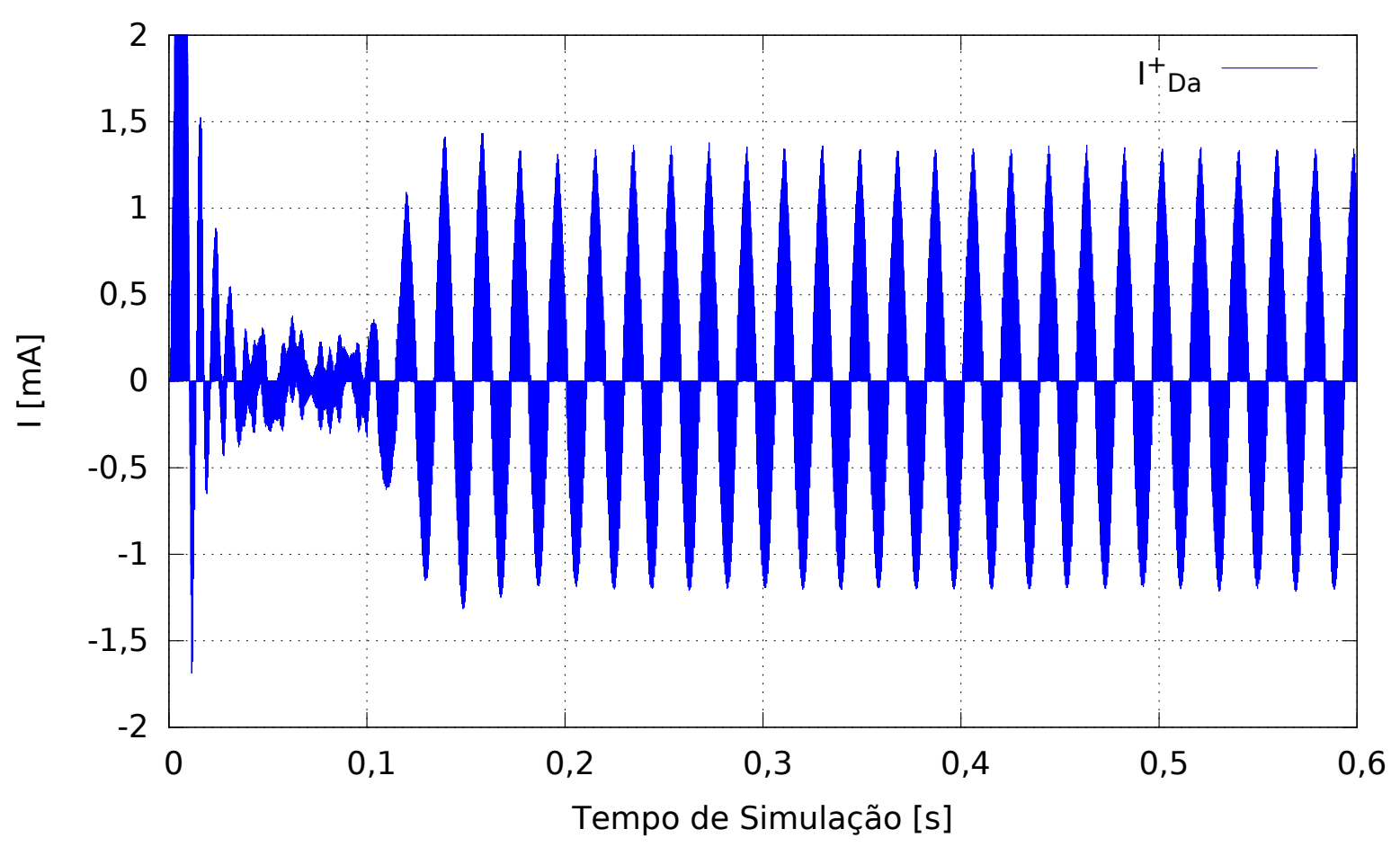

Figura 50 - Tensão de referência para o PWM por fase, gerada pelo controle.

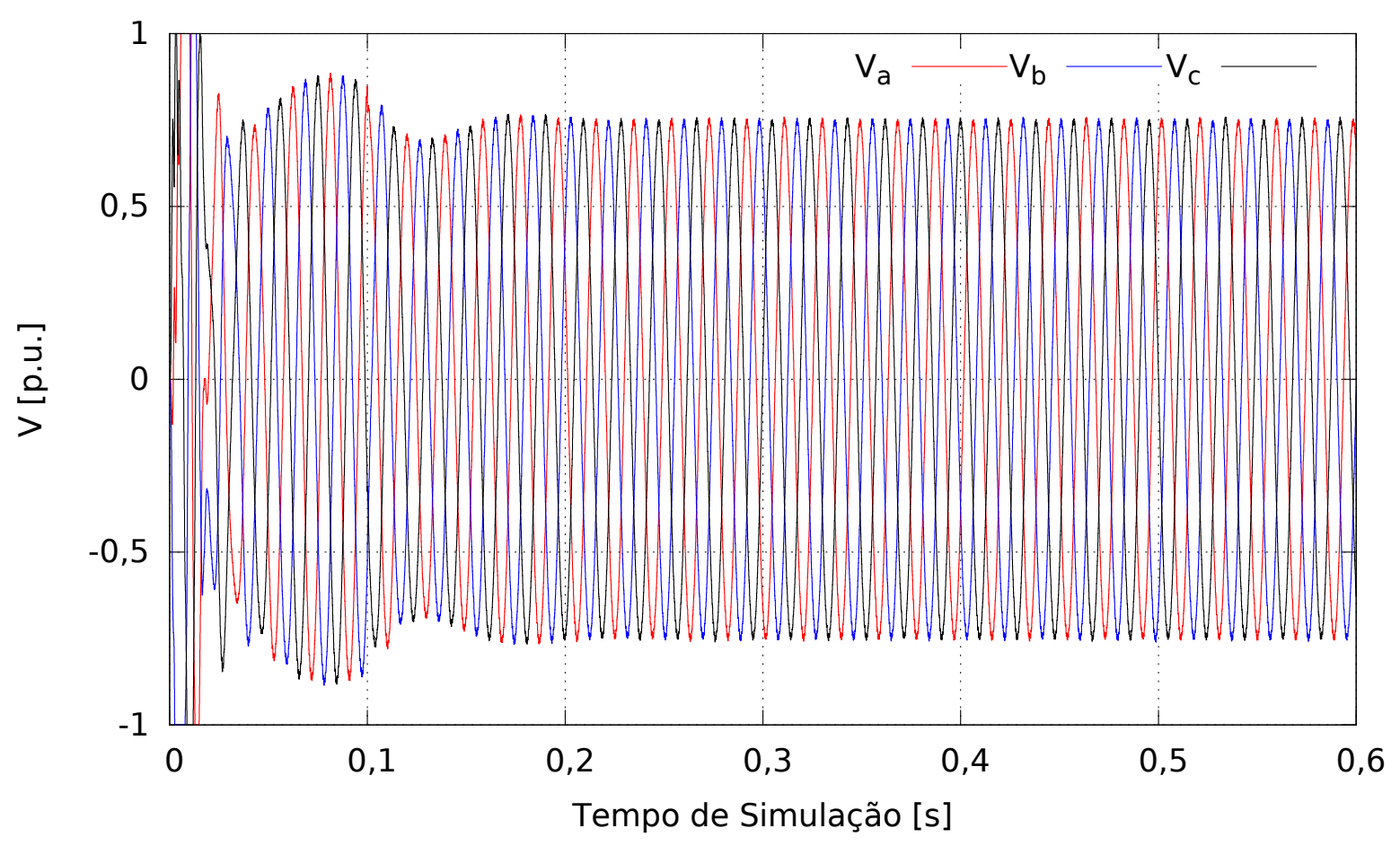




\subsection{Considerações}

Neste capítulo foram tratadas as possíveis formas de solução de transitórios eletromagnéticos no SEP, como também as formas de representar os componentes elementares dos circuitos elétricos, além de tratar os modelos mais comuns de linhas de transmissão.

Também foi apontada a escolha pelo método de equações de diferença, para solucionar os transitórios eletromagnéticos em sistemas VSC-HVDC, uma vez que, não foi possível determinar todos os estados operacionais do circuito através do modelo de espaço de estados.

Por fim, tratou-se do desenvolvimento e da estrutura do programa OEMTP. Estas designações são empregadas no próximo capítulo com o intuito de consolidar o método de CCP em sistemas VSC-HVDC. 


\section{Emprego da Simulação de Monte Carlo para Obter o Cálculo de Curto-Circuito Probabilístico em Sistemas VSC-HVDC}

Neste capítulo será explanado o emprego do CCP em sistemas VSC-HVDC. Respaldado neste capítulo, uma nova vertente de estudos é mostrada, provendo o conhecimento pertinente a respeito da parcela do sistema elétrico que constitui os HVDCs e a idealização de uma métrica que venha a apresentar parâmetros relevantes aos equipamentos e aos sistemas de proteção que serão nestes empregados.

A abordagem será realizada inicialmente através da apresentação do circuito teste, onde os transitórios eletromagnéticos são simulados através do programa OEMTP e as etapas de controle simuladas através da biblioteca Open Relay. A performance da biblioteca OEMTP é comparada com a de programas comerciais e o resultado do CCP-CC para dois cenários é mostrado. O cenário 1 mostra a condição em que o VSCs opera como retificador não-controlado e, no cenário 2, o VSC opera em condição convencional (controlado).

Ainda neste capítulo será mostrada a distância euclidiana medida entre histogramas, para definir o número de faltas realizadas, bem como a adoção da regra da raiz quadrada para definição da quantidade de classes adotadas para expressar as FDPs.

\subsection{Sistema de Teste}

A metodologia proposta neste estudo foi testada em um circuito com topologia monopolar simétrica, baseado em conversores do tipo VSC de dois níveis com IGBTs. O sistema é então composto pelo VSC 1 e VSC 2, como ilustrado na Figura 51. A tensão de linha do sistema equivalente alternado é $E_{n}=100 k V$ ( $n$ é a fase e $k$ e $m$ o inversor no qual esta conectado) e a frequência fundamental igual a $50 \mathrm{~Hz}$. As linhas possuem $75 \mathrm{~km}$ de comprimento e são desacopladas magneticamente. 
O sistema VSC-HVDC descrito é uma adaptação do sistema proposto por Schettler, Huang e Christl (2000) e Casoria (2007). Deste modelo a configuração do sistema CA e os VSCs se mantiveram, já os dados da linha e do filtro capacitivo foram alterados. O sistema será denominado por sistema de teste.

Figura 51 - Sistema de teste.

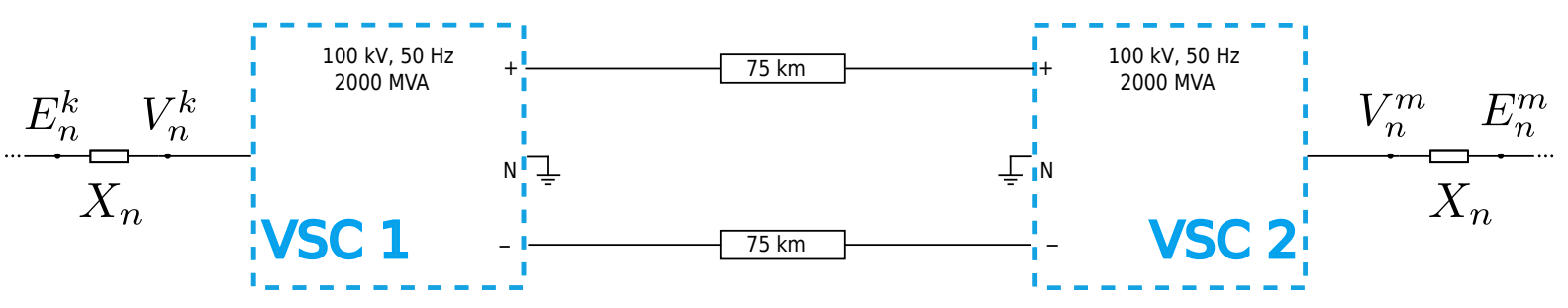

As alterações nos dados da linha e do filtro ocorre porque neste estudo serão considerados dois cenários para a execução do CCP-CC. O primeiro considera os VSC operando como retificadores não controlados. Este cenário, com algumas adaptações do sistema de teste e os resultados serão tratados na Seção 5.5. O segundo cenário considera o sistema operando de forma convencional (P e Q ajustados), este será tratado na Seção 5.6.

A configuração da parcela CA que liga o gerador ao reator se mantem igual (nos dois cenários) ao modelo proposto por Schettler, Huang e Christl (2000) e Schettler, Huang e Christl (2000), Casoria (2007). A Figura 52 mostra o circuito equivalente na baixa tensão.

Figura 52 - Equivalente da fonte ideal e reator referidos à baixa tensão.

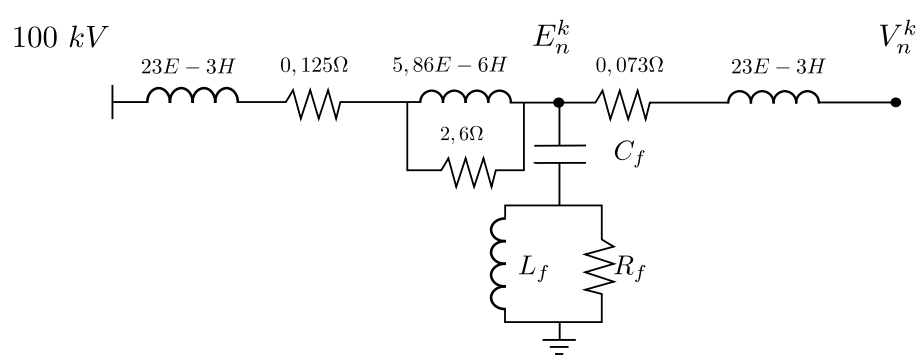

\subsection{Programa de Simulação de Transitório Eletro- magnético e Plataforma de Simulação}

Devido a necessidade de se realizar um número elevado de simulações para validar a aplicação da SMC no contexto de CCP-CC, foram implementadas técnicas de processamento paralelo no ambiente de computação em nuvem, Plataforma de Computação em Nuvem da Universidade de São Paulo (CloudUSP) (STI, 2014). Este é um supercomputador de acesso remoto. O acesso a esta máquina advêm de técnicas que associam os 
recursos computacionais gerando grande vantagem ao usuário, pois, em nuvem, os recursos são dinamicamente alocados de acordo com as necessidades de desempenho, escala e demanda.

De forma a prover o aproveitamento significativo dos recursos computacionais disponíveis na CloudUSP, foi implementado, em linguagem de programação $\mathrm{C}++$, a biblioteca com acesso livre de computação paralela Message Passing Interface (Open MPI). A utilização do Open MPI permitiu que através da troca de mensagens entre os nós de processamento, houvesse uma distribuição das tarefas de simulação. O processo de troca de mensagem se inicia mediante a escolha de um nó mestre. Este fará o gerenciamento das tarefas dos demais nós enviando as mensagens para início das tarefas como também recebendo e gerenciando as saídas das tarefas de cada nó.

Buscando satisfazer os requisitos necessários à SMC, as ferramentas CloudUSP, Open MPI e as equações de diferença capazes de solucionar os transitórios eletromagnéticos, motivaram o desenvolvimento do OEMTP. O fluxograma na Figura 53 expõe a relação entre tais ferramentas para compor a biblioteca desenvolvida. Além disso, foram introduzidas as ferramentas de controle dos VSC, através da biblioteca Open Relay. Os seguintes passos fazem parte do fluxograma:

$\square$ Determinar o número de simulações desejadas através da distância euclidiana;

$\square$ Definir o número de nós de processamento disponíveis, de forma que o processamento seja adequadamente distribuindo entre estes;

$\square$ Um nó, denominado nó 0 , será reservado para o gerenciamento das trocas de mensagens, ou seja, este definirá o processo que os demais nós irão realizar, como também, se encarregará de receber e gerenciar cada mensagem de solução e, em caso conveniente, até que se atinja o número de simulações determinada, encaminhar nova tarefa aos demais nós;

$\square$ É definido em cada nó, com exceção do nóo, o circuito com elementos modelados pelo método de integração trapezoidal com a impedância da linha, a impedância da falta $z_{f}$, ponto de operação (P e Q) e o tipo de falta definidos conforme o sorteio da SMC;

$\square$ Cada nó efetuará a simulação do circuito e retornará para o nó o máximo valor da corrente de falta, referente a contribuição do VSC 1;

$\square$ O nó armazenará o retorno de todos os nós e solicitará que cada nó realize a SMC e simule o circuito até atingir o número de simulações pré-determinado;

$\square$ Quando se atingir o número de simulações desejado o nó 0 retornará a FDP da corrente de falta de VSC 1. 
Capítulo 5. Emprego da Simulação de Monte Carlo para Obter o Cálculo de Curto-Circuito

Figura 53 - Algoritmo do curto-circuito probabilístico para linhas de transmissão em corrente contínua.

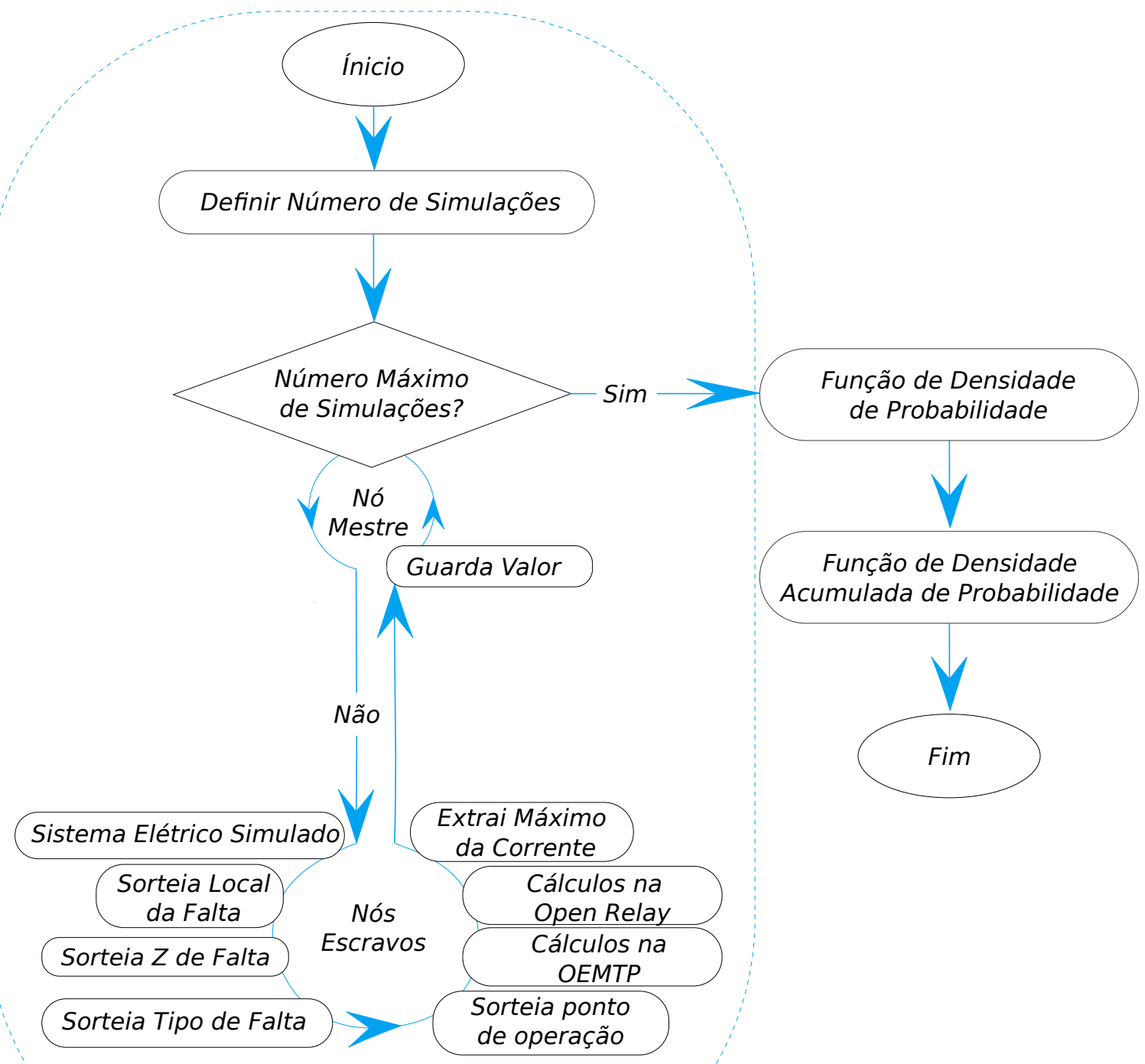

Cloud USP 
Assim, foram alocadas nesta pesquisa seis máquinas da CloudUSP. Cada máquina com oito processadores do tipo Intel(R) Xeon(R) CPU E7- 2870@ 2.40GHz e 16 GB de memória. Na Figura 54, pode-se observar o esquemáticos das seis máquinas utilizadas. Um dos processadores da máquina central é o nó zero e os demais processadores desta e das demais máquinas são nós escravos.

Figura 54 - Esquema das máquinas na Cloud USP com a comunicação através da Open MPI.

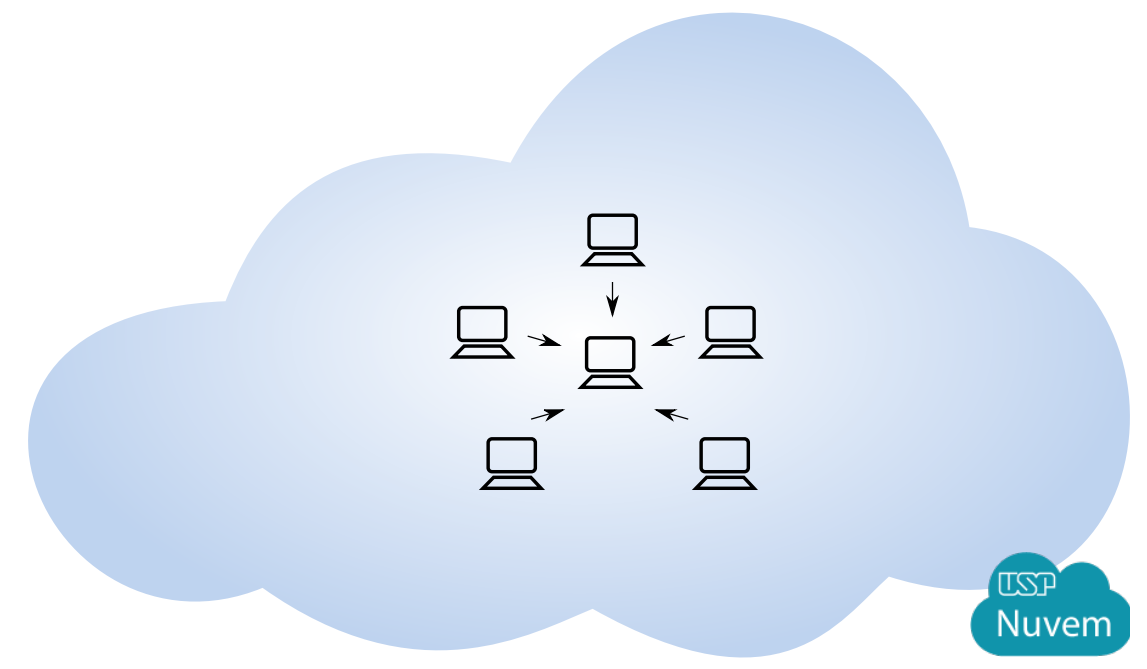

\subsection{Validação do Programa de Simulação de Transi- tório}

Esta seção pretende equiparar sinais de corrente e tensão das simulações do sistema de teste, gerados em programas distintos para comprovar a eficácia do programa desenvolvido neste estudo. O sistema de teste, mostrado na Figura 51, foi simulado no programa Matlab/Simulink com intuito de validar o programa de simulação de transitório OEMTP.

Para realização das simulações os mesmos parâmetros são ajustados em ambos os programas, onde não foram consideradas impedâncias nas faltas aplicadas e o retificador está no modo não-controlado, ou seja, os VSCs operam sem controle. Assim os IGBTs não chaveiam e apenas os diodos de roda livre estão ativos no circuito, além do que, quando a simulação se inicia (em $t=0 \mathrm{~s}$ ) as faltas já estão aplicadas. Foram combinadas diferentes posições e tipos de faltas afim de que comportamentos distintos fossem analisados.

A Figura 55 e Figura 56 mostram os sinais obtidos no OEMTP e no Matlab/Simulink, onde cada sinal foi impresso junto ao seu respectivo sinal gerado no OEMTP. Foram analisados sinais com características as mais diversas possíveis, que supostamente sofreram diferentes transitórios no decorrer da simulação. A primeira janela de cada figura contêm o sinal de tensão $V_{s}$, que é tensão da fonte CA na fase a ligada ao VSC 1. A segunda janela corresponde a corrente do diodo $I_{D a}^{+}$do VSC 1, responsável por transmitir a energia durante o semiciclo positivo de corrente da fase $a$. Na sequência, a terceira janela traz a 
tensão no capacitor $V_{c 1} \mathrm{e}$, por fim, a quarta janela mostra a contribuição de corrente do VSC 1 no polo positivo, $I_{c a b o}^{+}$.

Os sinais mostrados na Figura 55, foram obtidos mediante a ocorrência de uma falta entre polos, no meio da linha. Nesta ocasião todos os sinais se comportaram de forma sincronizada, com ressalva para pequenas oscilações que podem ser observadas no sinal $I_{D a}^{+}$ gerado pelo OEMTP, causadas pelo chaveamento de outros diodos do mesmo conversor. Entretanto essas oscilações não acarretaram em prejuízos na operação, de forma global. Estas pequenas oscilações também podem ser observadas nas demais figuras de validação. A Figura 56, mostra os sinais do sistema com um curto-circuito entre polo positivo e terra que ocorre a $10 \%$ do comprimento total do cabo, em relação ao VSC 1. As demais condições já descritas foram preservadas.

Os sinais representados nesta seção, mostram a efetiva operação da simulação do OEMTP, pois há forte pertinência entre os sinais gerados por este e os gerados pelo Matlab/Simulink. Esta pertinência foi calculada através da correlação linear entre os sinais de correntes $I_{c a b o}^{+}$, ilustrado na Figura 56. O valor da correlação linear obtida entre os sinais foi de 0,9993 que equivale a uma correlação forte e positiva. A equação que define a correlação entre os dois sinais foi descrita no Capítulo 3 (Equação 10).

Figura 55 - Sinais do sistema de teste para um curto-circuito entre polos em $50 \%$ do cabo.

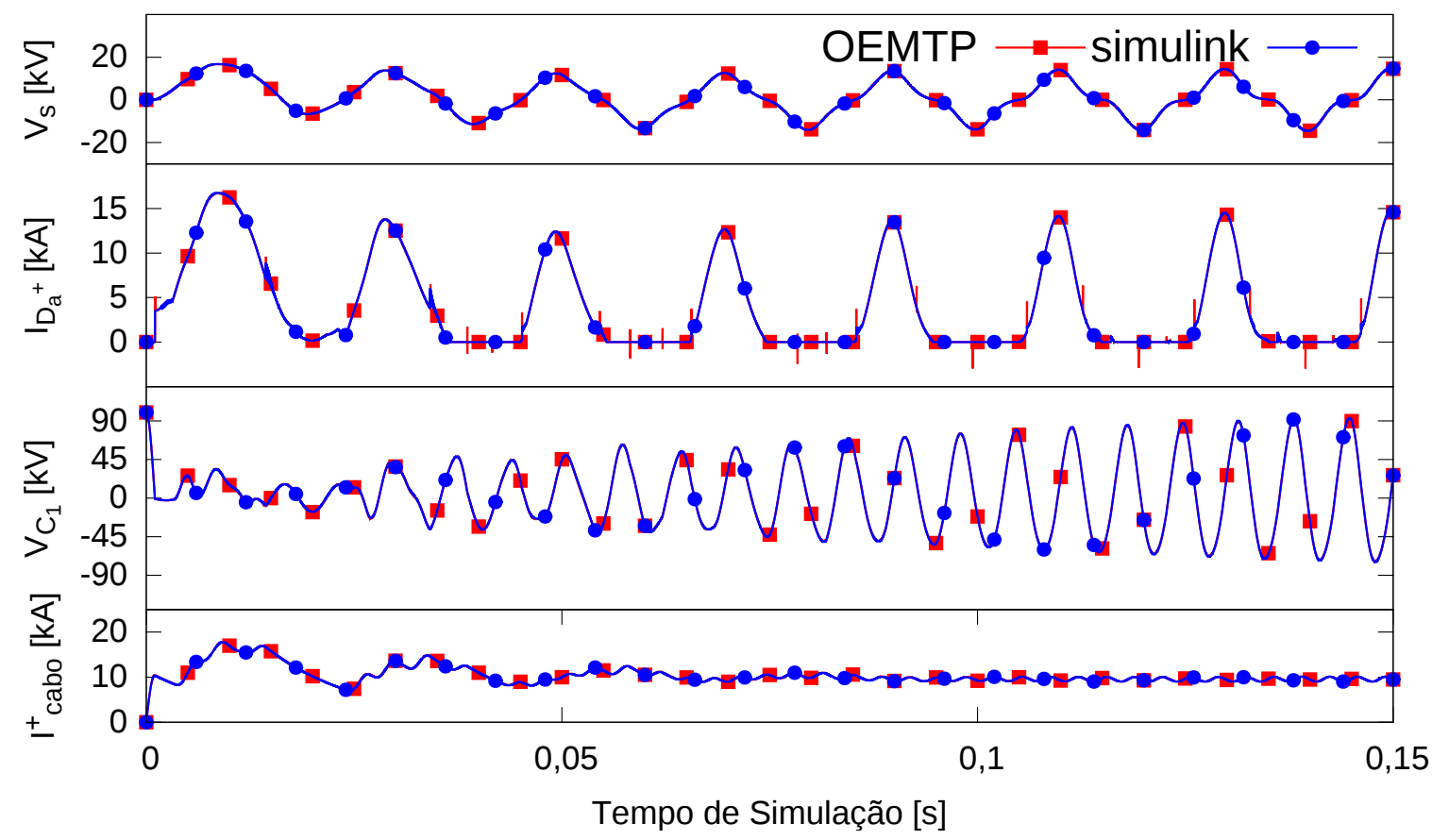


Figura 56 - Sinais do sistema de teste para um curto-circuito de polo positivo a terra em $10 \%$ do cabo.

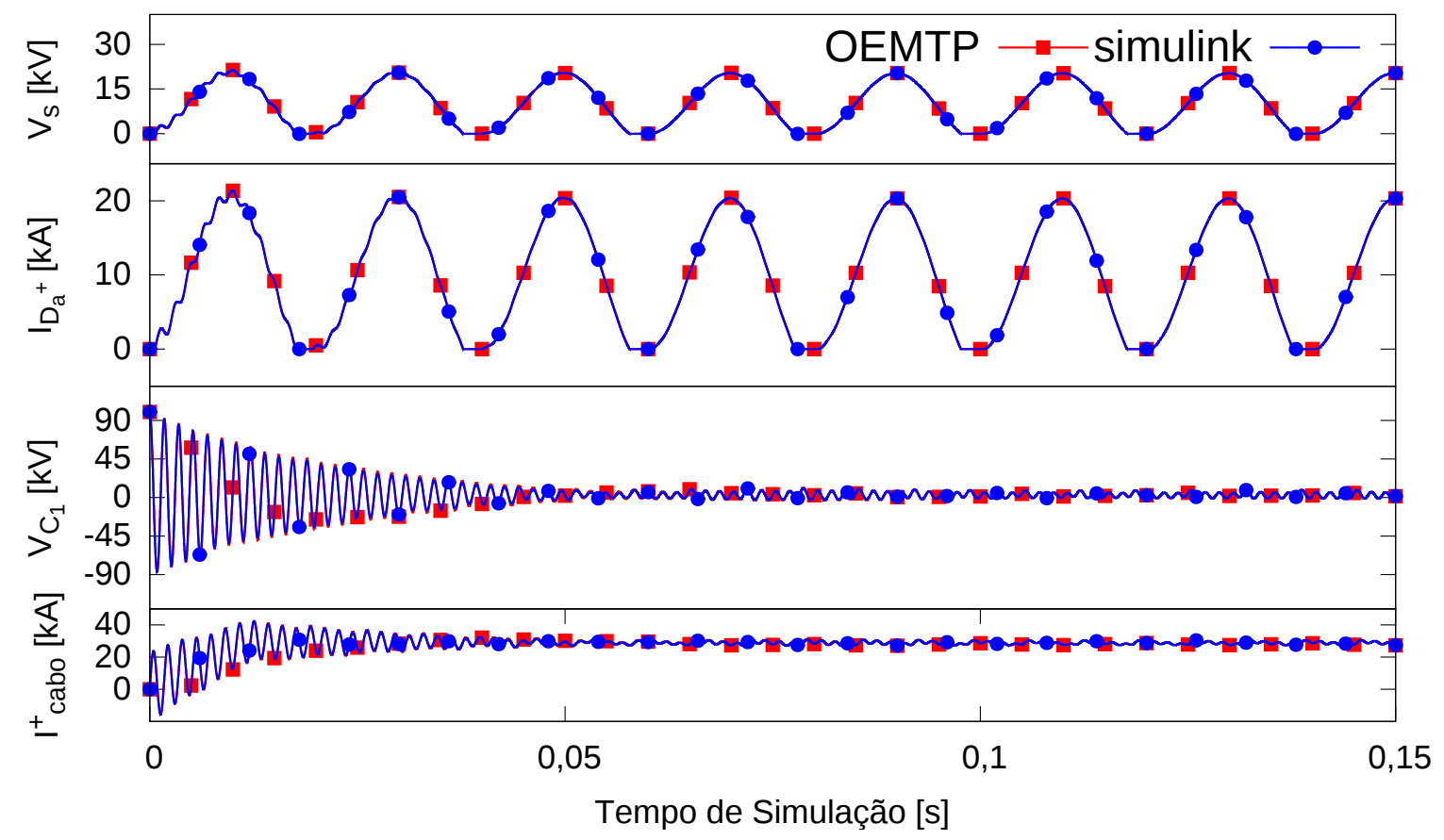

\subsection{Integração do OEMTP com a Open Relay}

A Open Relay executa a tarefa de controle das estações VSC, através das técnicas do MCV como foi tratado na Seção 2.3. Os parâmetros dos controladores do VSC 1 foram ajustados como segue descrito na Tabela 5, e os do VSC 2 na Tabela 6. As constantes $K_{p}$ e $\tau_{i}$ são declaradas para cada $P I^{\rho}$, onde $\rho$ é a grandeza controlada. Para melhor compreensão, estes PI's podem ser associados a Figura 16, Figura 17 e Figura 18. O VSC 1 controla potência ativa e reativa e o VSC 2 controla potência reativa e tensão $V_{c c}$, isso ocorre na malha mais externa, consecutivamente, mais lenta. As malhas mais internas, controlam $I_{d}$ e $I_{q}$.

Tabela 5 - Ajustes dos controles VSC 1.

\begin{tabular}{cccc}
\hline Ganho & $\mathrm{PI}_{1}^{I_{d}, I_{q}}$ & $\mathrm{PI}_{2}^{P}$ & $\mathrm{PI}_{2}^{Q}$ \\
\hline $\mathrm{K}_{p}$ & 0.3 & 0.25 & 0,25 \\
$\tau_{i}$ & 0,02 & 0,003 & 0,003 \\
\hline
\end{tabular}

Tabela 6 - Ajustes dos controles VSC 2.

\begin{tabular}{ccccc}
\hline Ganho & $\mathrm{PI}_{1}^{I_{d}, I_{q}}$ & $\mathrm{PI}_{3}^{P}$ & $\mathrm{PI}_{2}^{Q}$ & $\mathrm{PI}_{2}^{V_{c c}}$ \\
\hline $\mathrm{K}_{p}$ & 0,3 & 1,5 & 0,5 & 15 \\
$\tau_{i}$ & 0,02 & 0,003 & 0,003 & 0,015 \\
\hline
\end{tabular}

Aos VSCs do sistema de teste, simulado pela OEMTP, mostrado na Figura 51, foram 
acrescentadas as estratégias de controle descritas nesta seção, através da Open Relay. Esta implementação foi proposta para que a operação real de um sistema VSC-HVDC seja simulada. Para validar a operação conjunta das bibliotecas foram aplicados degraus nas referências da potência P e da potência Q do VSC 1 para verificar o tempo de acomodação, o sobressinal, e explorar a curva de capabilidade do conversor, ver Figura 57.

Pode-se constatar que o tempo de acomodação está na ordem de 0,06 s, tanto para $\mathrm{P}$ quanto para Q. O sobressinal ocorre apenas em $\mathrm{P}$ e é na ordem de 0,05 pu. A respeito da capabilidade, todas as combinações simuladas de P e Q estão descritas na Tabela 7. Notase na Figura 57 que para nenhuma das combinações houve sobremodulação do $\operatorname{sinal}^{1}$, o que indicaria limitações de operação do sistema.

Tabela 7 - Valores dos degrais nas referências de P e Q.

\begin{tabular}{cccccccccccc}
\hline Tempo $[\mathrm{s}]$ & 0,00 & 0,25 & 0,37 & 0,50 & 0,75 & 1,00 & 1,12 & 1,25 & 1,37 & 1,60 & 1,85 \\
\hline $\mathrm{P} \mathrm{pu}$ & 0 & 1 & 1 & 0 & 0 & 0 & $\frac{1}{\sqrt{2}}$ & $\frac{1}{\sqrt{2}}$ & $-\frac{1}{\sqrt{2}}$ & $-\frac{1}{\sqrt{2}}$ & -1 \\
$\mathrm{Q} \mathrm{pu}$ & 0 & 0 & -1 & -1 & 1 & $\frac{1}{\sqrt{2}}$ & $\frac{1}{\sqrt{2}}$ & $-\frac{1}{\sqrt{2}}$ & $-\frac{1}{\sqrt{2}}$ & $\frac{1}{\sqrt{2}}$ & -1 \\
\hline
\end{tabular}

Figura 57 - Degraus na referência da potência $\mathrm{P}$ e da potência Q.

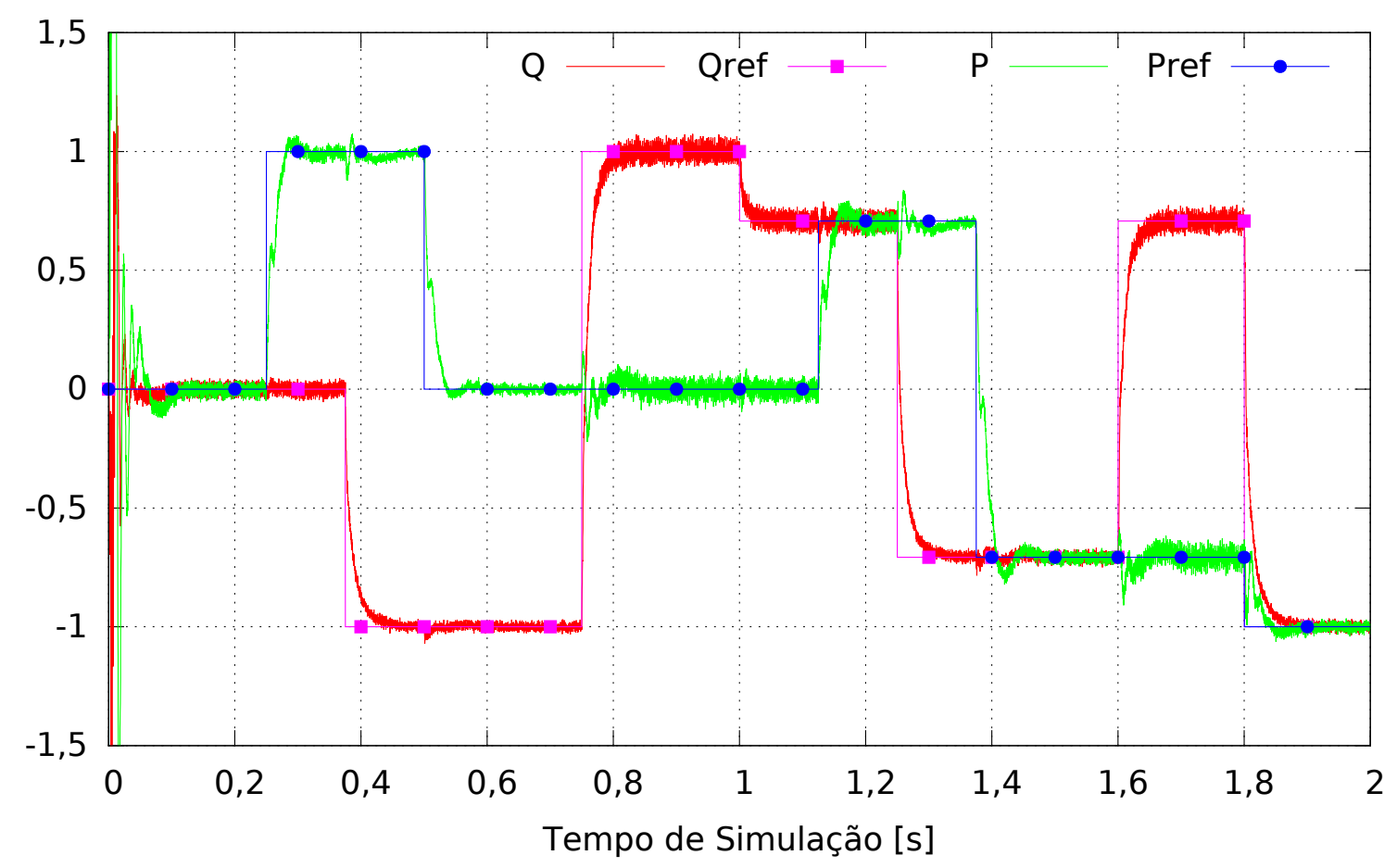

Na Seção 2.4 foi descrito a cerca do modo de proteção dos VSCs, isto é, como operam quando há sobre-corrente no sistema para que a integridade física dos conversores seja garantida. Para assegurar essa condição de operação uma lógica de sobrecorrente foi implementada através da Open Relay, para ativar o bloqueio dos PWMs quando uma

\footnotetext{
${ }^{1} \mathrm{~A}$ sobremodulação seria caracterizada por uma amplificação do ruído nos sinais de P e Q.
} 
ou ambas as correntes das linhas (polo positivo $I_{s p}$ ou negativo $I_{s n}$ ) superarem $2 \mathrm{pu}$, e assim assegurar que os IGBTs não estarão expostos a estas. A lógica foi implementada como mostra a Figura 58, na qual, a porta lógica OR, garante que se houverem correntes superiores a 2 pu, no polo positivo ou no polo negativo, o sinal de bloqueio do PWM será ativado, depois que o sinal Val for ativado na porta AND. O sinal Val garante que o bloqueio só poderá ser ativado depois do transitório de energização do sistema. O flip-flop mantém o bloqueio ativo mesmo que a corrente assuma valores inferior a $2 \mathrm{pu}$. O Reset do flip-flop garante que seu estado inicial seja nulo. Na Figura 59 mostram-se os sinais da lógica de sobrecorrente em operação, quando uma falta ocorre em $t=0,15 \mathrm{~s}$. Em $t=0,05 s$ o Reset do flip-flop é desativado. Em $t=0,1 s$ o sinal Val libera a porta AND, e no instante da falta o Block e o Trip são ativados.

Figura 58 - Lógica de sobrecorrente.

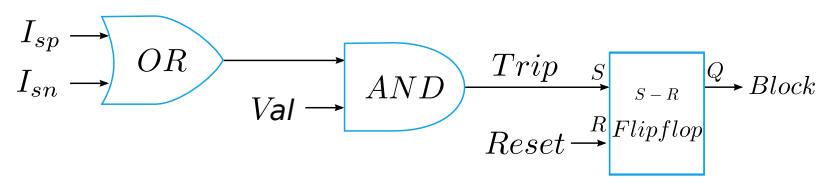

Durante a energização de um sistema real as potências P e Q são mantidas nulas. Depois que o sistema entra em regime as potências são setadas para os valores de operação desejados. De forma semelhante, as simulações realizadas neste estudo ajustam a referência de $\mathrm{P}$ e $\mathrm{Q}$ apenas em $t=0,1 \mathrm{~s}$. Apenas quando $\mathrm{P}$ e $\mathrm{Q}$ se acomodam é aplicada a falta $($ em $t=0,15 \mathrm{~s}$ ). A Figura 60 mostra $\mathrm{P}$ e Q em três cenários gerados aleatoriamente pela SMC. Os valores de P e Q se limitam a curva de capabilidade mostrada na Figura 37.

Figura 59 - Sinais da lógica de sobrecorrente.

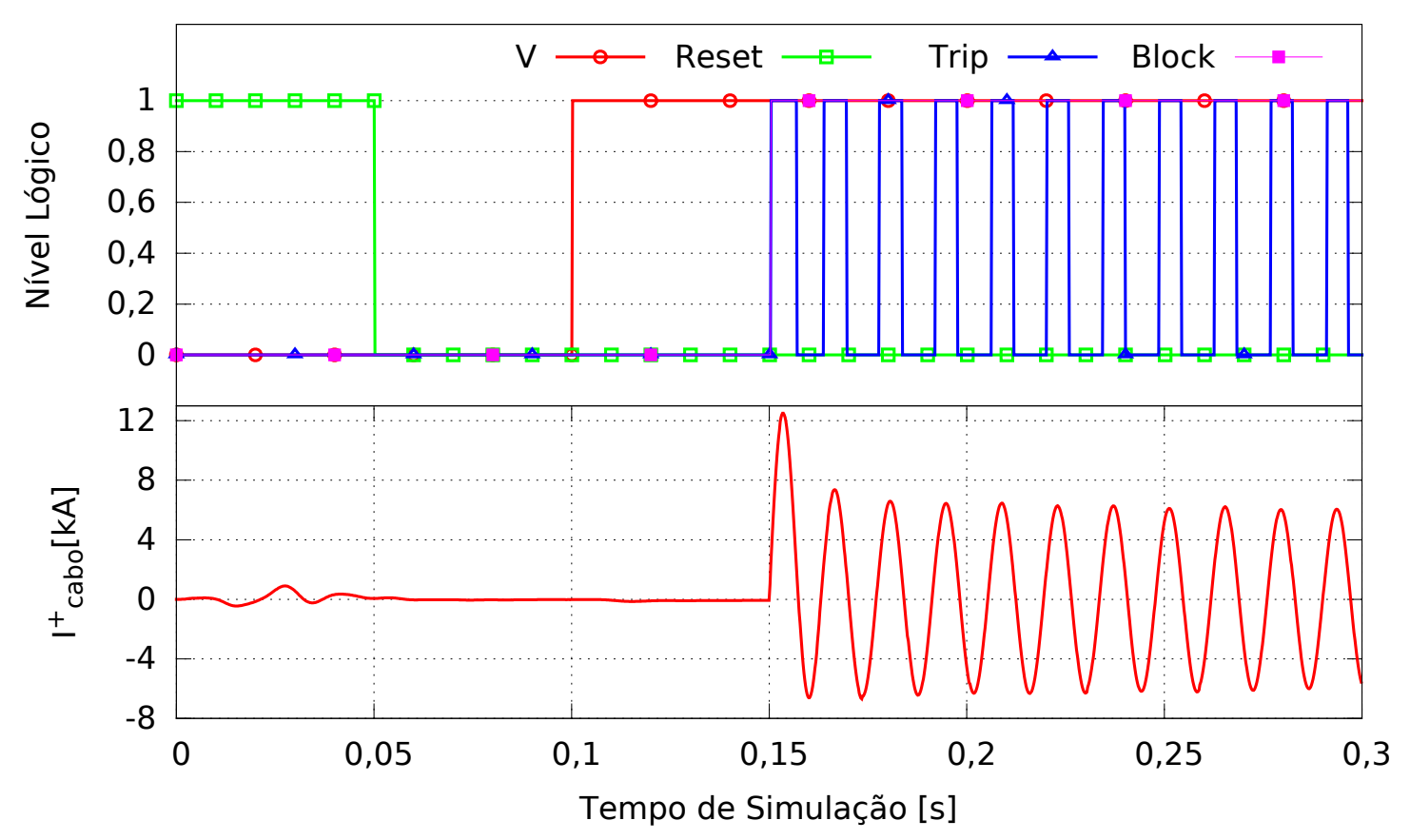


Figura 60 - Sinais de P e Q e referências definidas pela SMC.

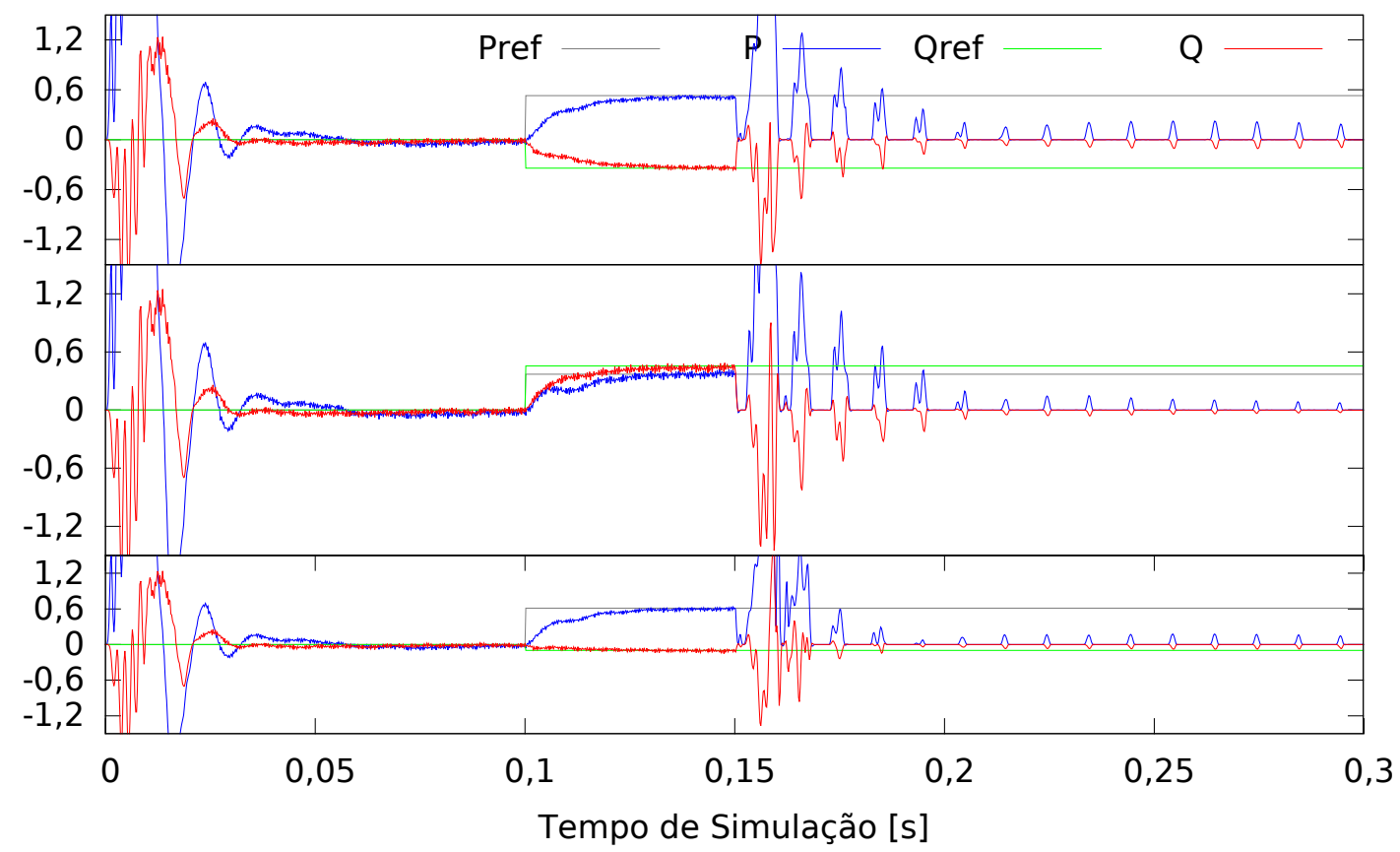

\subsection{Curtos-Circuitos Probabilísticos em Sistemas VSC- HVDC - Cenário 1}

A intensidade das correntes de curto-circuito é função das características nominais dos circuitos e do cenário em que o curto-circuito ocorre. Características nominais do circuito são variáveis de natureza determinística, como exemplo, a tensão no barramento. Já as características da condição de operação e das faltas são variáveis de natureza aleatória, como exemplo, o local, o tipo e a impedância que compõem o cenário do curto-circuito. Estas variáveis atribuem o carácter aleatório às correntes de falta, e nomeia esta frente de estudo como CCP. O emprego deste no SEP resulta na FDP da corrente de curto-circuito. Este resultado é obtido através da SMC, que define os parâmetros de natureza aleatória: a posição na linha, o tipo e a impedância de falta.

Nesta seção serão tratados CCP-CC para o sistema de teste (Seção 5.1), estando a operação das estações VSCs em modo de proteção (Seção 2.4). O sistema esta operando sem cargas. As condições são:

$\square$ Os PWMs estão bloqueados;

$\square$ A falta é aplicada em $t=0 s$;

$\square$ Com base na distância euclidiana entre os histogramas, $N=5 E 5$ faltas foram realizadas (Seção 5.7);

$\square$ Foram adotadas 708 classes no histograma, utilizando a regra da raiz quadrada (Seção 5.7); 
\ Foi considerada uma distribuição do tipo uniforme para determinar a posição na linha e impedância do curto-circuito (Seção 3.8);

$\square$ Nesta ocasião cada filtro capacitivo ligado às linhas CC, possuem capacitância igual a $C=280 E-6 F$

$\square$ A tensão inicial dos capacitores do filtro é de $V_{C 1}=V_{C 2}=100 \mathrm{kV}$;

$\square$ A corrente inicial das linhas de transmissão é $i=0 A$;

$\square$ As linhas são descritas por parâmetros concentrados ${ }^{2}$, onde $R=0,1088 \frac{\Omega}{k m}$ e $L=$ $0,0025 \frac{\mathrm{H}}{\mathrm{km}}$;

$\square$ A capacitância da linha foi desconsiderada devido a capacitância dos filtros ser muito maior.

Na Figura 61 são exibidas os resultados do $\mathrm{CCP}^{3}$, com variação da posição, tipo e impedância de falta sorteados pela SMC. Observa-se maiores probabilidades de faltas que geram corrente em torno de $1 k A$ e $6 k A$. Para investigar este comportamento foram geradas FDPs sem o sorteio do tipo de falta.

Foi simulado o CCP-CC apenas com faltas do tipo polo-polo ${ }^{4}$. O resultado desta simulação é mostrado na Figura $62^{3}$. Também foi simulado apenas com faltas do tipo polo a terra e o resultado está mostrado na Figura $63^{3}$. Como pode-se observar a função definida na Figura 62, aponta que este tipo de falta gera maior probabilidade de correntes em torno de $6 k A$ e a Figura 63 gera correntes em torno de $1 k A$, justificando o perfil obtido para FDP sorteando o tipo de falta, pois esta é a composição proporcional de faltas polo a polo e polo a terra.

Dispondo da FDP dos CCP-CC é interessante construir a DAP para que os intervalos de confiança sejam traçados. Portanto, a partir da FDP mostrada na Figura 61, foi construído a DAP das faltas que foram simuladas no circuito VSC-HVDC proposto. Esta função está mostrada na Figura 64. Nesta figura é observado que as considerações feitas a partir da FDP, acerca das correntes mais prováveis de falta, são reforçadas pela DAP, pois quase a totalidade das faltas apresentam correntes inferiores a $30 \mathrm{kA}$. A Tabela 8 exibe os intervalos de confiabilidade extraídos da DAP, apontando, por exemplo, que a probabilidade de corrente de faltas $>30 k A$ é de $0,08 \%$.

\footnotetext{
${ }^{2}$ Definidas no programa ATP, a partir do modelo físico dos cabos e torres. Mais detalhes na próxima seção.

${ }^{3} \mathrm{O}$ eixo x compreende diferentes escalas afim de realçar a região que concentra a maior parte dos dados.

${ }^{4} N=1,15 E 5$ simulações, o que equivale a $23,15 \%$ do total de faltas. A mesma quantidade definida pela Equação 18.
} 
Capítulo 5. Emprego da Simulação de Monte Carlo para Obter o Cálculo de Curto-Circuito

Figura 61 - FDP das correntes de curto-circuito geradas pela CCP-CC.

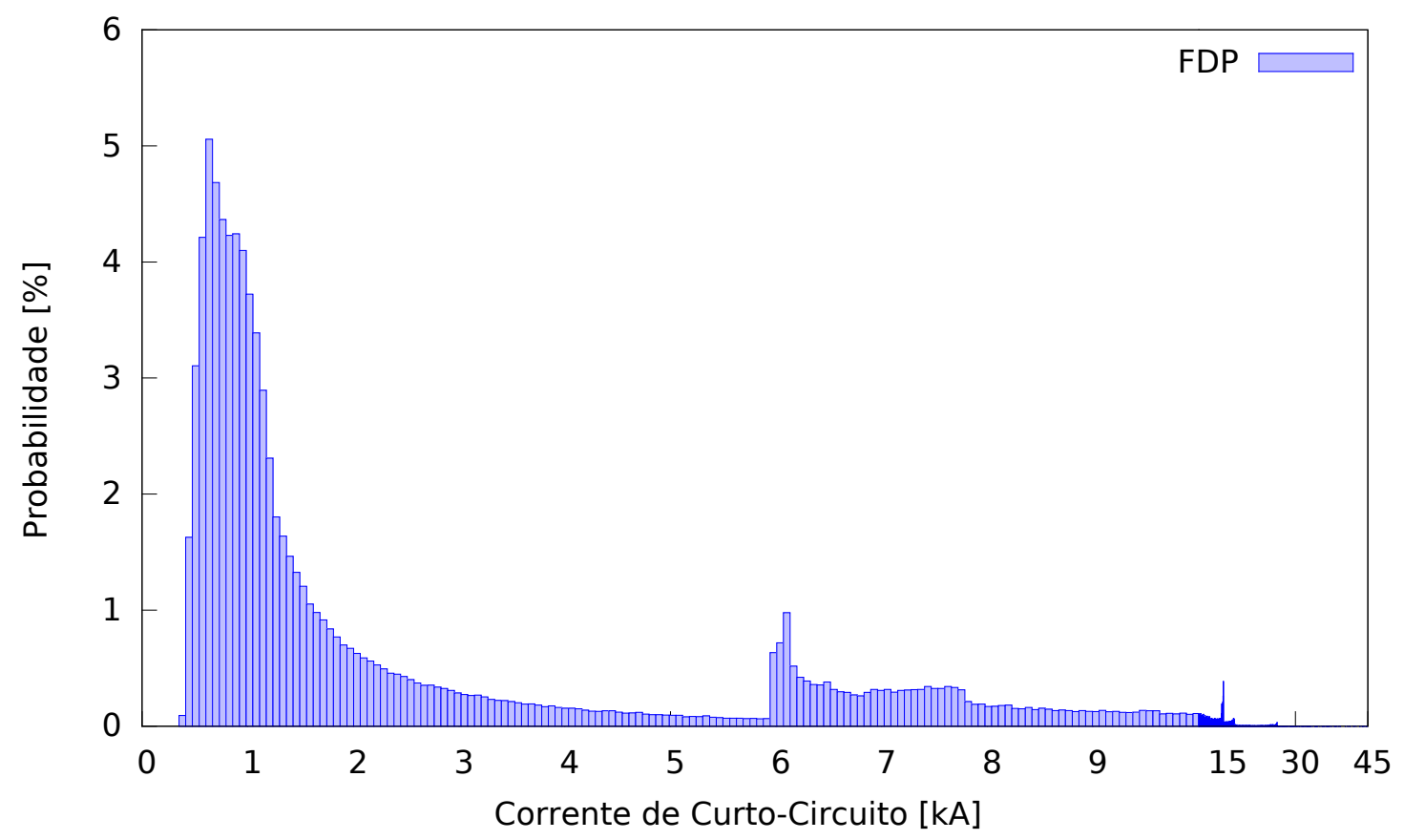

Figura 62 - FDP das correntes de curto-circuito do tipo polo a polo.

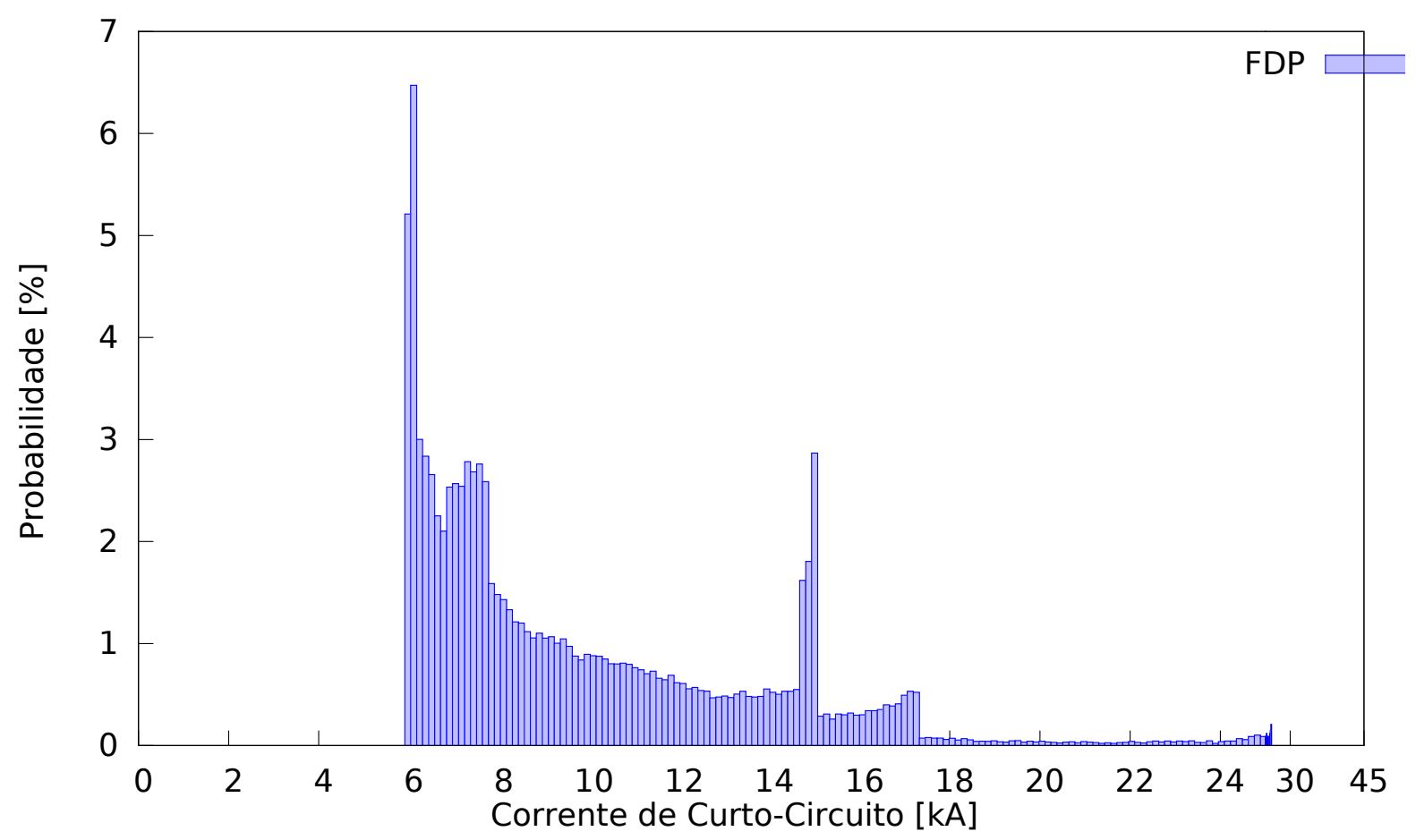


Figura 63 - FDP das correntes de curto-circuito do tipo polo a terra.

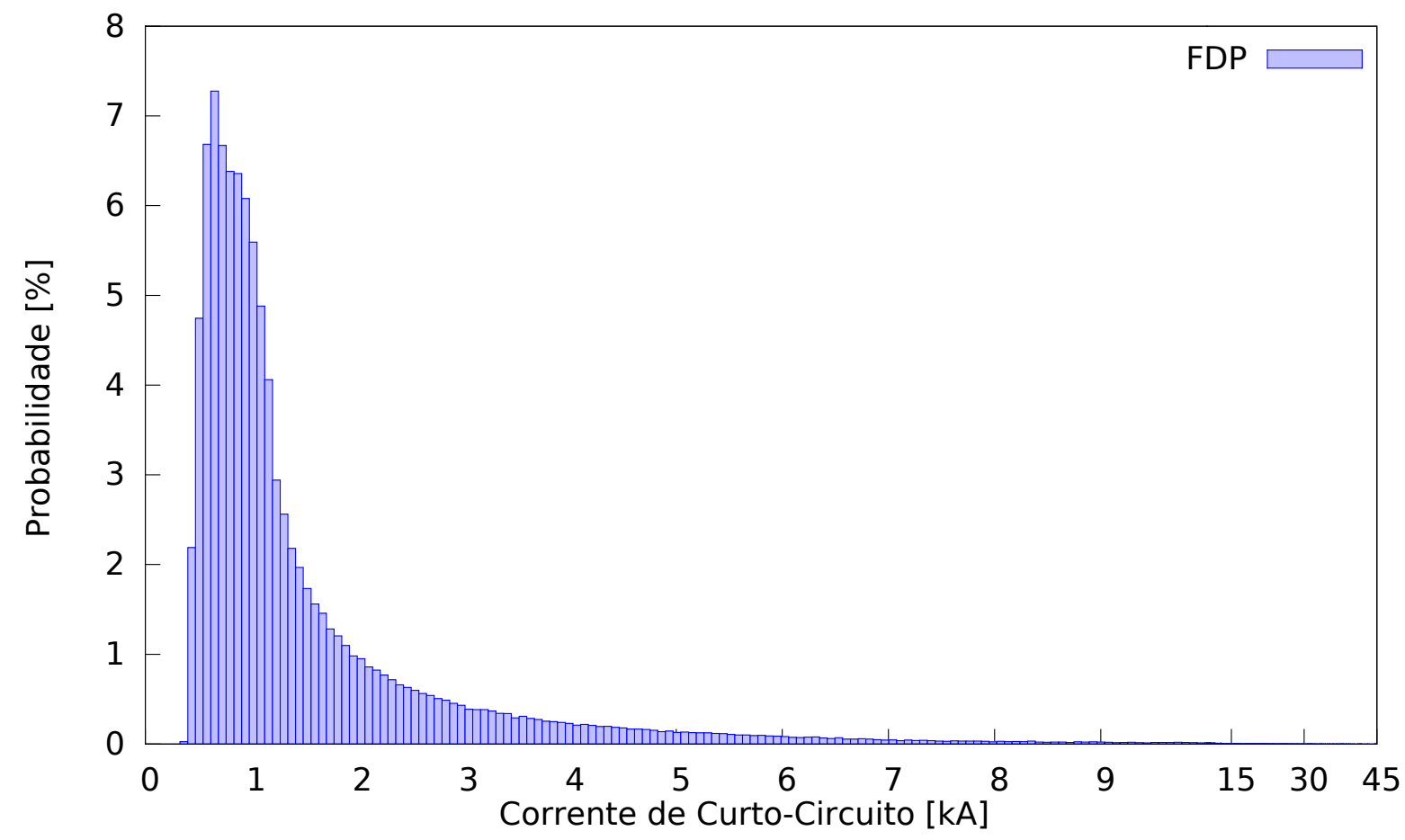

Figura 64 - DAP das correntes de curto-circuito geradas pela CCP-CC.

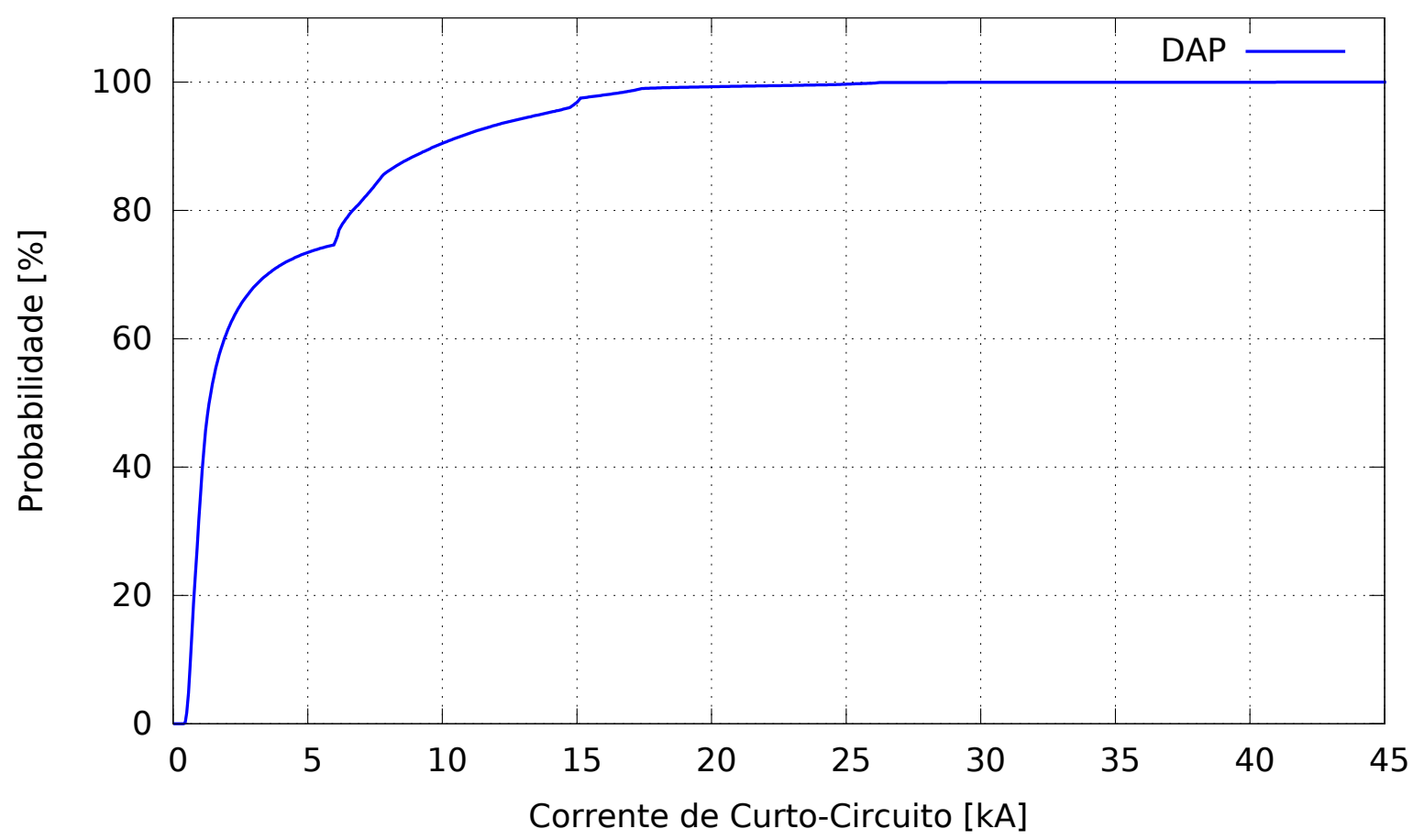


Capítulo 5. Emprego da Simulação de Monte Carlo para Obter o Cálculo de Curto-Circuito

Tabela 8 - Probabilidade para intervalos de correntes de curto-circuito do sistema modelo CC.

\begin{tabular}{cccc}
\hline $\mathrm{kA}$ & $<20$ & $<30$ & $<40$ \\
Probabilidade & $99,26 \%$ & $99,92 \%$ & $99,97 \%$ \\
\hline $\mathrm{kA}$ & $>20$ & $>30$ & $>40$ \\
Probabilidade & $0,74 \%$ & $0,08 \%$ & $0,03 \%$ \\
\hline
\end{tabular}

\subsubsection{Considerações do Cenário 1}

Nesta seção foram mostrados os resultados do CCP-CC, com os VSC operando como retificadores não controlados e as linhas são simuladas através de um modelo de parâmetros concentrados.

A importância de determinar intervalos de confiança é que, um intervalo de 99, 92 \%, reflete que este percentual em relação a todos os curtos circuitos que irão ocorrer nesta linha de transmissão, terão correntes menores que $30 k A$. Esta condição é relevante já que a máxima corrente de curto-circuito deste modelo esta na ordem de $45 k \mathrm{~A}$. Assim, ao considerar um nível complementar do intervalo de confiança igual a 0,08\%, está se admitindo esse percentual de erro ao afirmar que as correntes de curto-circuito não superarão $30 k A$. Esta avaliação implica que um dispositivo que pretenda interromper as correntes de curtos-circuitos no sistema de teste poderá ser projetado para interromper correntes da ordem de $30 k A$, assumindo $0,08 \%$ de probabilidade de falha.

\subsection{Curtos-Circuitos Probabilísticos em Sistemas VSC- HVDC - Cenário 2}

Na seção anterior tratou-se dos curto-circuito em sistemas HVDC não controlados. Nesta seção um novo cenário é considerado para a realização do CCP-CC. De forma análoga e pelas mesmas justificativas as variáveis determinísticas são definidas pelas características nominais do circuito, como a tensão no barramento e os dados das linhas, enquanto que são mantidas as variáveis aleatória (posição, o tipo e a impedância de falta) além de adicionada a condição de operação, já que dispomos das ferramentas de controle da Open Relay. São traçadas novas FDP para as corrente de curto-circuito do sistema de teste (Seção 5.1), considerando:

$\square$ Os PWMs são controlados pela técnica MCV e os parâmetros descritos na Seção 5.4;

$\square$ A falta é aplicada em $t=0.15 s$;

$\square$ Com base na distância euclidiana entre os histogramas, $N=5 E 5$ faltas foram consideradas adequadas (Seção 5.7);

$\square$ Foram adotadas 708 classes no histograma, utilizando a regra da raiz quadrada (Seção 5.7); 
$\square$ Foi considerada uma distribuição do tipo uniforme para determinar a posição na linha, a condição de operação e da impedância do curto-circuito, como descrito na seção 3.8;

- A função de distribuição da condição de operação atende ao mostrado na Figura 37;

$\square$ Nesta ocasião cada capacitor do filtro ligado as linhas CC, possui capacitância igual a $C=280 E-6 F \mathrm{e}$;

$\square$ Os dados da linha são: $L=0,0025 \frac{\mathrm{H}}{\mathrm{km}}, C=0,6321 E-08 \frac{\mathrm{F}}{\mathrm{km}}$ e $R=0,1088 \frac{\Omega}{\mathrm{km}}$. Estes são parâmetros distribuídos (Modelo Bergeron) calculados a partir dos parâmetros físicos de uma torre de transmissão de $110 \mathrm{kV}$ (ALI, 2013), através do subprograma Line Constants do Alternative Transient Program (ATP). No decorrer desta seção mais informações serão tratadas a respeito desta definição.

O subprograma Line Constants do ATP, gera os parâmetros distribuídos a partir dos parâmetros físicos dos cabos e torres. A saída deste programa será um arquivo (.lis) contendo as matrizes de susceptância e indutância equivalente por fase. Como as linhas de transmissão simuladas foram consideradas sem acoplamento magnético, os dados das diagonais das matrizes descreveram o RLC próprio de cada linha.

O programa para obter os dados da linha está descrito na íntegra no Algoritmo 8. O parâmetro METRIC inicia a descrição física dos componentes, onde cada coluna está descrita na Tabela 9.

Tabela 9 - Descritivo do conteúdo do cartão do ATP.

\begin{tabular}{l|l}
\hline Col. & Dados da coluna \\
\hline 1 & $\begin{array}{l}\text { Aponta o circuito no qual a linha esta inserida. Para um sistema HVDC do tipo } \\
\text { monopolar simétrico, um polo positivo e um polo negativo define os circuitos 1 e 2, } \\
\text { enquanto que o circuito 0 indica os dados do cabo pará-raios }\end{array}$ \\
\hline 2 & É a relação espessura pelo diâmetro do condutor (T/D) \\
\hline 3 & É a resistência do condutor $\frac{\Omega}{\mathrm{km}}$ \\
\hline 4 & $\begin{array}{l}\text { Indutância própria do condutor IX. Quando IX }=4 \text {, a indutância interna será cor- } \\
\text { rigida para o efeito pelicular e o cálculo da indutância própria será baseado na } \\
\text { geometria tubular do condutor }\end{array}$ \\
\hline 5 & O diâmetro externo do condutor \\
\hline 6 & Distância entre a torre e o condutor \\
\hline 7 & Altura do condutor ao solo, na torre \\
\hline 8 & Altura do condutor ao solo, no vão entre torres \\
\hline
\end{tabular}

Após o BLANK CARD é necessário definir as informações sobre passo de integração, frequência, resistividade do solo, tipo de correção de Carson e modos de impressão dos parâmetros da linha de transmissão, mais detalhes podem ser obtidos em M.C.D.Tavares, P.G.Campos e P.Prado (2014). 


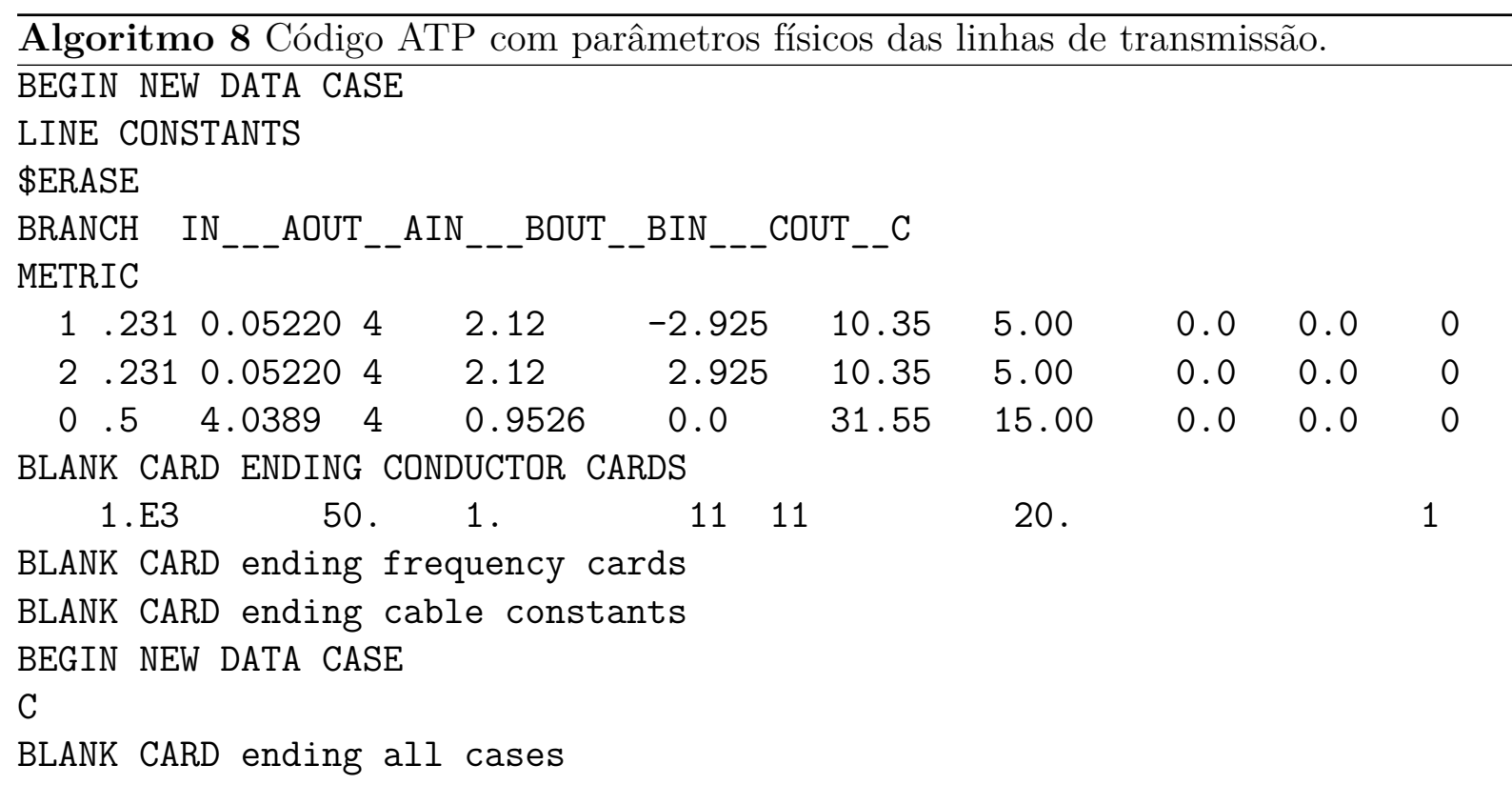

A Figura $65^{5}$ exibe os resultados do CCP-CC, com posição, tipo, impedância de falta e ponto de operação sorteados pela SMC. Observa-se maiores probabilidade de faltas que geram corrente em torno de $1 k A$ e $4 k A$.

Análogo ao que foi realizado para a seção anterior, foram gerados CCPs-CC sem sorteio do tipo de falta. O resultado da simulação com faltas do tipo polo a polo está mostrado na Figura 66 e no segundo caso (faltas do tipo polo a terra) na Figura 67. Como pode-se observar, a função definida na Figura 66 aponta que este tipo de falta gera correntes em torno de $4 k A$ e a Figura 67 gera correntes em torno de $1 k A$, justificando o perfil obtido para FDP.

A partir da FDP mostrada na Figura 65, foi construído a DAP, mostrada na Figura 68. Esta figura acentua a ideía de que as correntes de faltas identificadas a partir da FDP como sendo as mais factíveis (1 kA e $4 k A)$ são reforçadas pela função descrita na DAP. Esta função aponta que, aproximadamente, a totalidade de faltas apresentam correntes inferiores a $10 k A$. Na Tabela 10 exibem-se os intervalos de confiabilidade extraídos da DAP, apontando, por exemplo, que a probabilidade de corrente de faltas $>10 k A$ é de $0,03 \%$.

\footnotetext{
${ }^{5} \mathrm{O}$ eixo x compreende diferentes escalas afim de realçar a região que concentra a maior parte dos
} dados. 
Figura 65 - FDP das correntes de curto-circuito geradas pela CCP-CC.

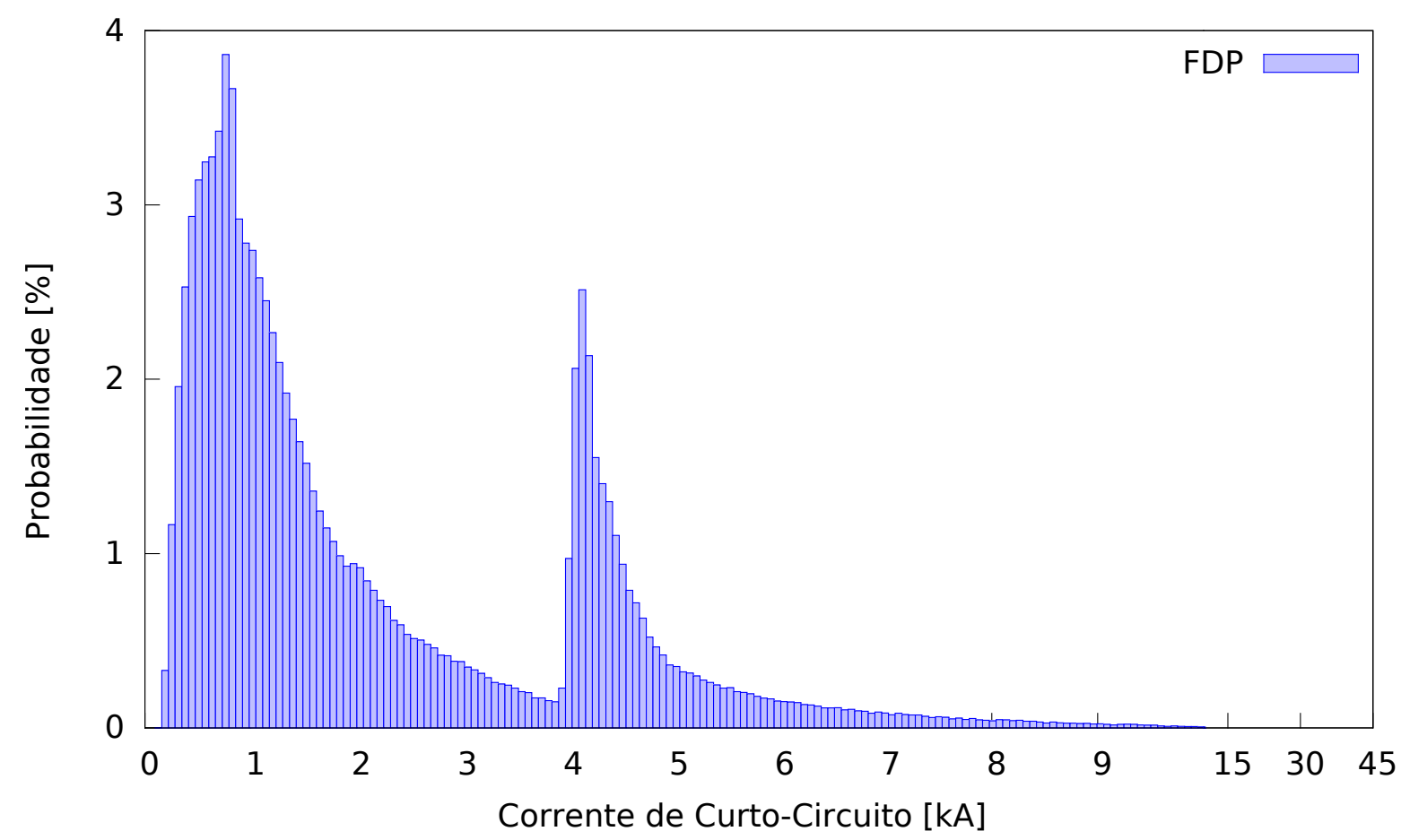

Figura 66 - FDP das correntes de curto-circuito geradas pela CCP-CC para faltas polo a polo.

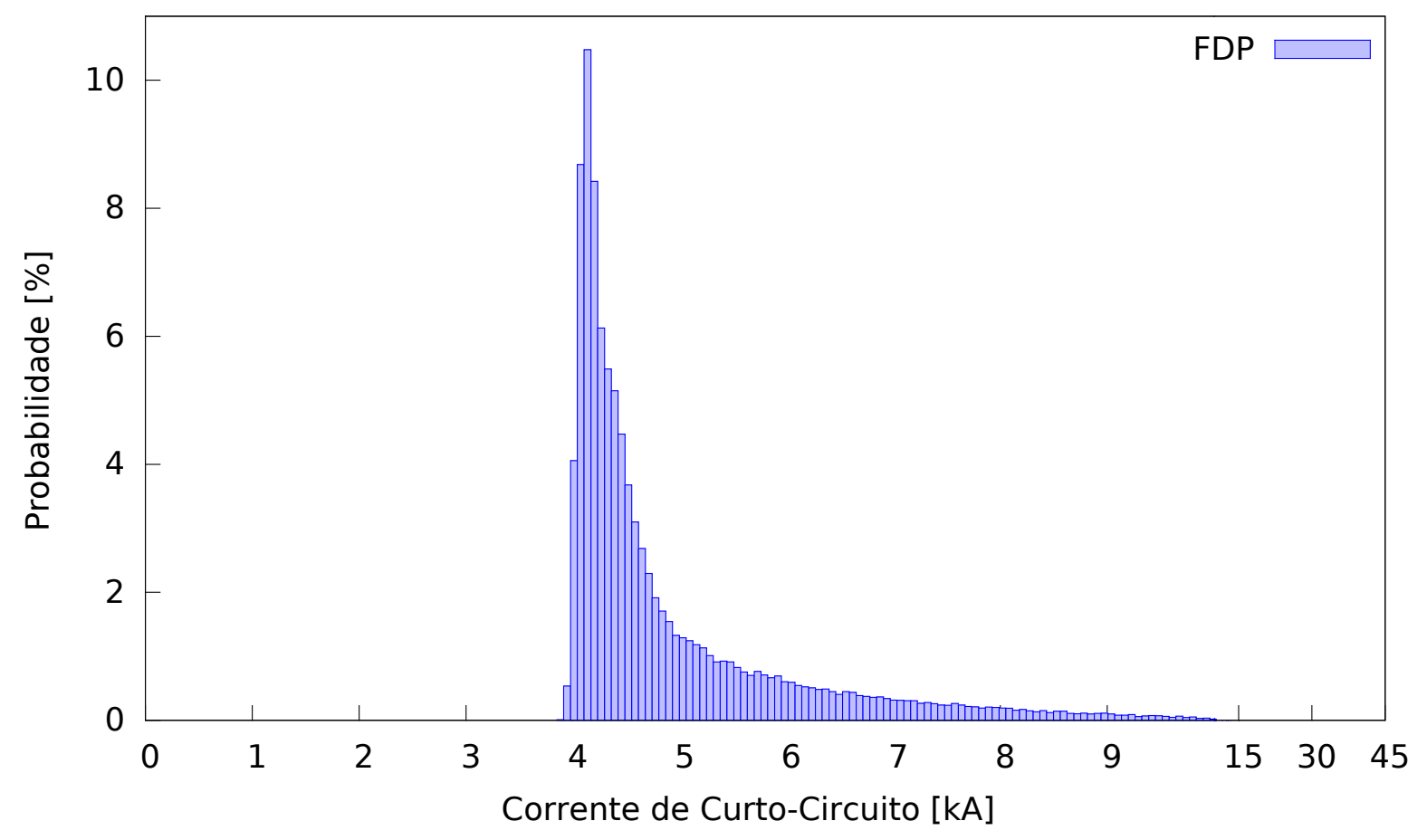


Capítulo 5. Emprego da Simulação de Monte Carlo para Obter o Cálculo de Curto-Circuito

Figura 67 - FDP das correntes de curto-circuito geradas pela CCP-CC para faltas polo a terra.

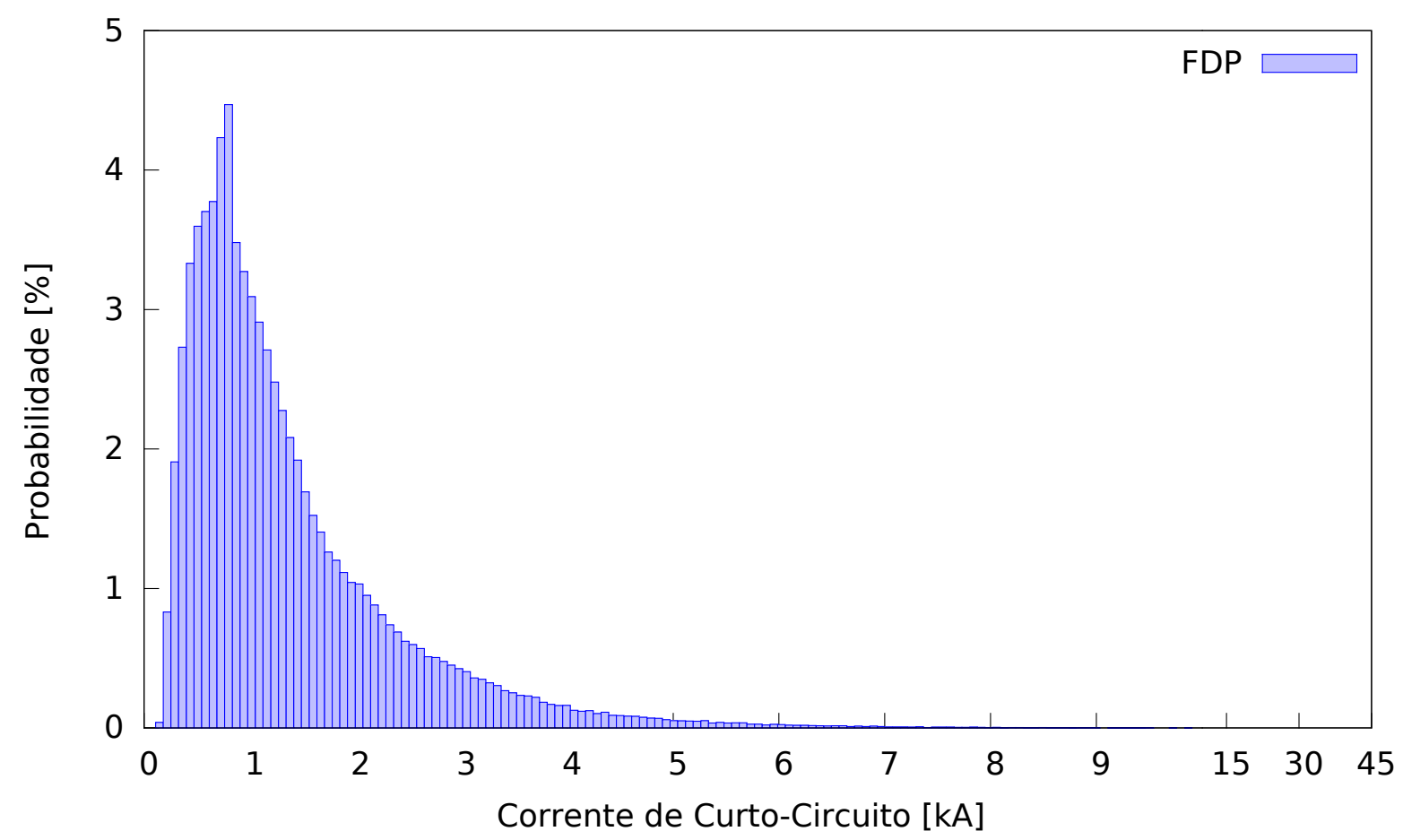

Figura 68 - DAP das correntes de curto-circuito geradas pela CCP-CC.

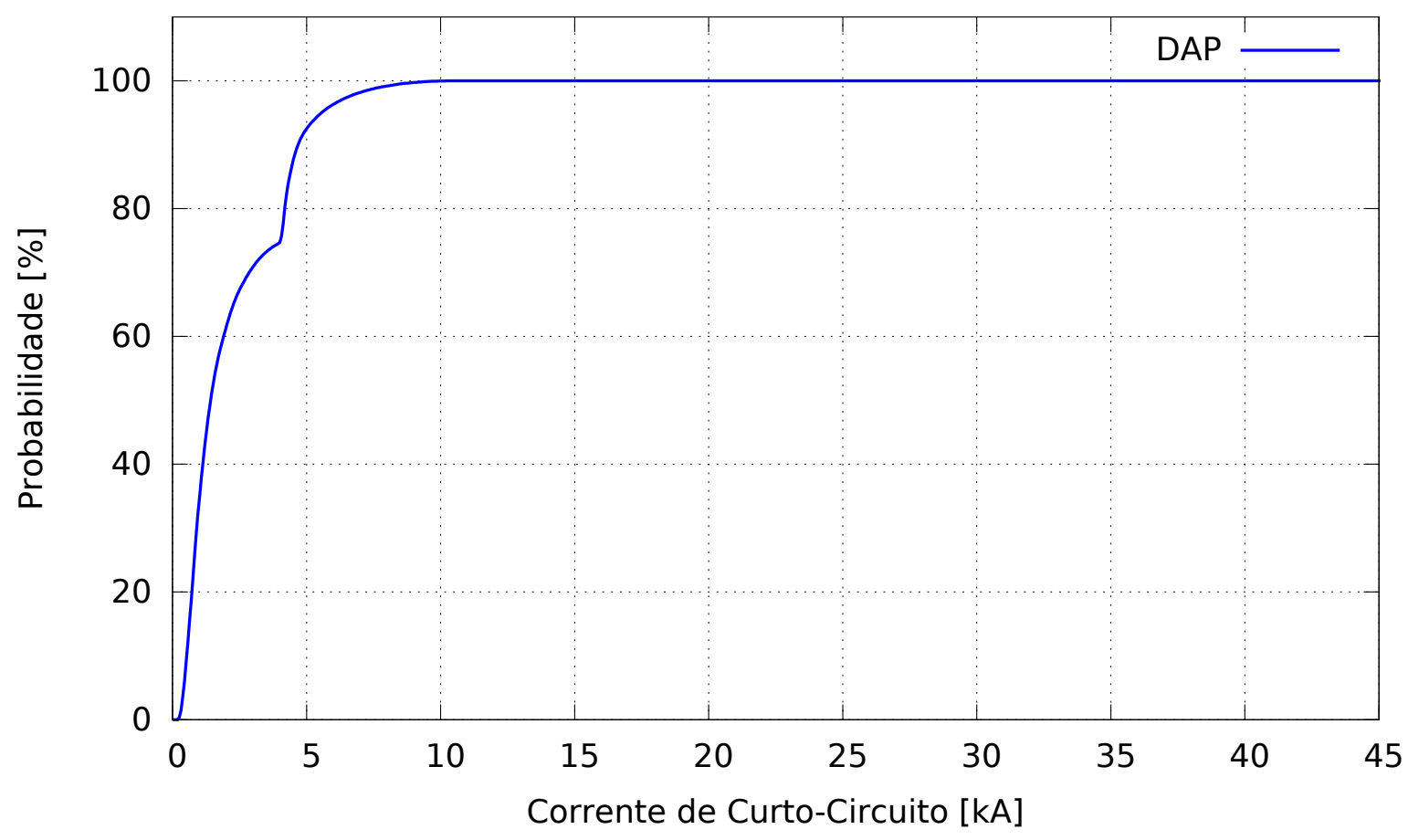


Tabela 10 - Probabilidade para intervalos de correntes de curto-circuito do sistema modelo CC controlado.

\begin{tabular}{cccc}
\hline $\mathrm{kA}$ & $<5$ & $<10$ & $<15$ \\
Probabilidade & $92,75 \%$ & $99,97 \%$ & $99,99 \%$ \\
\hline $\mathrm{kA}$ & $>5$ & $>10$ & $>15$ \\
Probabilidade & $7,25 \%$ & $0,03 \%$ & $0,01 \%$ \\
\hline
\end{tabular}

\subsubsection{Considerações do Cenário 2}

Nesta seção foram mostrados os resultados do CCP-CC, com VSCs operando sob a técnica de controle MCV e com os parâmetros RLC das linhas distribuídos, determinados através das características físicas das linhas e torres, no programa ATP.

Quando os resultados desta seção são confrontados com os apresentados na Seção 5.5, observam-se funções similares, descritas pelas FDPs. Os intervalo $0 k A \leq I_{\text {falta }} \leq 3 k A$, na Figura 61 e da Figura 65, apontam as máximas probabilidades de seus respectivos cenários. Estes equivalem a faltas do tipo de polo a terra (como justificado em cada seção), com impedância de falta entre $0 \Omega$ e $100 \Omega$. Em vista dessa semelhança, pode-se afirmar que para este tipo de falta a condição de regime e controle do sistema (implementados no cenário 2) não influenciou nos resultados do CCP. Entretanto foram observadas pequena alterações da função no intervalo $3 k A \leq I_{\text {falta }} \leq 45 k A$. As faltas descritas neste intervalo são atribuídas ao tipo de polo a polo, onde em ambos os cenários são consideradas faltas francas, ao passo que a alteração da função é atribuída ao uso do modelo Pi no cenário 1 e modelo Bergeron no cenário 2.

Em sistema CA as condições de pré-falta são os sinais elétricos do SEP em operação nominal. Para estes, as correntes de pré-falta podem ser consideradas nulos em condição de falta (STEVENSON, 1978). Se esta mesma consideração for feita para sistemas HVDCVSC, as tarefas de controle dos conversores não deveria influenciar o resultado final do CCP, pois os valores máximos das correntes de falta não seriam alterados com ou sem o controle das estações conversoras.

\subsection{Número de Simulações}

O número de simulações necessárias para obter representatividade estatística foi obtido medindo a distância euclidiana entre as FDP oriundas de um número de simulações crescente, como tratado no Capítulo 3. Assim, a cada $5 E 3$ simulações é gerada uma nova FDP, até obter uma FDP com $5 E 5$ simulações.

A distância euclidiana está representada na Figura 69 para o cenário 1 e o cenário 2. O cenário 1 é o descrito na Seção 5.5 e o cenário 2 na Seção 5.6. Como pode-se observar, a distância euclidiana de ambos os cenários é bastante semelhante. Onde o aumento do número de simulações implica no decrescimento da distância, de forma que foi considerada adequada realizar $5 E 5$ simulações em ambos os cenários, o que equivale 
a distância $D 6=0.01$ (distância entre $5 E 5$ e 4,95E5 simulações).

O CCP-CC para os cenários 1 e 2 foram obtidos para $5 E 5$ simulações, pois as distâncias entre histogramas gerados com essa quantidade e com uma quantidade maior de simulações é consideravelmente pequena. Assim, acredita-se que este valor atribui representatividade estatística aos cenários.

Figura 69 - Distância euclidiana normalizada entre FDPs com um número crescente de simulações.

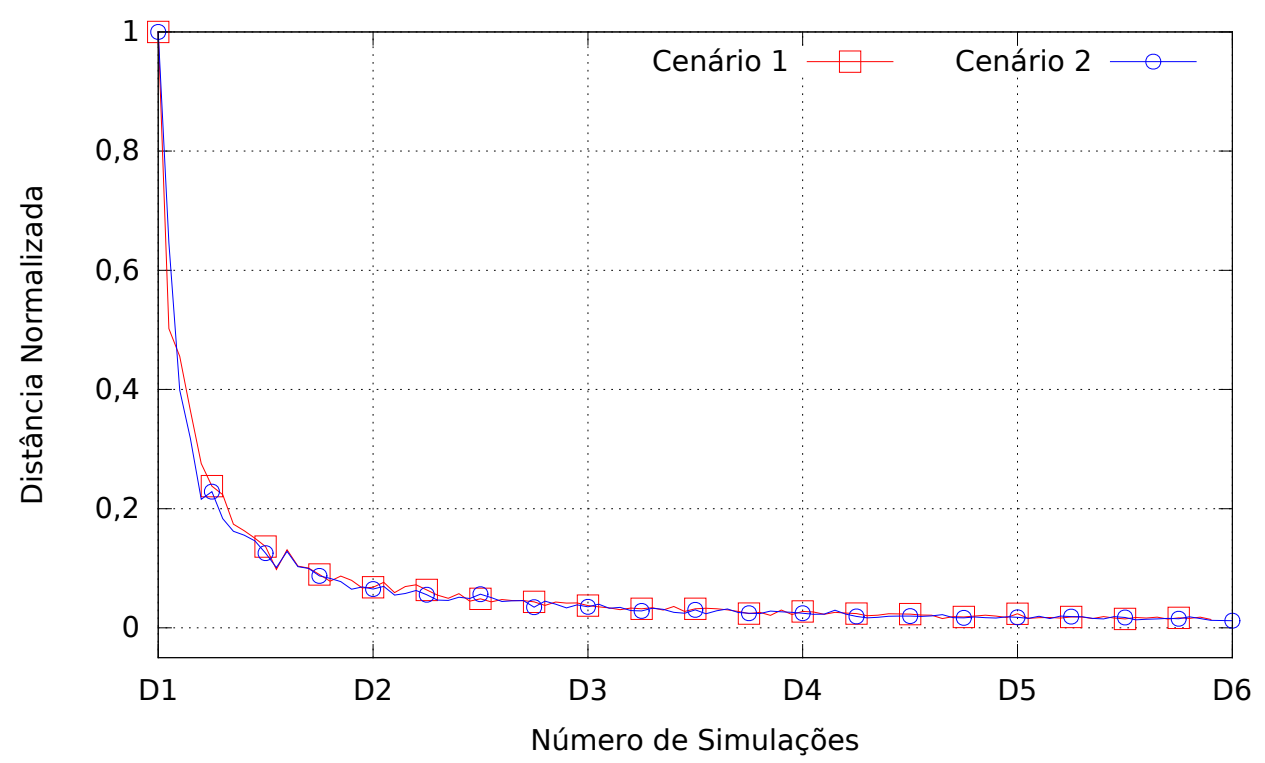

\subsection{Quantidade de Barras/Classes dos Histogramas}

A quantidade de classes utilizada para gerar o histograma define o escopo dos dados. Na literatura alguns métodos se dedicam a determinar um número apropriado destas classes (VENABLES; RIPLEY, 2002). A Equação 32 e a Equação 33, mostram-se dois destes métodos, o Square-Root Choice (SRC) e o Sturge's Rule (SR), respectivamente (MACIEJEWSKI, 2011). Onde $k$ é o número de classes e $n$ é o número de simulações.

$$
\begin{gathered}
k=\sqrt{n} \\
k=1+\log _{2} n
\end{gathered}
$$

A FDP gerada para o cenário hipotético, com $n=1 E 5$, foi representada através dos dois métodos para exemplificar a influência do número de classes nas curvas geradas. Foram encontradas 317 e 18 classes, respectivamente. O resultado é mostrado na Figura 70 (apenas a faixa de $0 k A \leq I_{\text {falta }} \leq 20 k A$ está mostrada, pois concentra a maioria dos dados). Como pode-se observar, o SR gera intervalos maiores que o SRC, onde cada um destes intervalos concentram muitos valores em uma única classe. Por outro lado, o SRC 
mostra resultados mais representativos, pois as descontinuidades presentes na função não são ocultadas pela largura da classe.

Figura 70 - FDP com número de classe definido pelo SRC e SR.

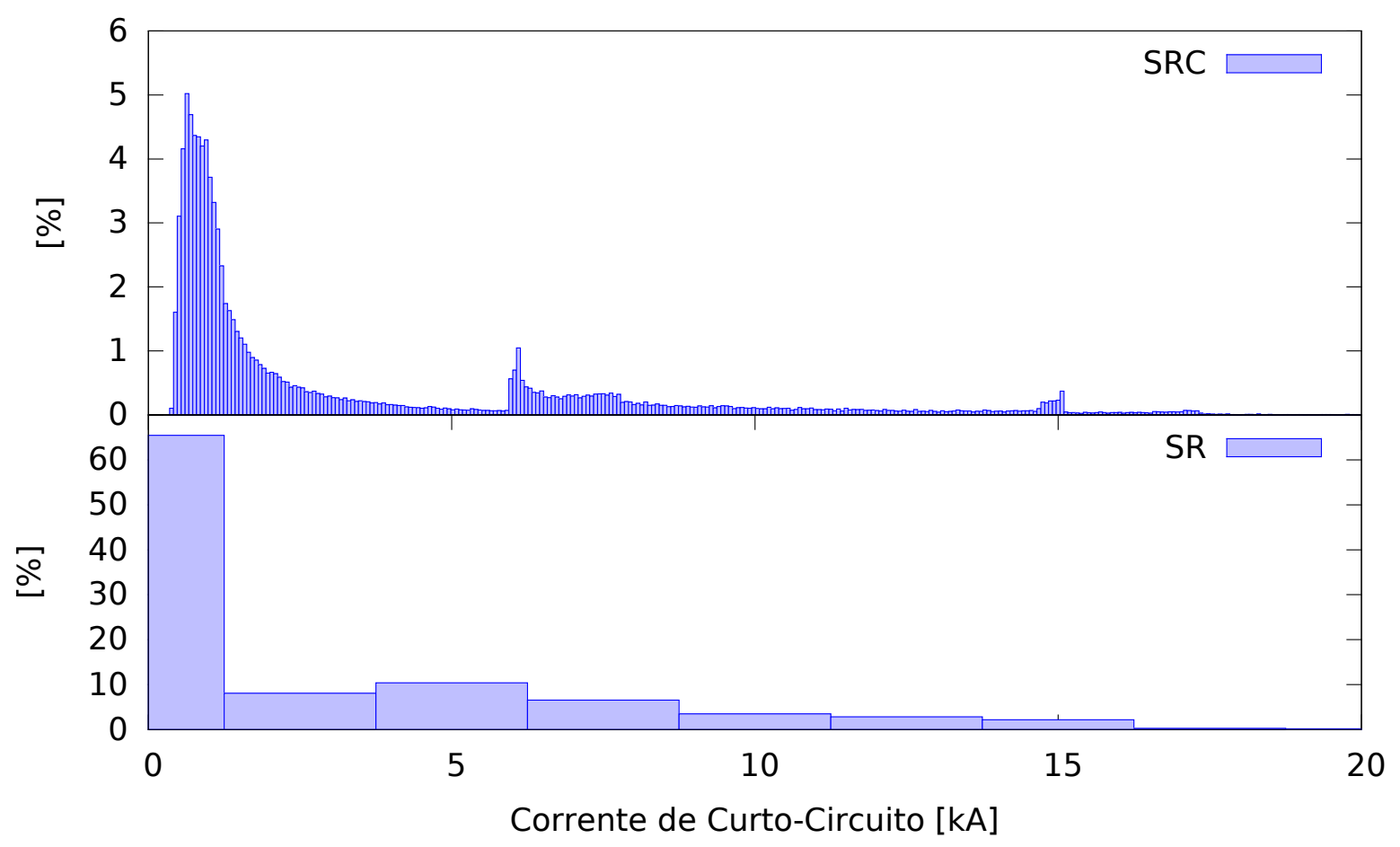

\subsection{Considerações}

Neste capítulo foi apresentado o sistema de teste, utilizado para examinar e validar a metodologia e o programa desenvolvido neste estudo. Foram também tratadas todas as etapas de execução do CCP em sistemas VSC-HVDC, além da validação do programa criado e também foram mostrados os resultados obtidos em dois cenários: VSCs como retificadores não controlados no cenário 1 e no cenário 2 com VSCs operando na forma convencional, controlada. Cada cenário teve suas especificidades tratadas, respectivamente na Seção 5.5 e na Seção 5.6. Além disso, uma avaliação foi traçada a respeito da inclusão dos controles das estações e da alteração do modelo da linha.

O próximo capítulo irá contemplar conclusões a respeito dos resultados deste capítulo, além da avaliação a cerca da metodologia e dos resultados globais do estudo . 


\section{Considerações Finais}

Para que todos os benefícios fornecidos pelos sistemas HVDC sejam adicionados ao SEP, o sistema de proteção deverá estar configurado para atender as novas características deste conjunto. Devido a isto, são apreciados estudos que contribuam neste contexto com projetos de equipamentos e soluções de proteção para sistemas HVDC e estes estão na vanguarda para um desenvolvimento consistente do SEP e sua atual circunstância de complexibilidade, causada pelas diferentes formas de geração de energia e interligação entre grandes blocos de sub-sistemas.

Projetos de equipamentos de proteção CC, requerem dados dos sistemas em condições anormais, tais como, faltas, chaveamentos e descargas atmosféricas, pois são em condições como estas que estes equipamentos irão operar. Estas condições são alguns dos transitórios eletromagnéticos que o sistema sofre durante sua vida útil. Grande parte destes fenômenos ocorrem com uma frequência muito baixa. Assim, o estudo em questão se concentra nos curtos-circuitos por serem os fenômenos mais frequentes nas linhas de transmissão aéreas HVDC. Este tipo de transitório ocorre mais vezes porque as linhas são os elementos elétricos que possuem maior extensão física no SEP e, portanto, estão mais expostas a fenômenos climáticos e geográficos que possam causar contato entre os polos ou de um polo a terra. Dessa forma, devido a sua maior frequência e, consequentemente, maior possibilidade de danos à operação nominal do SEP, este estudo investiga quais as amplitudes máximas das faltas em linhas HVDC.

Para este fim, o método de CCP permite traçar o perfil de corrente de curto-circuito através das funções de distribuição de probabilidade das variáveis aleatórias do sistema. Em SEPs, tanto em CA quanto em CC, variáveis aleatórias estão ligadas a fenômenos de faltas. São parâmetros que mudam a cada nova falta, como é o caso da posição em que ocorre a falta, da impedância e também do tipo de falta. Quando um grande número de faltas são simuladas em um sistema elétrico, sendo as variáveis aleatórias sorteadas, os resultados são capazes de descrever as correntes de curtos-circuitos que venham a ocorrer na parcela do sistema elétrico considerado. É exatamente esta abordagem que o método de CCP se propõe. Portanto o CCP, em sistemas de transmissão VSC-HVDC, se 
mostra promissor mediante a hipótese de projetos de equipamentos para aplicação nestes sistemas, dado que a especificação de tais equipamentos de proteção e manobra, utiliza os parâmetros de curto-circuito do sistema para definir a capacidade nominal destes.

O CCP-CA utiliza a técnica de componentes simétricas para o cálculo da corrente de falta. Entretanto, esta técnica não se mostra satisfatória para sistema CC devido ao comportamento contínuo dos sinais. Assim, a ferramentas usadas para realização do cálculo de corrente de curto-circuito neste estudo, foi a simulação de transitórios eletromagnéticos através de equações de diferença.

Apesar de haverem diversos programas comerciais que executam simulações de transitórios eletromagnéticos, a execução do CCP-CC seria ineficaz nestes, uma vez que despendem de muito tempo para acessar os dados em arquivos. Este fato motivou o desenvolvimento da biblioteca de código livre OEMTP que executa o transitório eletromagnético do circuito através de equações de diferença. Para complementar a OEMTP, a biblioteca Open Relay é empregada para executar as tarefas de controle, como exemplo, a operação de chaveamento das estações conversoras. Portanto, a operação integrada destas duas bibliotecas de código livre, permite que os sinais elétricos sejam acessados ainda em memória, oferendo dinamismo e eficiência às simulações.

Esta pesquisa teve início abordando a metodologia de CCP, através da Simulação de Monte Carlo, em um sistema elétrico em corrente alternada (CCP-CA), baseado na literatura, tendo sido simulado em um programa comercial (Matlab). A execução neste programa não teve implicações no tempo de execução porque a técnica de componentes simétricas requer tarefas mais simples ao programa, não apontando desvantagens em relação a programas de código livre. Esta etapa de pesquisa foi essencial ao desenvolvimento consistente da metodologia proposta, já que para este cenário há base para comparação dos resultados. O passo seguinte foi definir as similaridades entre sistemas CA e CC, para que o CCP-CC fosse desenvolvido. A medida que progredia, a complexibilidade do circuito e o tempo para a recuperação dos valores máximos das correntes em arquivo tornou-se oneroso. Neste ponto, novos recursos foram determinados para calcular as correntes de falta.

Foi considerado o desenvolvimento de um programa em linguagem $\mathrm{C}++$, para que o acesso aos sinais elétricos ocorresse ainda em memória. Duas alternativas possibilitariam este desenvolvimento: a primeira e mais simples, através do método de espaço de estados, e a segunda, e mais complexa, por equações de diferença (Método do Dommel).

Considerada a primeira alternativa viável, uma solução através de espaço de estados foi implementada. Então, equações diferenciais ordinárias foram traçadas para o sistema de teste e as matrizes de estado construídas. Após seu desenvolvimento notou-se que haviam estados não previstos pelas equações definidas. A nova estrategia adotada foi utilizar equações de diferença, para modelar o circuito e finalmente obter as correntes de curtocircuito. Esta alternativa sanou as necessidades correntes e gerou soluções apropriadas 
dos transitórios eletromagnéticos, quando comparado a programas comerciais.

A implementação do programa em linguagem $\mathrm{C}++$ motivou o uso das ferramentas de computação em nuvem (utilização da CloudUSP) e de métodos de processamento paralelo, incluídas através da Open MPI, de modo a proporcionar elevada eficiência computacional as simulações realizadas neste estudo.

O CCP-CC foi inicialmente realizado para um circuito simplificado, onde os VSCs operam em modo de proteção (retificador não-controlado) e com linhas do modelo de parâmetros concentrados. Esta etapa compôs o cenário 1.

Posteriormente, o programa desenvolvido, intitulado de OEMTP, foi integrado à biblioteca já existente, Open Relay, para que fosse ajustado o controle das estações VSC, com o objetivo de obter os perfis de corrente de curtos-circuitos para a condição de operação nominal do sistema e também mediante diferentes carregamentos do mesmo. Além disso, um modelo de linha com parâmetros distribuídos (Bergeron) foi implementado, para promover a melhora das características de simulação empregadas no sistema teste. Esta etapa compôs o cenário 2.

Quando os resultados do CCP-CC do cenário 1 e 2 são comparados, observa-se funções similares, descritas pelas FDPs. O intervalo que aponta as maiores probabilidades de faltas tem grande semelhança entre os dois cenários, pois ambos tem essa maior probabilidade em torno de $1 k A$. Entretanto foram observadas alterações da função nos intervalos subsequentes. Esta alteração é atribuída a mudança do modelo da linha, que foi modelo Pi no cenário 1 e modelo Bergeron no cenário 2. Esta atribuição é devido as correntes de pré-falta serem consideradas nulas em condição de falta em sistemas CA. Se esta consideração for válida também para sistemas HVDC-VSC, as tarefas de controle dos conversores não deveria influenciar o resultado final do CCP, pois os valores máximos das correntes de falta não seriam alterados com ou sem o controle das estações conversoras, que foram incluídos no cenário 2. Portanto, pode-se afirmar que a condição de regime e controle do sistema (implementados no cenário 2) não influenciou nos resultados do CCP e sim o modelo da linha adotado distintamente em cada cenário.

As variáveis aleatórias, parâmetros chave da SMC, foram modeladas por funções de distribuição. Dada a falta de dados estatísticos sobre faltas em sistemas CC, a maior parte das funções usadas neste estudo foram inspiradas em dados disponíveis para sistemas CA. A consideração usada para adaptar os dados CA para CC, se baseia na similaridade dos aspectos construtivos de torres e linhas de transmissão.

Outro aspecto investigado foi o número de simulações necessárias para dar representatividade estatística para os resultados obtidos a partir da SMC. Algumas técnicas são propostas na literatura mas não foram consideradas convenientes para esta abordagem. Este estudo propôs a distância euclidiana entre duas consecutivas FDPs para definir o número de simulações requerido. Foi também mostrado que a técnica da raiz quadrada define o número adequado de classes da FDP para os casos estudados. 
Percebe-se que a proposta deste estudo, para auxiliar o dimensionamento de equipamentos de proteção em sistemas HVDC, ofereceu uma interessante oportunidade para que outras problemáticas, que venham a surgir, sejam resolvidas através da simulação dos transitórios eletromagnéticos em um programa de código livre, o OEMTP.

Portanto, o empenho em analisar e propor um novo modelo e metodologia preconizado se mostra eficaz para atribuir confiabilidade à operação do sistema elétrico de potência em geral, já que os sistemas contemporâneos são redes complexas, com parcelas em corrente alternada e em corrente contínua. Assim, vale ressaltar que a principal contribuição desta pesquisa não são apenas os resultados numéricos apresentados, mas também, a metodologia proposta, pois estes são produto do CCP em sistemas hipotéticos. Neste horizonte, o presente estudo pretende extrair as informações a respeito dos curtos-circuitos através do CCP em sistemas VSC-HVDC, buscando caracterizar as correntes de faltas, que possam vir a ocorrer, de forma a prover as informações básicas ao desenvolvimento de melhores projetos de equipamentos e ajustes de proteção e controle.

\subsection{Continuidade da Pesquisa}

As sugestões propostas para a continuidade deste estudo são:

Investigar os estados não modelados pelo Método de Espaço de Estados;

$\square$ Desenvolver a metodologia para faltas em outros componentes do sistema, não apenas na linha de transmissão e;

$\square$ Uma avaliação a respeito da possibilidade de melhoria do gerador de número aleatório, dentre outras.

\subsection{Publicações}

No decorrer do desenvolvimento desta pesquisa alguns artigos científicos foram produzidos. O primeiro deles, a partir dos resultados obtidos na Seção 5.5, geraram um artigo que foi submetido a revista Electric Power Systems Research, intitulado Probabilistic Short Circuit Analysis in Direct Current Transmission Systems using the Open Electromagnetic Transient Program.

Também foi produzido um resumo, onde se investiga distorção harmônica causada por multi-terminais HVDC, intitulado Harmonic and Interharmonic Distortion Analysis of AC Buses in a Multi-terminal High Voltage Direct Current Transmission System, aceito em julho de 2015 para a 19th Power Systems Computation Conference, que ocorrerá entre 20 e 24 de junho de 2016, na Itália. 


\section{Referências}

ABB. Transmissão de Energia em Quantidade para Longas Distâncias. 2014. Disponível em: <http://new.abb.com/systems/hvdc>. 08 de Agosto de 2014.

ALI, S. A. Modeling of power networks by ATPDraw for harmonics propagation study. Transactions on Electrical and Electronic Materials, 2013. The Korean Institute of Electrical and Electronic Material Engineers, v. 14, n. 6, p. 283-290, 2013.

ANDERSON, J. Monte Carlo computer calculation of transmission-line lightning performance. Power Apparatus and Systems, Part III. Transactions of the American Institute of Electrical Engineers, 1961. v. 80, n. 3, p. 414-419, April 1961. ISSN 0097-2460.

ARAUJO, A. D.; NEVES, W. Cálculos de transitórios eletromagnéticos em sistemas de energia. [S.1.]: UFMG, 2005. ISBN 9788570414489.

ARRILlaga, J.; LIU, Y.; WATSON, N. Flexible Power Transmission: The HVDC Options. [S.1.]: Wiley, 2007. ISBN 9780470511855.

ASPLUND G., S. K. J. H. L. J. P. R. DC transmission based on voltage source converters. CIGRÉ session, 1998. v. 14, n. 1, p. 302, 1998.

BAJRACHARYA, C. Control of VSC-HVDC for wind power. 2008. Institutt for elkraftteknikk, 2008.

BALOUKTSIS, A.; TSANAKAS, D.; VACHTSEVANOS, G. Probabilistic short-circuit analysis by Monte Carlo simulations and analytical methods. Power Systems, IEEE Transactions on, 1986. v. 1, n. 3, p. 135-140, Aug 1986. ISSN 0885-8950.

BARNES, M.; BEDDARD, A. Voltage source converter HVDC links - the state of the art and issues going forward. Energy Procedia, 2012. v. 24, n. 0, p. 108 - 122, 2012. ISSN 1876-6102. Selected papers from Deep Sea Offshore Wind R\&amp;D Conference, Trondheim, Norway, 19-20 January 2012. Disponível em: <http://www.sciencedirect.com/science/article/pii/S1876610212011320>.

BILLINTON, R.; SANKARAKRISHNAN, A. Adequacy assessment of composite power systems with HVDC links using Monte Carlo simulation. Power Systems, IEEE Transactions on, 1994. v. 9, n. 3, p. 1626-1633, Aug 1994. ISSN 0885-8950. 
BISQUERRA, R.; SARRIERA, J.; MATÍNEZ, F. Introdução a Estatística: Enfoque informático com o pacote estatístico SPSS. [S.1.]: Bookman, 2007. ISBN 9788536311364.

BOUZADA, M. A. C. Simulação versus métodos analíticos: Uma ferramenta didática na forma de discussão teórica. REA-Revista Eletrônica de Administração, 2013. v. 12, n. 1, p. 84-95, 2013.

BRACALE, A. et al. Probabilistic short circuit analysis in electric power distribution systems including distributed generation. In: Power Generation, Transmission, Distribution and Energy Conversion (MEDPOWER 2012), 8th Mediterranean Conference on. [S.l.: s.n.], 2012. p. 1-6.

BRAGA, L. Compreendendo Probabilidade e Estatística. [S.l.]: E-PAPERS, 2010. ISBN 9788576502821.

CABRAL, R. J. Análise Numérica de Curto Circuito Utilizando Componentes Simétricas E Componentes de Fases para Obter Índices de Afundamentos de Tensão. Dissertação (Mestrado) — Universidade Federal do Rio Grande do Sul, 2010.

CASORIA, S. VSC-Based HVDC Link. 2007. Disponível em: <http://www . mathworks.com/help/physmod/sps/powersys/ug/vsc-based-hvdc-link.html>. 08 de Agosto de 2014.

CIGRÉ B4. HVDC and FACTS for Distribution Systems. [S.1.]: CIGRÉ, 2005. Components Testing of VSC System for HVDC Applications. [S.l.]: CIGRÉ, 2011.

Influence of Embedded HVDC Transmission on System Security and AC Network Performance. [S.l.]: CIGRÉ, 2013.

DANIEL, L. de O. Modelagem, Análise e Controle de um Elo de Tensão Contínua com Conversores VSC Conectados em back-to-back. Dissertação (Mestrado) — Universidade Federal do Rio de Janeiro, 2011.

DANTAS, C. Probabilidade: Um Curso Introdutório Vol. 10. [S.l.]: EDUSP, 2008. ISBN 9788531403996.

DOMMEL, H. Digital computer solution of electromagnetic transients in single-and multiphase networks. Power Apparatus and Systems, IEEE Transactions on, 1969. PAS-88, n. 4, p. 388-399, April 1969. ISSN 0018-9510.

ECKHARD, R. Stan ulam, john von neumann and the Monte Carlo method. Los Alamos Science, 1987. p. 131-136, 1987.

ELÉTRICO, O. N. do S. Estudos de Curto-circuito. Setembro 2014. Disponível em:<http://www.ons.org.br/operacao/estudos_curto_circuito.aspx $>$. 11 de Setembro de 2014.

ESMERALDO, P.; ARAÚJO, E.; JR., D. C. HVDC madeira transmission system planning development and final design. CIGRÉ, 2010. 2010. 
FLOURENTZOU, N.; AGELIDIS, V.; DEMETRIADES, G. VSC-based HVDC power transmission systems: An overview. Power Electronics, IEEE Transactions on, 2009. v. 24, n. 3, p. 592-602, March 2009. ISSN 0885-8993.

FORD, G.; SENGUPTA, S. Analytical methods for probabilistic short-circuit studies. Electric Power Systems Research, 1982. v. 5, n. 1, p. 13 - 20, 1982. ISSN 0378-7796. Disponível em: <http://www.sciencedirect.com/science/article/pii/0378779682900049>.

FRANCK, C. HVDC circuit breakers: A review identifying future research needs.

Power Delivery, IEEE Transactions on, 2011. v. 26, n. 2, p. 998-1007, April 2011. ISSN 0885-8977.

FUCHS, R. Transmissao de energia eletrica: linhas aereas ; teorias das linhas em regime permanente. [S.l.]: Livros Tecnicos e Cientificos, 1979. ISBN 9788521600824 .

GREINER, C. et al. Availability evaluation of multi-terminal dc networks with dc circuit breakers. In: PowerTech, 2011 IEEE Trondheim. [S.l.: s.n.], 2011. p. 1-8.

GSL. Random number generator algorithms. 2015. Disponível em: <https://www.gnu.org>. 10 de Julho de 2015.

HEDMAN, D. et al. Teoria das linhas de transmissão II. [S.l.]: UFSM, 1983. (Série PTI).

HYDRO, M. DC Transmission System. 2014. Disponível em: <https:

//www.hydro.mb.ca/corporate/facilities/ts_nelson.shtml>. 22 de Outubro de 2014.

IEEE Standard American National Standard Canadian Standard Graphic Symbols for Electrical and Electronics Diagrams (Including Reference Designation Letters). IEEE Std 315-1975 (Reaffirmed 1993), 1993. p. i-244, 1993.

ITAIPU. Integração ao Sistema Brasileiro. March 2010. Disponível em: <https://www.itaipu.gov.br/energia/integracao-ao-sistema-brasileiro>. 14 de Setembro de 2014.

JÚNIOR, L. Transitórios Eletromagnéticos em Sistemas de Potência Vol. 52. [S.l.]: EDUSP, 2003. ISBN 9788531407550.

LAW AVERILL M, K. W. D. Simulation Modeling and Analysis. [S.l.]: McGraw-Hill New York, 1991.

LU, B.; SHARMA, S. A literature review of igbt fault diagnostic and protection methods for power inverters. In: Industry Applications Society Annual Meeting, 2008. IAS '08. IEEE. [S.l.: s.n.], 2008. p. 1-8. ISSN 0197-2618.

MACIEJEWSKI, R. Data Representations, Transformations, and Statistics for Visual Reasoning. [S.1.]: Morgan \& Claypool, 2011. (Synthesis digital library of engineering and computer science). ISBN 9781608456253.

MAMEDE, J. P. Previsão da Manutenção de Disjuntores dos Alimentadores de Distribuição de Energia Elétrica pelo Método de Curto-Circuito Probabilistico. Dissertação (Mestrado) - Universidade Estadual de Campinas, 2004. 
M.C.D.TAVARES; P.G.CAMPOS; P.PRADO. Guia Resumido do ATP - Alternative Transient Program. 2014. Disponível em: <http://www.dsce.fee.unicamp.br/ cristina/pos\%20graduacao/GUIA.ATP.pdf>. 15 de Julho de 2015.

MEAH, K.; ULA, S. Comparative evaluation of HVDC and HVAC transmission systems. In: Power Engineering Society General Meeting, 2007. IEEE. [S.l.: s.n.], 2007. p. 1-5. ISSN 1932-5517.

MONARO, R. M. et al. Sistema integrado para desenvolvimento e execução em tempo real de algoritmos de proteção de sistemas elétricos. Sba: Controle \& Automação Sociedade Brasileira de Automatica, 2012. scielo, v. 23, p. 202 - 215, 04 2012. ISSN 0103-1759.

MOURAD, M.; BOUZID, B.; MOHAMED, B. Gath-geva approach to forecast electric energy consumption. In: Power Engineering, Energy and Electrical Drives (POWERENG), 2013 Fourth International Conference on. [S.l.: s.n.], 2013. p. 330-333. ISSN 2155-5516.

\section{PAUCAR, B. C. SISTEMA HVDC BASEADO EM CONVERSORES}

MULTINIVEL MODULARES. Tese (Doutorado) - Universidade Federal do Rio de Janeiro, 2014.

RODRIGUES, A. et al. Probabilistic assessment of voltage sag in radial distribution networks. In: Power Tech, 2005 IEEE Russia. [S.l.: s.n.], 2005. p. 1-7.

RTE. Description of a Protection Plan for DC Networks - Preliminary Results towards the real-time experimentation of a small-scale model of a DC network and the $120 \mathrm{kV}$ DC breaker prototype tests. 2012. Disponível em: <http://www.twenties-project.eu/system/files/2012-10-09-Twenties_D11. 2-extended_2012-12-07.pdf>. 22 de Julho de 2015.

S. FÁBIO Y., A. J. d. P. L. F. B. K.; PISSOLATO, J. Representação de linhas de transmissão por meio de variáveis de estado levando em consideração o efeito da freqüência sobre os parâmetros longitudinais. Sba Controle e Automação, 2007. 2007.

SCHETTLER, F.; HUANG, H.; CHRISTL, N. HVDC transmission systems using voltage sourced converters design and applications. In: Power Engineering Society Summer Meeting, 2000. IEEE. [S.l.: s.n.], 2000. v. 2, p. 715-720 vol. 2.

SCHWAAB, M. Análise de Dados Experimentais: I. Fundamentos de Estatística e Estimação de Parâmetros. [S.1.]: E-PAPERS, 2003. ISBN 9788576501367.

SIVANAGARAJU, S.; REDDY, B. Electrical Power System Analysis. [S.1.]: Laxmi Publications Pvt Limited, 2007. ISBN 9788131800874.

SOOD, V. HVDC and FACTS Controllers: Applications of Static Converters in Power Systems. [S.1.]: Springer US, 2004. (HVDC and FACTS Controllers: Applications of Static Converters in Power Systems). ISBN 9781402078903.

STEVENSON, W. Elementos de análise de sistemas de potência. [S.l.]: McGraw Hill, 1978.

STI. Projeto Cloud USP - Panorama Atual. 2014. Disponível em: $<$ http://www.sti.usp.br/?q=node/5370>. 21 de Setembro de 2014. 
TIKU, D. DC Power Transmission Mercury-Arc to Thyristor HVDC Valves. April 2014. Disponível em: <http://magazine.ieee-pes.org/marchapril-2014/ history-12/>. 13 de Setembro de 2014.

VENABLES, W.; RIPLEY, B. Modern Applied Statistics with S. [S.l.]: Springer, 2002. (Statistics and Computing). ISBN 9780387217062.

VICENTE, W.; CAIRE, R.; HADJSAID, N. Interval arithmetic for short-circuit computation in mv radial networks with distributed generation. In: Power and Energy Society General Meeting, 2012 IEEE. [S.l.: s.n.], 2012. p. 1-6. ISSN 1944-9925.

VRANA, T. K. Documents related to the development of HVDC Grids. 2014. Disponível em: <http://b4.cigre.org/Publications/Documents-related-to-thedevelopment-of-HVDC-Grids>. 21 de Setembro de 2014.

WANG, Y.-J.; PIERRAT, L. Probabilistic modelling of current harmonics produced by an ac/dc converter under voltage unbalance. Power Delivery, IEEE Transactions on, 1993. v. 8, n. 4, p. 2060-2066, Oct 1993. ISSN 0885-8977.

WATSON, N.; ARRILlaGA, J.; ENGINEERS, I. of E. Power Systems Electromagnetic Transients Simulation. [S.1.]: Institution of Engineering and Technology, 2003. (IEE power and energy series). ISBN 9780852961063.

YANG, J. Short-circuit and ground fault analyses and location in VSC-based DC network cables. IEEE Transactions on Industrial Electronics, 2012. v. 59, p. 11, 2012 .

ZHANG, X.-P.; REHTANZ, C.; SONG, Y. A grid for tomorrow. Power Engineer, 2006. v. 20, n. 5, p. 22-27, Oct 2006. ISSN 1479-8344.

ZIMA-BOCKARJOVA, M. et al. Distance protection algorithm for power transmission lines based on Monte-Carlo method. In: PowerTech, 2009 IEEE Bucharest. [S.l.: s.n.], 2009. p. 1-7. 
Anexos 



\section{Camada 2 do OEMTP}

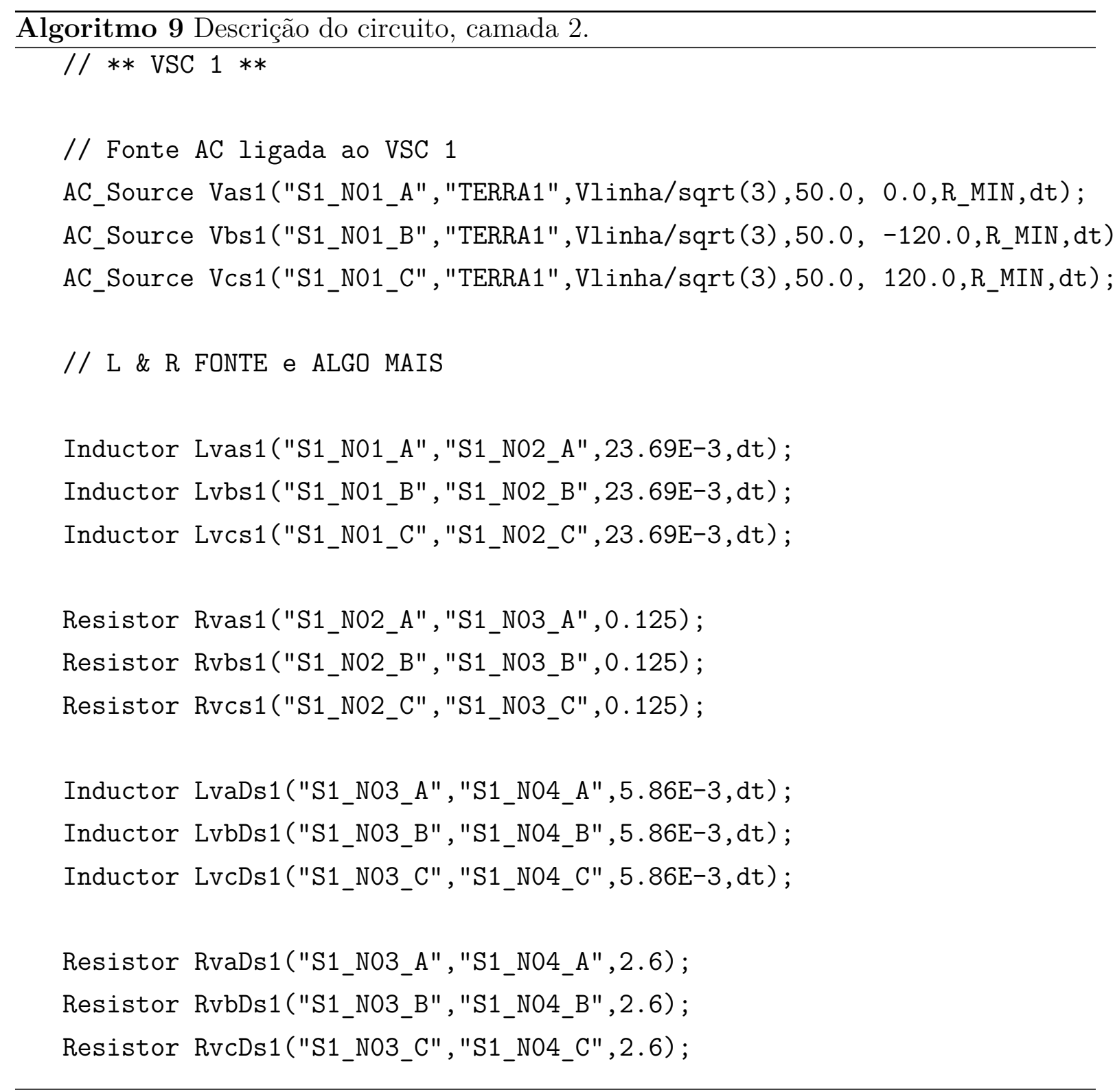




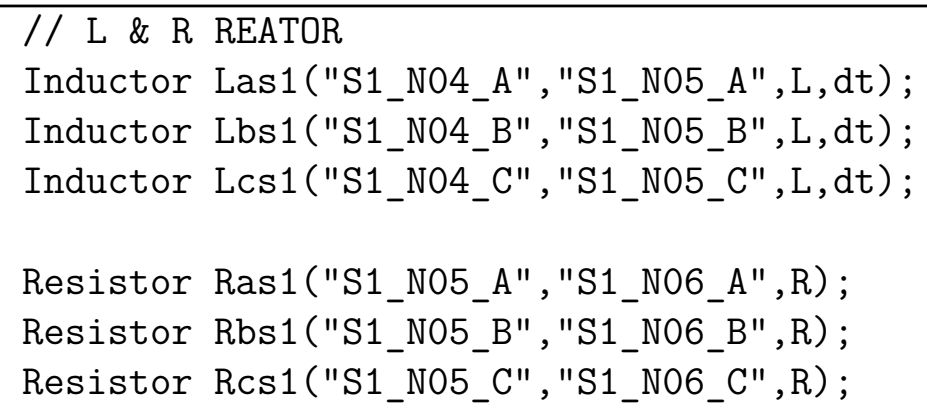

\section{// FILTRO PARALELO}

Capacitor Ca_fs1("S1_N04_A", "S1_N09_A", Cf, dt);

Capacitor Cb_fs1("S1_N04_B", "S1_N09_B", Cf, dt);

Capacitor Cc_fs1("S1_N04_C", "S1_N09_C", Cf, dt);

Inductor La_fs1("S1_N09_A", "TERRA2", Lf , dt);

Inductor Lb_fs1("S1_N09_B", "TERRA2", Lf, dt);

Inductor Lc_fs1("S1_N09_C", "TERRA2", Lf , dt);

Resistor Ra_fs1("S1_N09_A", "TERRA2", Rf);

Resistor Rb_fs1("S1_N09_B", "TERRA2", Rf);

Resistor Rc_fs1("S1_N09_C", "TERRA2", Rf);

// IGBT - VSC 1

Switch S1s1("S1_N07", "S1_N06_AA"); //Amperimetro em S1_N06_AA

Switch S2s1 ("S1_N06_A", "S1_N08");

Switch S3s1 ("S1_N07", "S1_N06_B");

Switch S4s1 ("S1_N06_B", "S1_N08");

Switch S5s1 ("S1_N07", "S1_N06_C");

Switch S6s1 ("S1_N06_C", "S1_N08");

// Diodos paralelos

Diode D1s1("S1_N06_AA", "S1_N07");

Diode D2s1 ("S1_N08", "S1_N06_A");

Diode D3s1 ("S1_N06_B", "S1_N07");

Diode D4s1 ("S1_N08", "S1_N06_B");

Diode D5s1("S1_N06_C", "S1_N07");

Diode D6s1("S1_N08", "S1_N06_C");

S1s1.Open()；S2s1.Open()；S3s1.Open()；S4s1.Open()； S5s1.Open();

S6s1.Open();

// FILTRO CAPACITIVO DC

Capacitor C1s1("S1_N07", "TERRA" ,280E-6, dt);

Capacitor C2s1 ("TERRA", "S1_N08",280E-6, dt); 
// MEDIDA DE TENSÃO V_conversor (referência pro controle de potência) Voltmeter mVa_s1("S1_N04_A", "TERRA");

Voltmeter mVb_s1("S1_N04_B", "TERRA");

Voltmeter mVc_s1("S1_N04_C", "TERRA");

// Amperimetro no IGBT

Ammeter mIS1s1("S1_N06_A", "S1_N06_AA");

// LINHA DE TRANSMISSÃO BERGERON MONOFASICA (sem acoplamento) ligando VSC 1 ao Line Ls1pf("S1_N107", "S_N77", 75.0, Lline, Cline, Rline, dt);

Line Ls1nf("S1_N108", "S_N88",75.0, Lline, Cline, Rline, dt);

Line Ls2pf ("S_N77", "S2_N107", 75.0, Lline, Cline, Rline, dt);

Line Ls2nf("S_N88", "S2_N108",75.0, Lline, Cline, Rline, dt);

//--- Chaves para provocar falta nos polos

Switch S_pp ("S_N77", "S_N88");

Switch S_pt ("S_N77", "TERRA");

Switch S_nt ("S_N88", "TERRA");

S_pp.Open(); S_pt.Open(); S_nt.Open();

// MEDIDA DE Corrente na linha VSC1

Ammeter mIps1("S1_N07", "S1_N107");

Ammeter mIns1("S1_N08", "S1_N108");

// MEDIDA DE Corrente na linha VSC2

Ammeter mIps2("S2_N07", "S2_N107");

Ammeter mIns2("S2_N08", "S2_N108");

//** VSC $2 * *$

AC_Source Vas2("S2_N01_A", "TERRA3",VIinha/sqrt (3), 50.0, 0.0,R_MIN,dt);

AC_Source Vbs2("S2_N01_B", "TERRA3",Vlinha/sqrt (3), 50.0, -120.0,R_MIN,dt);

AC_Source Vcs2("S2_N01_C", "TERRA3", Vlinha/sqrt (3), 50.0, 120.0,R_MIN,dt);

// L \& R FONTE e ALGO MAIS

Inductor Lvas2("S2_N01_A", "S2_NO2_A" , 23.69E-3, dt);

Inductor Lvbs2 ("S2_N01_B", "S2_N02_B", 23.69E-3, dt);

Inductor Lvcs2("S2_N01_C", "S2_NO2_C", 23.69E-3, dt);

Resistor Rvas2("S2_N02_A", "S2_N03_A", 0.125);

Resistor Rvbs2("S2_N02_B", "S2_N03_B",0.125);

Resistor Rvcs2("S2_N02_C", "S2_N03_C", 0.125); 
Inductor LvaDs2("S2_N03_A", "S2_N04_A", 5.86E-3, dt);

Inductor LvbDs2("S2_N03_B", "S2_N04_B", 5.86E-3,dt);

Inductor LvcDs2("S2_N03_C", "S2_N04_C", 5.86E-3, dt);

Resistor RvaDs2("S2_N03_A", "S2_NO4_A", 2.6);

Resistor RvbDs2("S2_N03_B", "S2_N04_B", 2.6);

Resistor RvcDs2("S2_NO3_C", "S2_NO4_C", 2.6);

// L \& R REATOR

Inductor Las2("S2_N04_A", "S2_N05_A", L , dt) ;

Inductor Lbs2("S2_N04_B", "S2_N05_B", L, dt);

Inductor Lcs2("S2_N04_C", "S2_N05_C", L, dt) ;

Resistor Ras2("S2_N05_A", "S2_N06_A", R);

Resistor Rbs2("S2_N05_B", "S2_N06_B", R);

Resistor Rcs2("S2_N05_C", "S2_N06_C", R);

\section{// FILTRO PARALELO}

Capacitor Ca_fs2("S2_N04_A", "S2_N09_A", Cf, dt);

Capacitor Cb_fs2("S2_N04_B", "S2_N09_B", Cf, dt);

Capacitor Cc_fs2("S2_N04_C", "S2_N09_C", Cf, dt);

Inductor La_fs2("S2_N09_A", "TERRA4", Lf , dt);

Inductor Lb_fs2("S2_N09_B", "TERRA4", Lf , dt);

Inductor Lc_fs2("S2_NO9_C", "TERRA4", Lf , dt);

Resistor Ra_fs2("S2_N09_A", "TERRA4", Rf);

Resistor Rb_fs2("S2_N09_B", "TERRA4", Rf);

Resistor Rc_fs2("S2_N09_C", "TERRA4", Rf);

\section{// IGBT - VSC 2}

Switch S1s2("S2_N07", "S2_N06_A");

Switch S2s2("S2_N06_A", "S2_N08");

Switch S3s2("S2_N07", "S2_NO6_B");

Switch S4s2("S2_N06_B", "S2_N08");

Switch S5s2("S2_N07", "S2_NO6_C");

Switch S6s2("S2_N06_C", "S2_N08");

Diode D1s2("S2_N06_A", "S2_N07");

Diode D2s2("S2_N08", "S2_N06_A");

Diode D3s2 ("S2_N06_B", "S2_NO7");

Diode D4s2 ("S2_N08", "S2_N06_B");

Diode D5s2("S2_N06_C", "S2_NO7");

Diode D6s2("S2_N08", "S2_N06_C");

S1s2.Open(); S2s2.Open(); S3s2.Open(); S4s2.Open()； S5s2.Open();

S6s2.Open(); 
//FILTRO CAPACITIVO DC

Capacitor C1s2("S2_N07", "TERRA", 280E-6, dt);

Capacitor C2s2("TERRA", "S2_N08", 280E-6, dt);

// MEDIDA DE TENSÃO V_conversor (referencia pro controle de ppotencia)

Voltmeter mVa_s2("S2_N04_A", "TERRA");

Voltmeter mVb_s2("S2_N04_B", "TERRA");

Voltmeter mVc_s2("S2_N04_C", "TERRA");

// MEDIDA DE TENSÃO Vdc

Voltmeter mVdcp_s2("S2_N07", "TERRA");

Voltmeter mVdcn_s2("S2_N08", "TERRA");

Circuit Circ1; 